\title{
Low-Rank Coal Grinding Performance Versus Power Plant Performance
}

\author{
Final Report
}

10/01/2002-9/30/2008

Rajive Ganguli, PhD, PE

Associate Professor of Mining Engineering

Sukumar Bandopadhyay, PhD, PE

Professor of Mining Engineering

\section{September 2008}

\section{DE-FC26-01NT41248}

FY02 Task 1.6

\section{Institute of Northern Engineering \\ University of Alaska Fairbanks}

PO Box 755910

Fairbanks, Alaska 99775-5910 


\section{Disclaimer}

This report was prepared as an account of work sponsored by an agency of the United States Government. Neither the United States Government nor any agency thereof, nor any of their employees, makes any warranty, express or implied, or assumes any legal liability or responsibility for the accuracy, completeness, or usefulness of any information, apparatus, product, or process disclosed, or represents that its use would not infringe privately owned rights. Reference herein to any specific commercial product, process, or service by trade name, trademark, manufacturer, or otherwise does not necessarily constitute or imply its endorsement, recommendation, or favoring by the United States Government or any agency thereof. The views and opinions of authors expressed herein do not necessarily state or reflect those of the United States Government or any agency thereof. 


\begin{abstract}
The intent of this project was to demonstrate that Alaskan low-rank coal, which is high in volatile content, need not be ground as fine as bituminous coal (typically low in volatile content) for optimum combustion in power plants. The grind or particle size distribution (PSD), which is quantified by percentage of pulverized coal passing 74 microns (200 mesh), affects the pulverizer throughput in power plants. The finer the grind, the lower the throughput. For a power plant to maintain combustion levels, throughput needs to be high. The problem of particle size is compounded for Alaskan coal since it has a low Hardgrove grindability index (HGI); that is, it is difficult to grind. If the thesis of this project is demonstrated, then Alaskan coal need not be ground to the industry standard, thereby alleviating somewhat the low HGI issue (and, hopefully, furthering the salability of Alaskan coal).

This project studied the relationship between PSD and power plant efficiency, emissions, and mill power consumption for low-rank high-volatile-content Alaskan coal. The emissions studied were $\mathrm{CO}, \mathrm{CO}_{2}, \mathrm{NO}_{x}, \mathrm{SO}_{2}$, and $\mathrm{Hg}$ (only two tests). The tested PSD range was 42 to 81 percent passing 76 microns. Within the tested range, there was very little correlation between PSD and power plant efficiency, $\mathrm{CO}, \mathrm{NO}_{\mathrm{x}}$, and $\mathrm{SO}_{2}$. $\mathrm{Hg}$ emissions were very low and, therefore, did not allow comparison between grind sizes. Mill power consumption was lower for coarser grinds.
\end{abstract}




\section{Table of Contents}

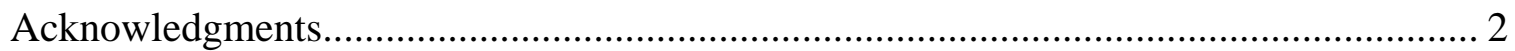

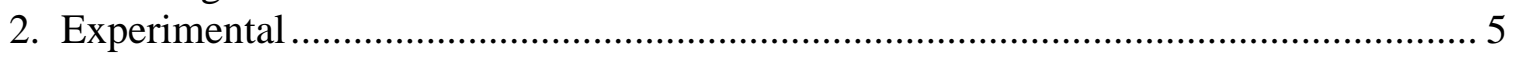

2.1 The Power Plant........................................................................................ 5

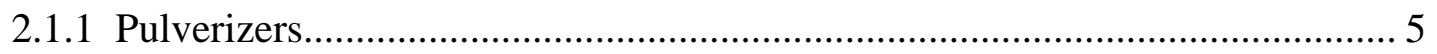

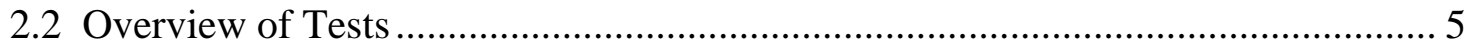

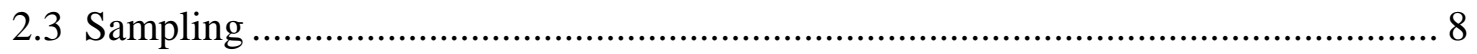

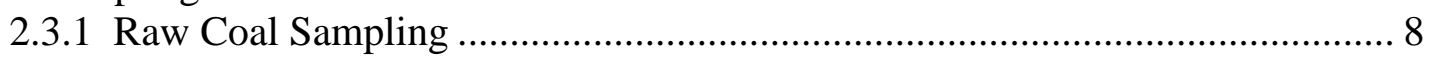

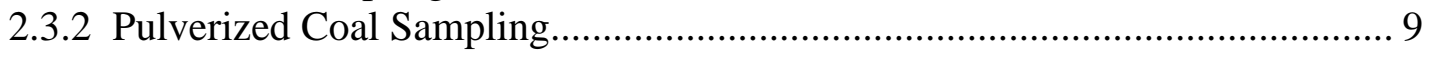

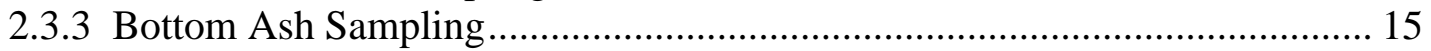

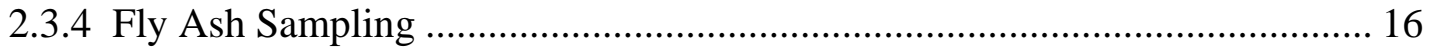

2.4 Reduction in the Number of Pulverized Coal Samples ...................................... 17

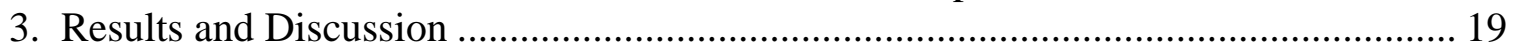

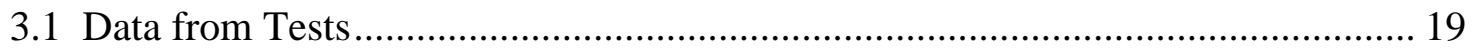

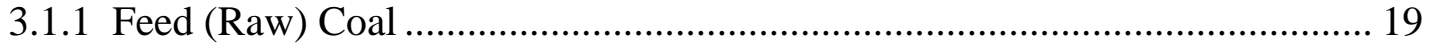

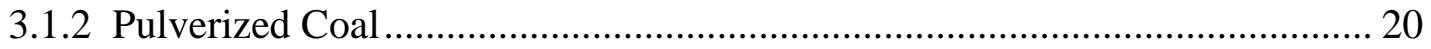

3.1.3 Fly Ash Data ....................................................................................... 22

3.1.4 Bottom Ash Data.............................................................................. 23

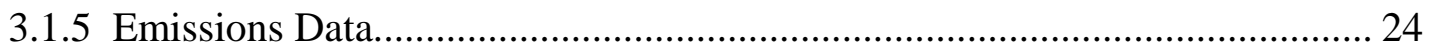

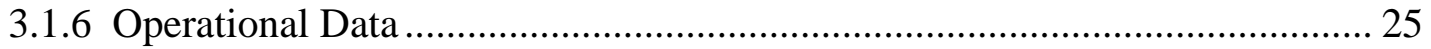

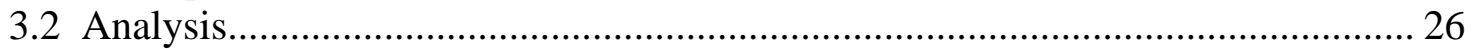

3.2.1 PSD Versus Power Plant Efficiency .......................................................... 26

3.2.2 PSD76 Versus $\mathrm{SO}_{2}, \mathrm{NO}_{\mathrm{x}}, \mathrm{CO}$, and $\mathrm{CO}_{2}$ Emissions .................................... 31

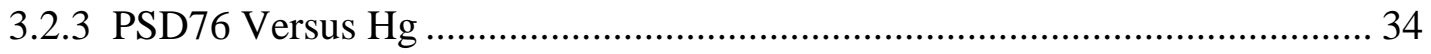

3.2.4 PSD76 Versus Mill Power Consumption .................................................... 34

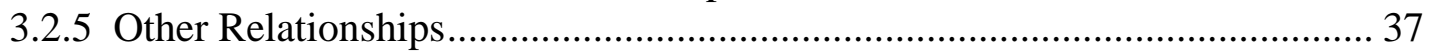

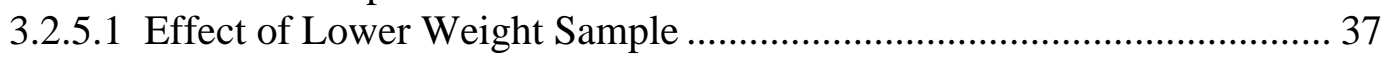

3.2.5.2 PSD in Different Pipes................................................................... 44

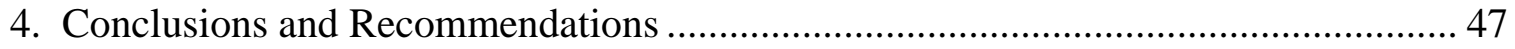

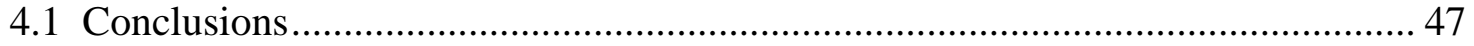

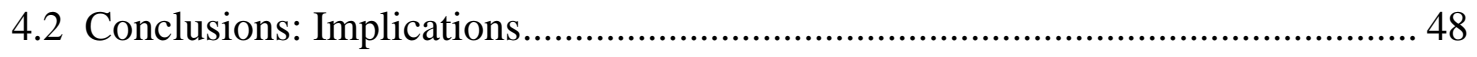

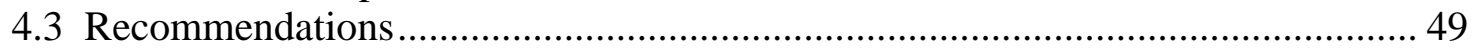

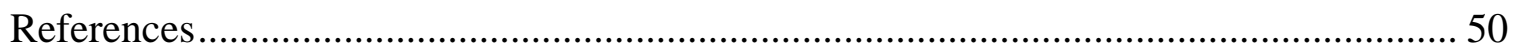

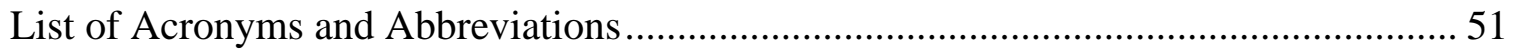

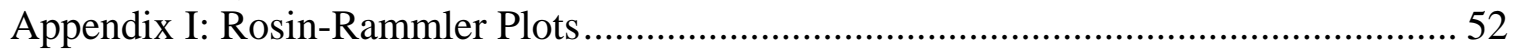




\section{Acknowledgments}

The authors would like to acknowledge the contribution of Mr. David Hoffman, Plant Superintendent of Golden Valley Electric Association's Healy Unit\#1, and his staff. They were always willing to help us meet the objectives of the project. Thanks are also due to Dr. Terril Wilson, who helped start this project. Many students played a big role in the project. These include Mr. Dinesh Malav, Dr. Sridhar Dutta, Mr. Abhishek Choudhury and Ms. Rupali Panda.

The financial support from the United States Department of Energy, that made this project feasible, is gratefully acknowledged. 


\section{Executive Summary}

The intent of this project was to demonstrate that Alaskan low-rank coal, which is high in volatile content, need not be ground as fine as bituminous coal (typically low in volatile content) for optimum combustion in power plants. The grind or particle size distribution (PSD) affects the pulverizer throughput in power plants. The finer the grind, the lower the throughput. For a power plant to maintain combustion levels, throughput needs to be high. The problem of particle size is compounded for Alaskan coal since it has a low Hardgrove grindability index (HGI); that is, it is difficult to grind. If the thesis of this project is validated, then Alaskan coal need not be ground to the industry standard, thereby alleviating somewhat the low HGI issue (and, hopefully, furthering the salability of Alaskan coal).

A total of 26 field tests were conducted at the Golden Valley Electric Association's (GVEA) Healy Unit \#1 to study the relationship between the PSD of pulverized coal being burnt at a power plant and its impact on power plant performance. The PSD was quantified, as is commonly done in the power industry, as the percentage passing 76 microns (PSD76). Performance was measured through power plant efficiency (ratio of megawatt [MW] generated to MW burned as coal), mill power consumption, emissions $\left(\mathrm{SO}_{2}, \mathrm{NO}_{\mathrm{x}}, \mathrm{CO}\right.$, and $\left.\mathrm{CO}_{2}\right)$ as measured by a continuous emissions monitoring system (CEMS), carbon content in fly ash and bottom ash, and Hg emissions in the stack. Other data collected included proximate analysis of raw coal, HGI of raw coal, and proximate analysis of pulverized coal. Operational data collected included mill amps, coal flow rate, air flow rate, and oxygen.

The project reached the following conclusions about low-rank high volatile Alaskan coal:

- $\quad$ For PSD in the tested range (40-80), there is very little correlation between the PSD of pulverized coal and power plant efficiency.

- $\quad$ There is very little correlation between PSD and $\mathrm{SO}_{2}, \mathrm{NO}_{\mathrm{x}}$, and $\mathrm{CO}$.

- $\quad$ The data displayed a correlation between PSD and $\mathrm{CO}_{2}$, with finer grinds resulting in higher concentration of $\mathrm{CO}_{2}$. However, this correlation has been difficult to explain. It could be a new revelation or an artifact of measurement errors.

- $\quad$ Mill power consumption is greater when coal is ground more. Additionally, the HGI and coal flow rate impact mill power consumption. Harder coal was found to consume more power than softer coal, and power consumption went up as the coal flow rate increased.

0 If coal were to be burned at a PSD of 50 instead of 70, the 28 MW Healy Unit \#1 would see a savings of over $\$ 56,000$ per year.

- $\quad$ Total Hg emissions are very low. 
When the tests are split into two groups, one that averaged $50 \%$ passing 76 microns (the "coarse" group) and the other that averaged 73\% passing 76 microns (the "fine" group), the following is observed:

o The coal burned in the fine group had more moisture (17.4\%) and less heating value $(18,774 \mathrm{~kJ} / \mathrm{kg}$ or $8078 \mathrm{BTU})$ compared to the coarse group (15.2\% and 19,337 kJ/kg or 8320 BTU). On a HGI basis, the coal was harder in the coarse group (HGI=34) than in the fine group (HGI=37.8). The fixed carbon content was higher in the coarse group (32.3\%) than in the fine group (29.5\%). There was no difference in the ash and volatile contents.

o The coarse group had higher unburned carbon in fly and bottom ash. However, this could be explained by its higher fixed carbon content.

o The fine group had an efficiency of $23.75 \%$ compared to $23.05 \%$ for the coarse group. Given that the fine group only had six data points, the observed difference could be due to the very low number of tests in the fine group or due to differences in the coal type.

o The coarse group had lower $\mathrm{SO}_{2}$ emissions, though the two groups had similar sulfur contents.

- Observations not central to the project, but interesting nonetheless, included the following:

o Pulverized coal samples that were underweight had PSDs similar to recommended weight samples.

o PSD sometimes varied between pipes. The coal in pipe A1 was generally coarser than the coal in pipe A2. 


\section{Experimental}

\subsection{The Power Plant}

A total of 26 field tests were conducted at Golden Valley Electric Association's 28 MW Healy Unit \#1 power plant. The power plant, located on the banks of the Nenana River, is adjacent to the Usibelli Coal Mine (UCM). The mine provides low-rank high volatile coal to its customers, including GVEA.

The power plant (Figure 2.1a shows the system) has been described in detail in Malav (2005). It has two pulverizers (or mills), A and B, which feed the combustion chamber through four pipes: A1, A2 and B1, B2.

\subsubsection{Pulverizers}

Unit \#1 has two Foster-Wheeler MBF-19.5 pulverizers, each with a capacity of approximately 10,800 kg (24,000 lb) per hour. These medium-speed pulverizers (Figure 2.1b) are air swept and have fixed rollers and vertical spindles. The plant is designed for a particle size of $65 \%$ passing 76 microns. The raw coal to the pulverizers is designed to be $-32 \mathrm{~mm}\left(-1 \frac{1}{4} \mathrm{in}\right.$.) in size. The primary air, which comes to the pulverizers from the wind box, carries the pulverized coal to the classifiers. Particles that are finer than the desired size proceed through the classifiers to the combustion chamber, while the coarser particles continue to be retained in the pulverizer.

\subsection{Overview of Tests}

The basic goal of the project was to conduct the different tests at different PSDs (within operational limits) to examine how plant efficiency (ratio of MW, or MW generated to MW fed as coal) and emissions varied with PSD. However, since there is no direct way to "set" the PSD at a plant, tests were conducted by varying the primary air flow and classifier openings to achieve a target PSD. These two parameters affect the PSD of grind the most. The primary air flow through the pulverizer ensures that the coal remains in suspension. If the primary air flow is increased (without increasing the coal feed), coal does not reside in the pulverizer as long as before, resulting in coarser particles exiting the pulverizer. Similarly, the PSD is coarser when the classifiers are more open. The classifiers are simply vanes that direct the primary air to the outlet of the mill. 


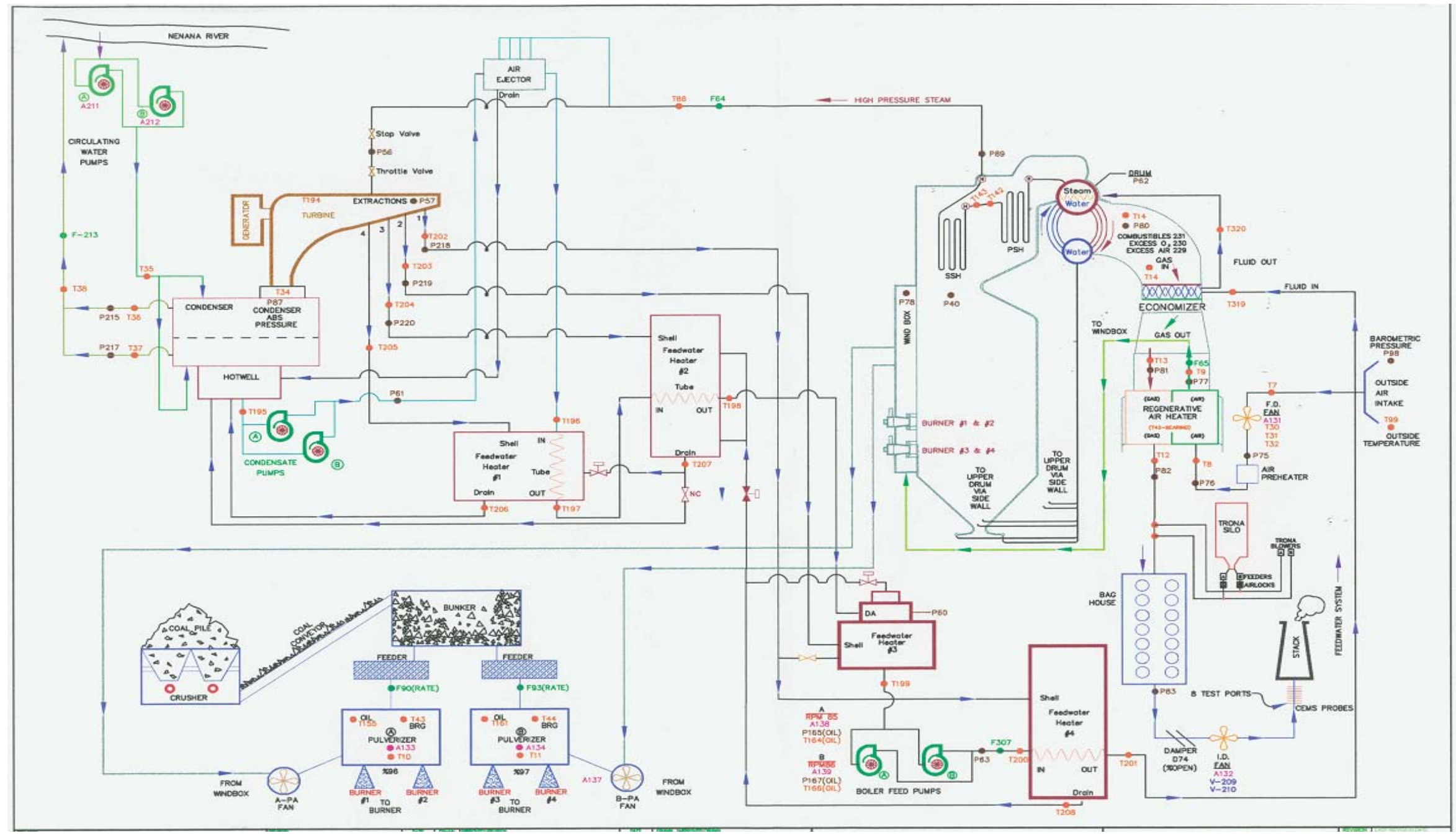

Figure 2.1a. System layout of GVEA Healy Unit \#1. 


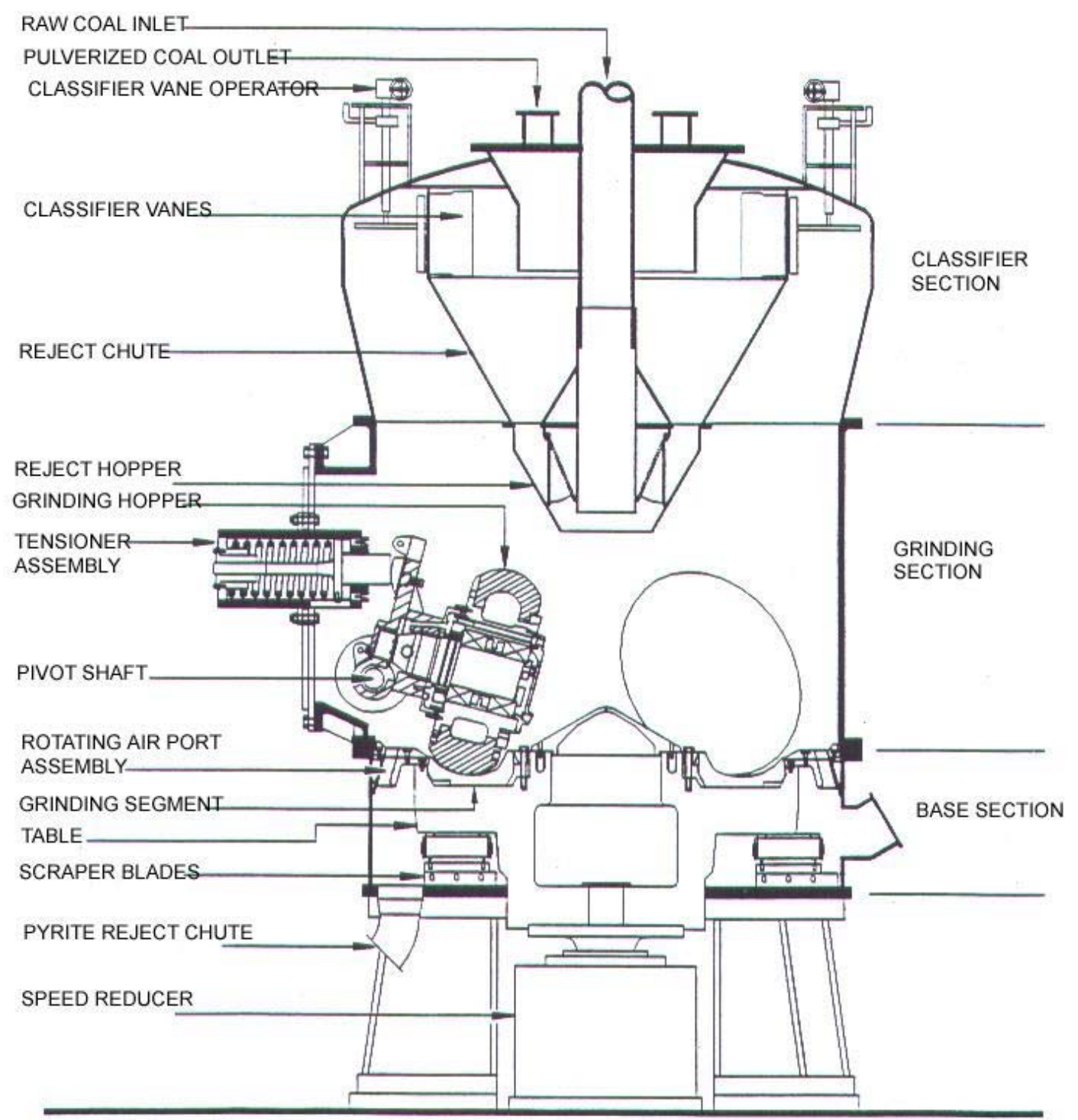

Figure 2.1b. The pulverizers (courtesy of GVEA). 
Given that the PSD was never known at the time of testing (it was only known weeks after the test when the results returned from the lab), lab results often revealed that target PSD76 was not achieved for a given test. However, given the number of tests done, the required spectrum of PSD76 (from really coarse grind to really fine grind) was achieved.

Test duration was usually in the two- to three-hour range. It depended on the duration for which the power plant could maintain experiment conditions. Factors such as load response or classifier settings could affect the power plant's ability to maintain stable experiment conditions.

The samples collected (and analysis done on them) during the tests are listed in Table 2.1.

Table 2.1. Samples collected during tests

\begin{tabular}{|l|l|}
\hline Sample collected & Analysis done on samples \\
\hline \multirow{2}{*}{ Raw coal feed } & HGI \\
\cline { 2 - 2 } & Proximate analysis \\
\hline \multirow{2}{*}{ Pulverized coal } & PSD \\
\cline { 2 - 2 } & Proximate analysis \\
\hline Bottom ash & Unburned carbon \\
\hline Fly ash & Unburned carbon \\
\hline Stack gas & Hg \\
\hline
\end{tabular}

Done only in two tests

The samples shown in Table 2.1 were sent to commercial labs (SGS or Intertek) for analysis. In addition, the automated continuous emissions monitoring system (CEMS) was used to obtain data on various emissions such as $\mathrm{CO}, \mathrm{CO}_{2}, \mathrm{NO}_{\mathrm{x}}$, and $\mathrm{SO}_{\mathrm{x}}$, and operational data such as mill amps, oxygen, coal flow rate, and primary air flow rate.

\subsection{Sampling}

\subsubsection{Raw Coal Sampling}

Raw coal samples were collected from a sampling port located just above the pulverizers. Each mill, A and B, had a port for collecting raw coal samples. During a test, two samples, each approximately $9.5 \mathrm{~L}$ ( $2.5 \mathrm{gal})$ in volume were collected from each port. The diameter of the sampling port was $38 \mathrm{~mm}$ (1.5 in.). The two samples from the same port were combined, ultimately resulting in just two raw coal samples per test. Figure 2.2 shows Dr. Terril Wilson and Mr. Abhishek Chowdhury (both with UAF) collecting the feed samples. 


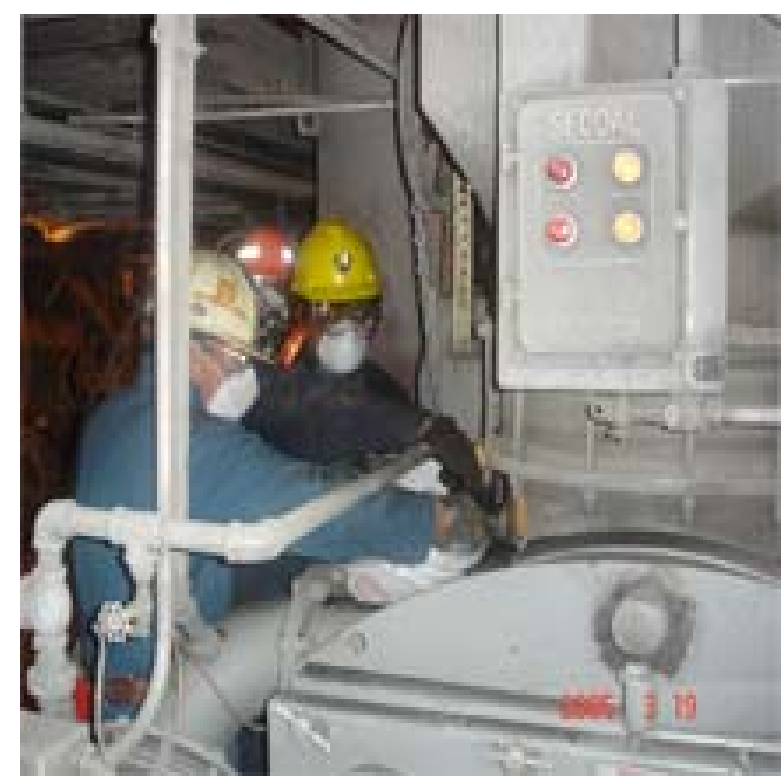

Figure 2.2. Raw (feed) coal sampling.

\subsubsection{Pulverized Coal Sampling}

Sampling of pulverized coal was by far the most challenging aspect of the project. ASTM standard D-197 was used as a guideline for this part for the first 22 tests, with the more stringent ISO 9931 standards used for the last 4 tests. See the next section for details on the number of pulverized coal samples that were taken during each test.

Figure 2.3 shows the layout of the plant relevant to pulverized coal sampling. Two pipes from each mill carry air-pulverized coal mixture to the combustion chamber. Each of these four pipes, A1, A2, B1, and B2, have sampling ports, with each pipe having two perpendicular ports.

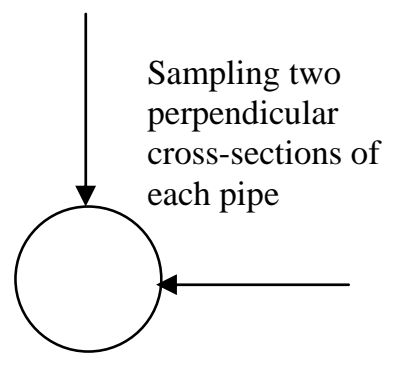

Section C-C

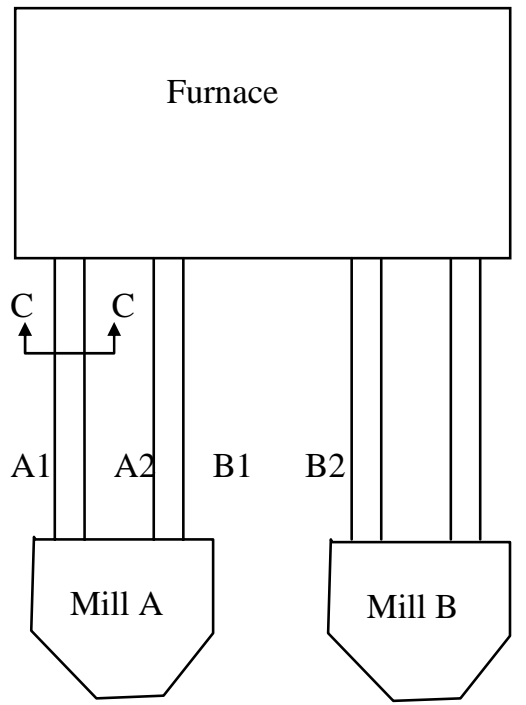

Pipes A1, A2, B1, and B2 carry the pulverized coal-air mixture from the two mills, A and B, to the burners.

Figure 2.3. Schematic showing pulverized coal sampling (Malav et al., 2008). 


\section{ASTM D-197 Sampling Procedure}

The ASTM D-197 sampling procedure is described in detail in ASTM manuals. For the sake of the reader, however, it is described briefly here.

The process requires two sampling ports (in the pipe being sampled) that are perpendicular to each other, with the intent being to sample the pipe in two perpendicular directions (Figure 2.4). The sampling device consists of a probe connected to a cyclone collector (Figure 2.5). It connects to the port through a dustless connection.

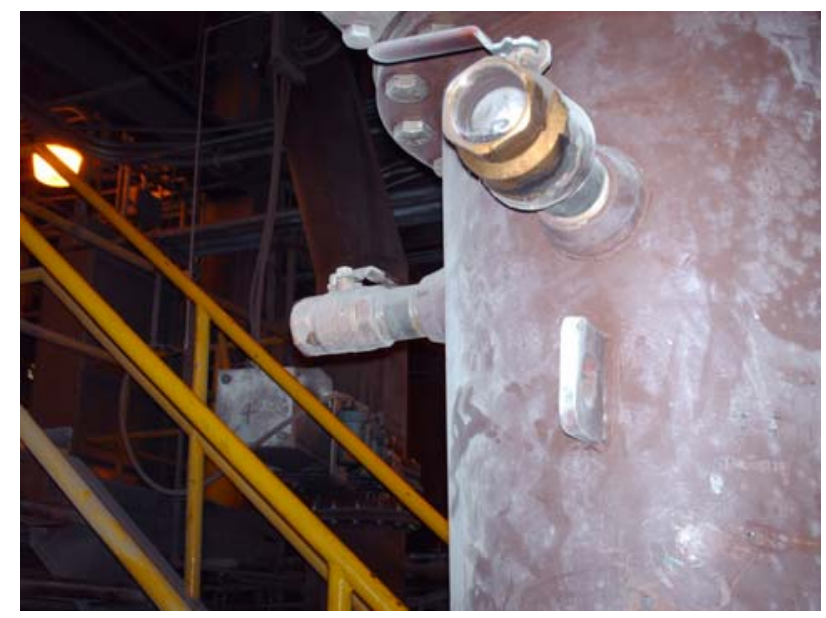

Figure 2.4. The perpendicular sampling ports.

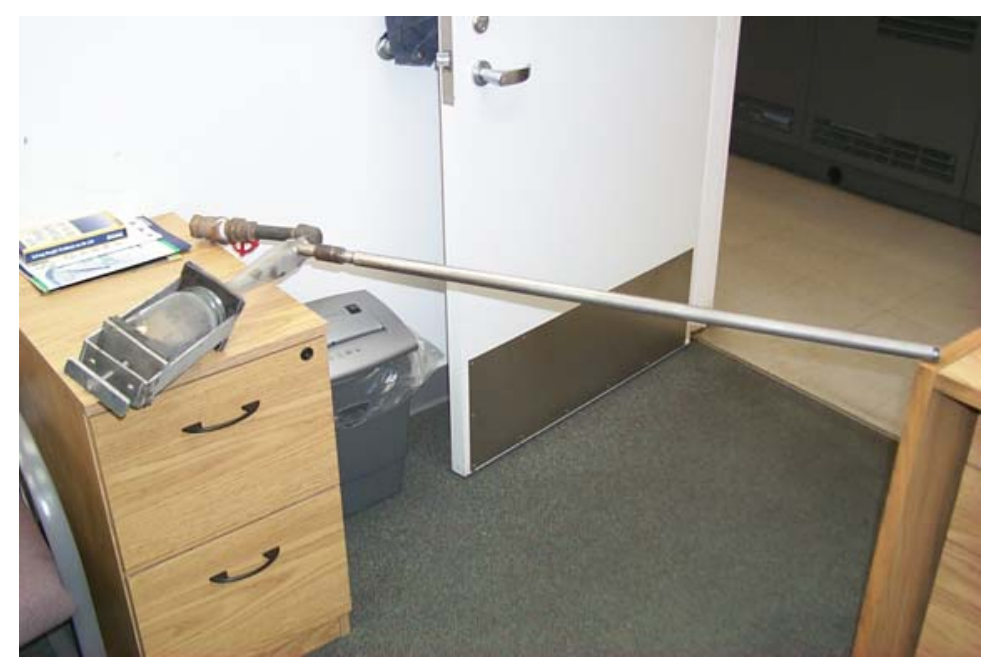

Figure 2.5. The sampling probe connected to the cyclone collector. 
The procedure calls for isokinetic sampling of the air-coal mixture flowing through the pipe. The probe, which contained a sampling aperture of $197 \mathrm{sq} . \mathrm{mm}(0.305 \mathrm{sq}$. in.) near its tip, is inserted into the port. Over a period of 1 minute, it is slowly withdrawn from the pipe. During the withdrawal, the probe is stopped at 12 locations for about 5 seconds so that equal areas are sampled each time. This process is illustrated in Figure 2.6.

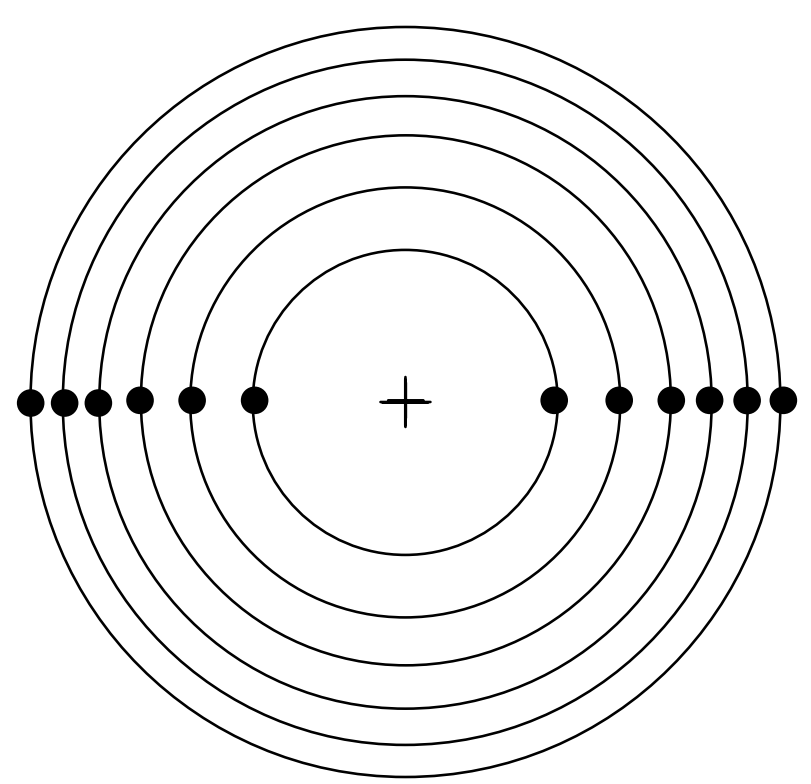

Figure 2.6. Equal area method of sampling. Each sampling "stop” shown by a dark circle.

The process is repeated at the other (perpendicular) port as well, resulting in a total sampling duration of two minutes per pipe. Due to limitations in the equipment, the sampling was not isokinetic. However, sample validity was verified using the RosinRammler plot (as directed by the ASTM method).

Figure 2.7 shows the probe being set up for sampling. 


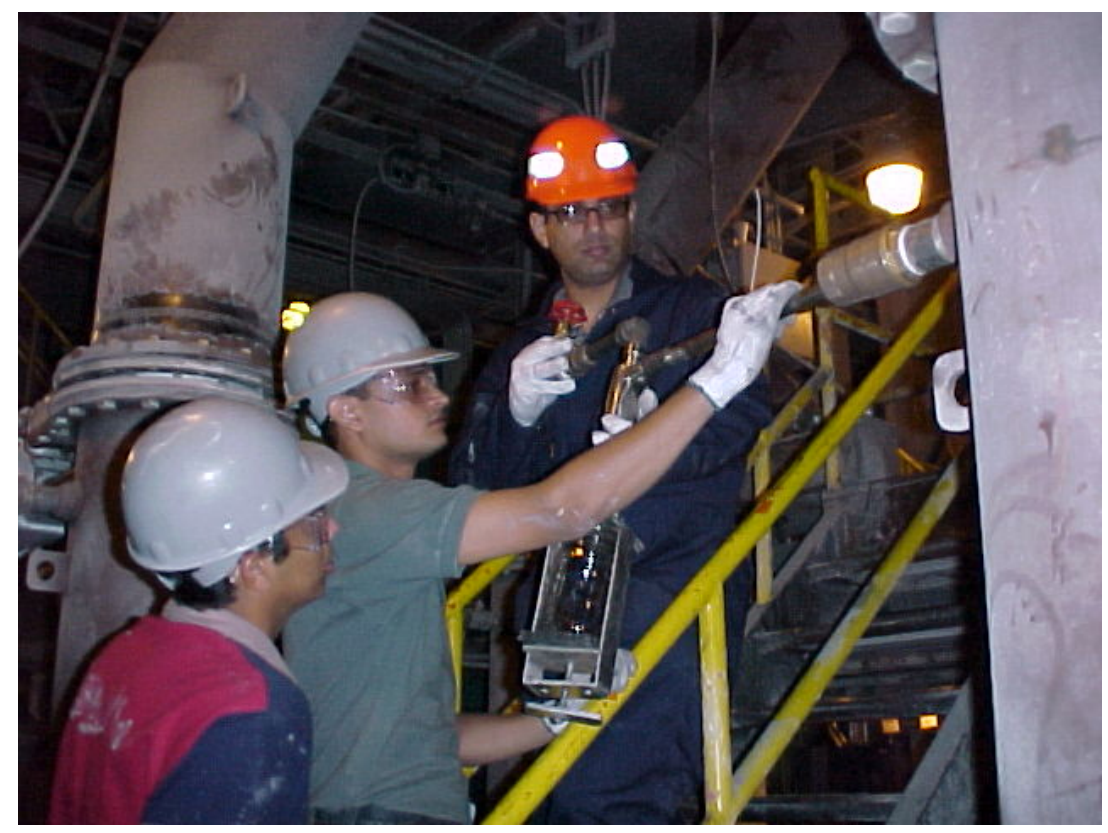

Figure 2.7. From left to right, Srdhar Dutta, Dinesh Malav, and Rajive Ganguli (all with UAF) setting up the probe.

\section{ISO 9931 Sampling Procedure}

During the course of this investigation, the sampling probe for the ASTM method got damaged. Therefore, GE Energy, which uses the ISO 9931 isokinetic sampling procedure, was hired to obtain the pulverized coal samples. This process is described in detail in ISO's official manual ${ }^{1}$. However, it is described here briefly for the benefit of the reader.

The method uses the Rotorprobe ${ }^{\mathrm{TM}}$, a GE Energy device certified for this method. The device (Figure 2.8) is similar to the ASTM method probe (shown in Figure 2.5), but with a major difference. The Rotorprobe has two sampling tips (each with two sampling apertures for a total of four apertures) that rotate on a vertical axis at the end of the probe. During sampling, the tips are rotated, resulting in the collection of samples from all around the pipe and not just from two perpendicular diameters.

\footnotetext{
${ }^{1}$ www.iso.org
} 


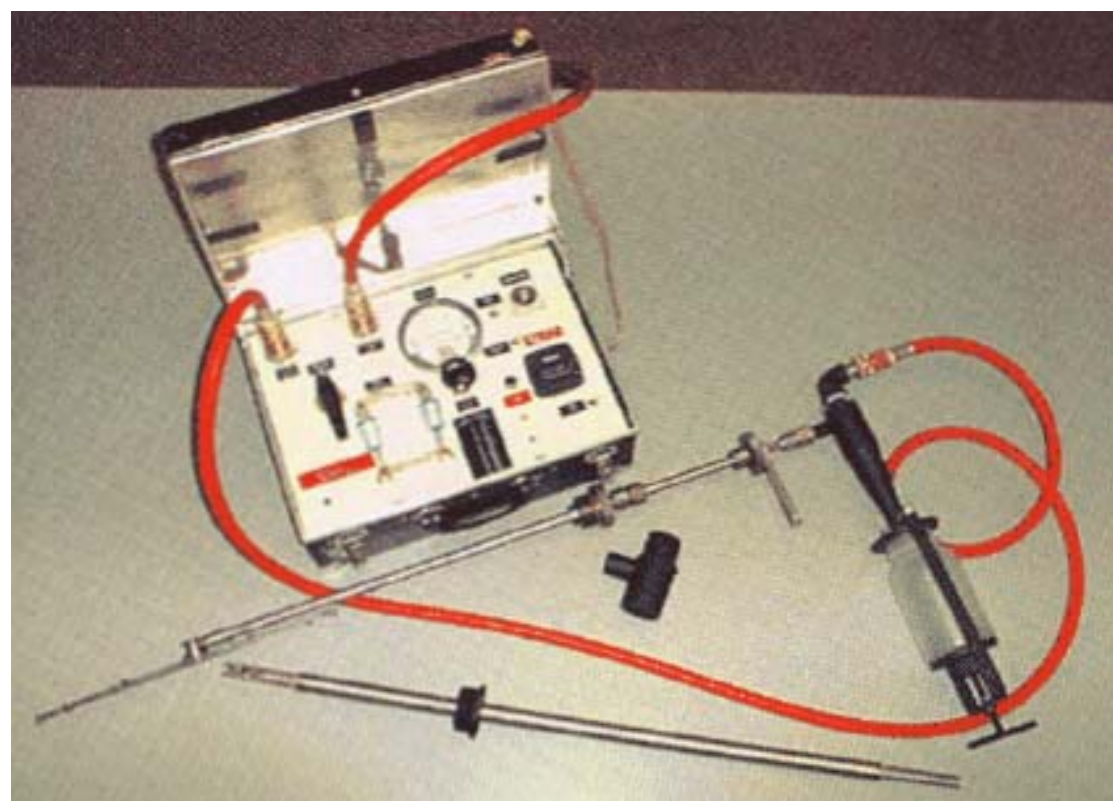

Figure 2.8. GE Rotorprobe and control box.

Figures 2.9 and 2.10 show sampling using the Rotorprobe procedure. A four-minute sample is collected from each pipe, during which time the tips are rotated twice $\left(720^{\circ}\right)$. During this rotation, however, the tips are paused for 15 seconds at 8 sampling points (similar to what is done in the previous method). 


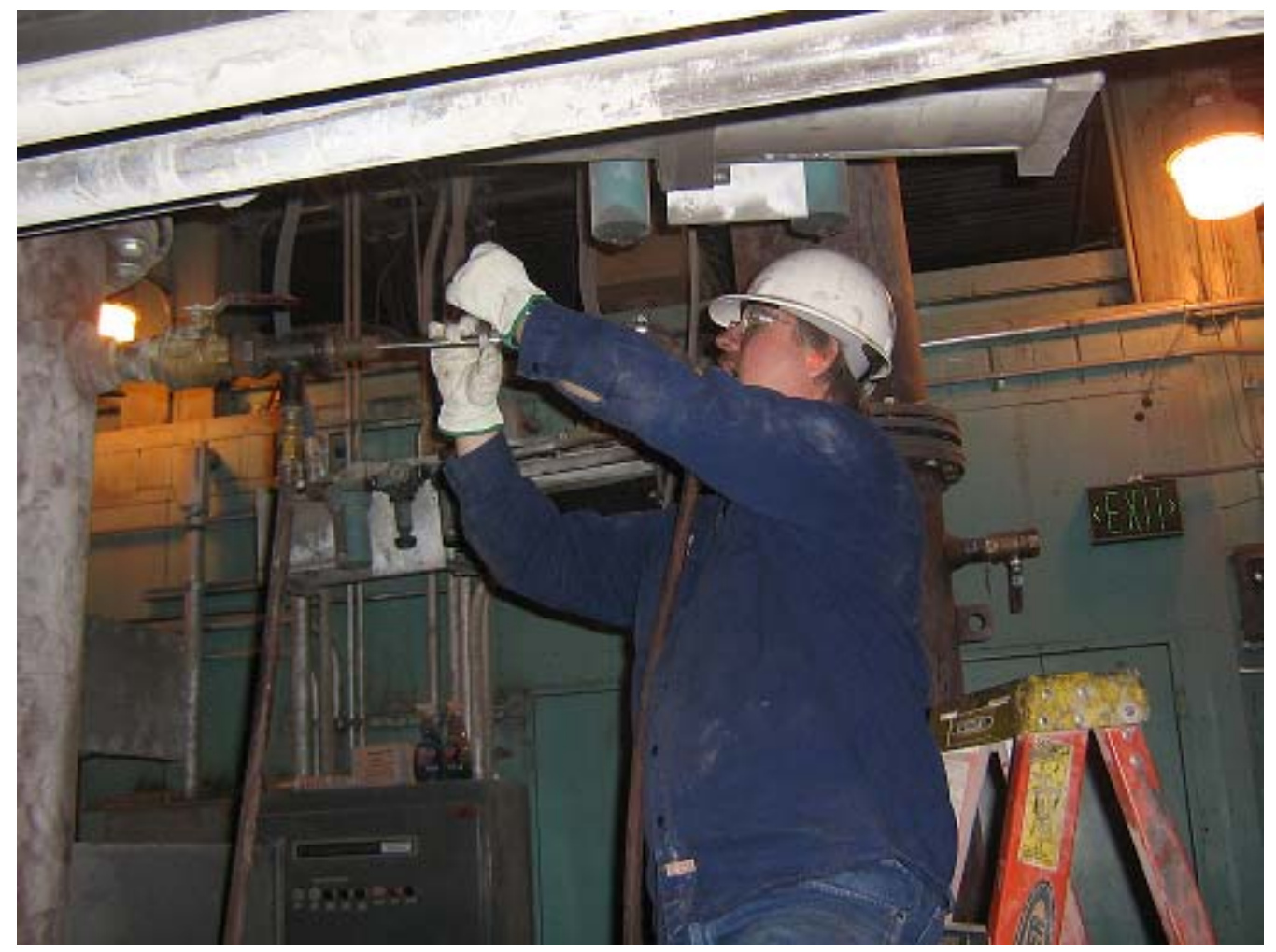

Figure 2.9. Dale Wilson, GE Energy, using the Rotorprobe.

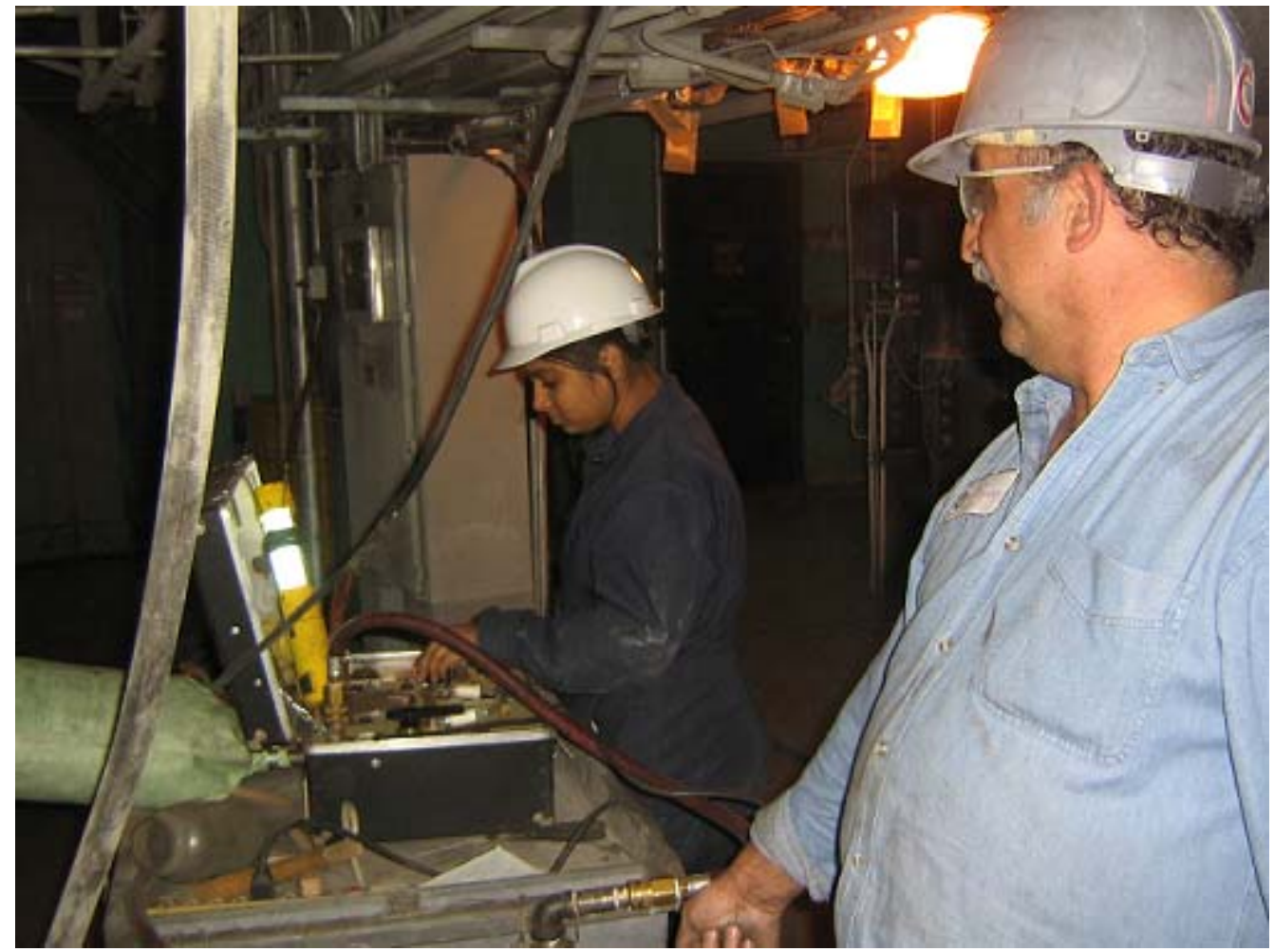

Figure 2.10. Frank Coen (GE Energy) and Rupali Panda (UAF) operating the Rotorprobe control box. 


\section{Quantification of PSD}

All pulverized coal samples were analyzed for PSD as percent passing 1180 microns, 600 microns, 300 microns, 150 microns, 76 microns, and 38 microns (16 mesh, 28 mesh, 48 mesh, 100 mesh, 200 mesh, and 400 mesh). This analysis was necessary for the RosinRammler plots. However, in the power plant industry, it is common to quantify the PSD of grind as percent passing 76 microns (200 mesh). Therefore, the same nomenclature is used throughout the report. The "PSD76" of a test implies the percentage of samples that are smaller than 76 microns, while "PSD" implies the entire particle size distribution.

\subsubsection{Bottom Ash Sampling}

Prior to the start of each test, the bottom ash was flushed out of the combustion chamber by flooding the bottom with water. At the conclusion of the test, the process was repeated, though modified slightly, so that a sample could be collected during the flushing. There was no other way to sample the bottom ash. This was a tedious process and somewhat hazardous. If not done carefully, hot embers flew out of the chamber when the access door was opened. GVEA staff was required to help take the samples. Figure 2.11 shows the bottom ash sample being scooped up against the flaming red combustion chamber in the background. The wet sample was always air dried before being sent to the lab.

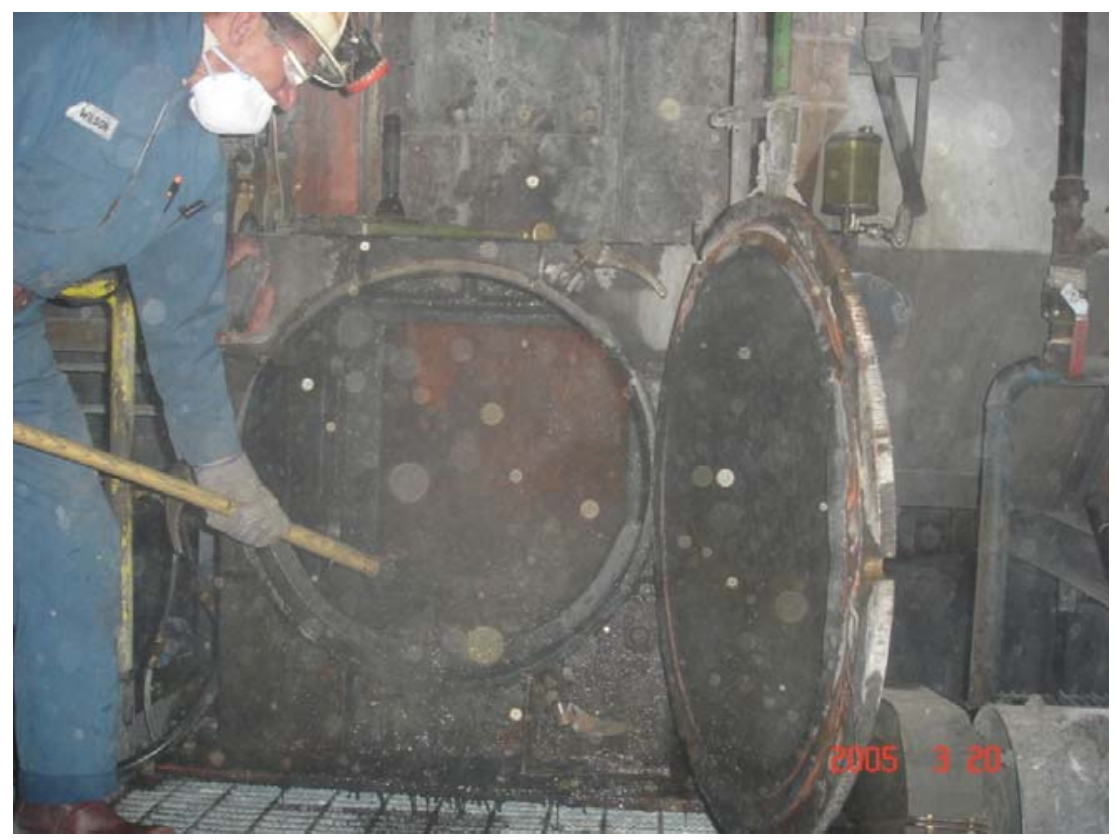

Figure 2.11. Dr. Terril Wilson (UAF) scoops up the bottom ash sample. 


\subsubsection{Fly Ash Sampling}

GVEA Healy Unit \#1 has a total of 12 fabric filters (bag houses), arranged in 2 columns, A and B, of 6 each. Figure 2.12 shows this arrangement.

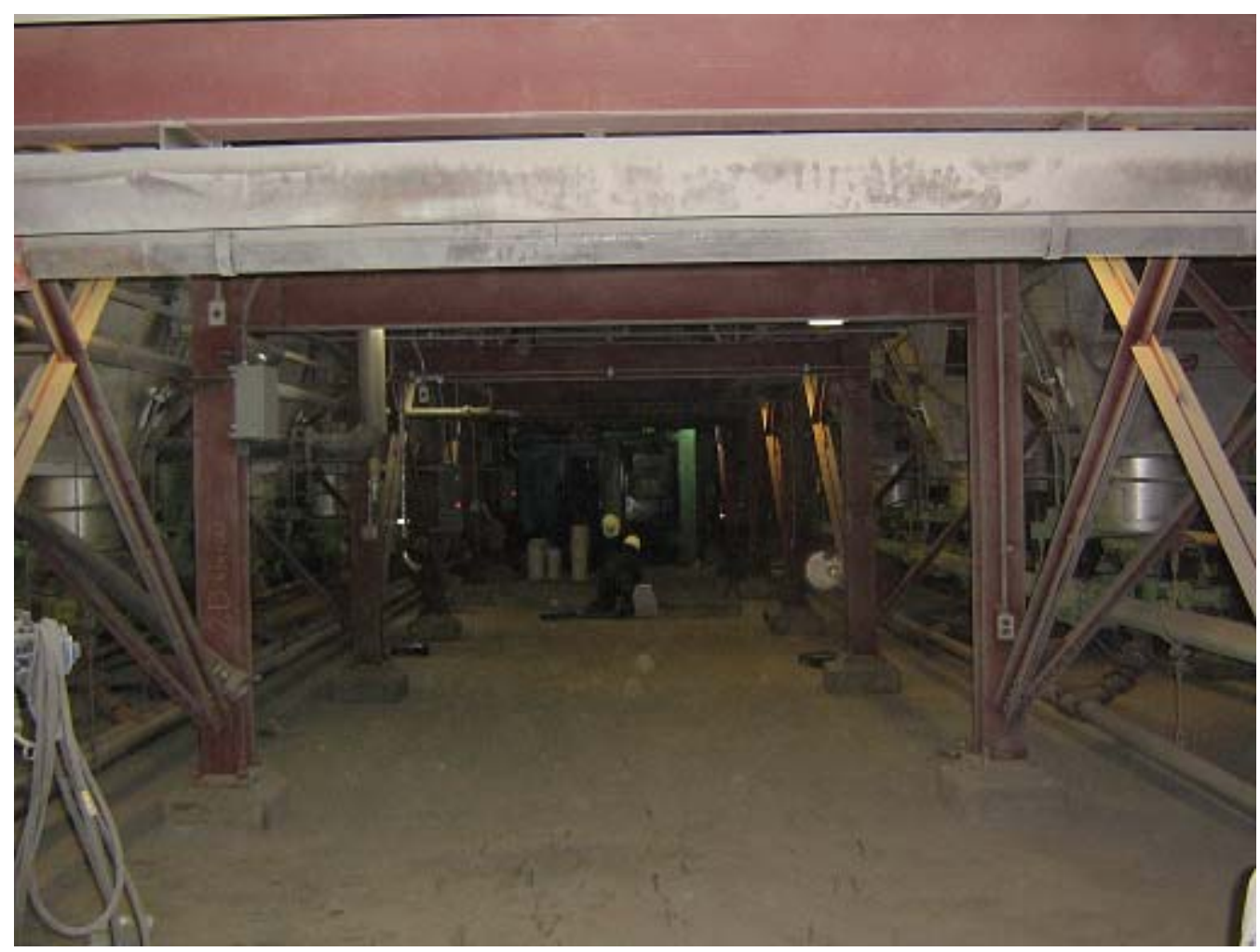

Figure 2.12. The arrangement of fabric filters on either side of the aisle. Rupali Panda and Abhishek Choudhury are seen at a distance handling the samples.

The fabric filters were emptied prior to each test. Every fabric filter had a sampling port and required a probe to obtain the samples. Samples from the same two rows in each column were pooled to obtain a composite sample. Therefore, each test resulted in three fly ash samples. Figure 2.13 shows a fly ash sample being taken. 


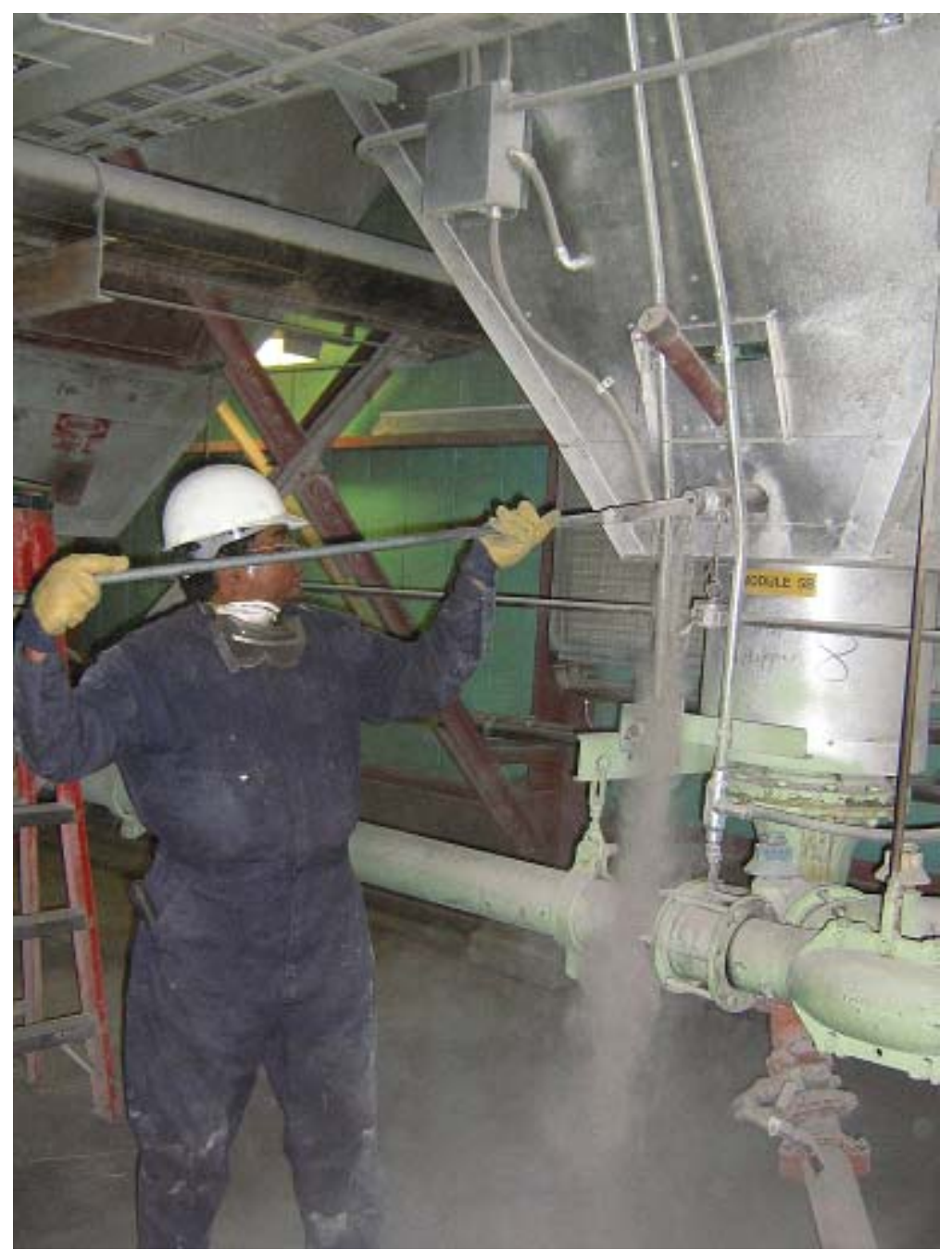

Figure 2.13. Abhishek Choudhury collecting a fly ash sample.

\subsection{Reduction in the Number of Pulverized Coal Samples}

When the project was started, it was decided to take as many pulverized coal samples as possible during a three-hour test. However, given how expensive the analysis was, the team decided to examine if indeed that many samples were needed. 
Initially, the team took six cycles of pulverized coal samples in three hours. A cycle is described as samples from all four pipes. Thus, a test typically yielded 24 samples. To examine the possibility of reduction in the number of samples, the obtained PSD76 values from Test 1 were used in a statistical simulation, where "n" samples (out of 23 for Test 1) were randomly selected. Selection was such that a value was picked from every pipe (A1, A2, B1, and B2); that is, the selection was in complete cycles. Using the $t$-test, the selected group was compared to the entire sample group (size 23). This experiment was repeated 500 times for each "n." The selected group was identical to the entire group over $95 \%$ of the time according to the $t$-test for all $\mathrm{n} \geq 4$. Similar results were produced for Test 2 (24 samples total).

Thus, the simulation from the first two tests showed that four samples were sufficient to estimate the average PSD76 during the test. Also, according to the same simulation, there was no improvement in the standard deviation of the means after 12 samples per test. Therefore, it was decided that there was no need to take more than 12 samples per test.

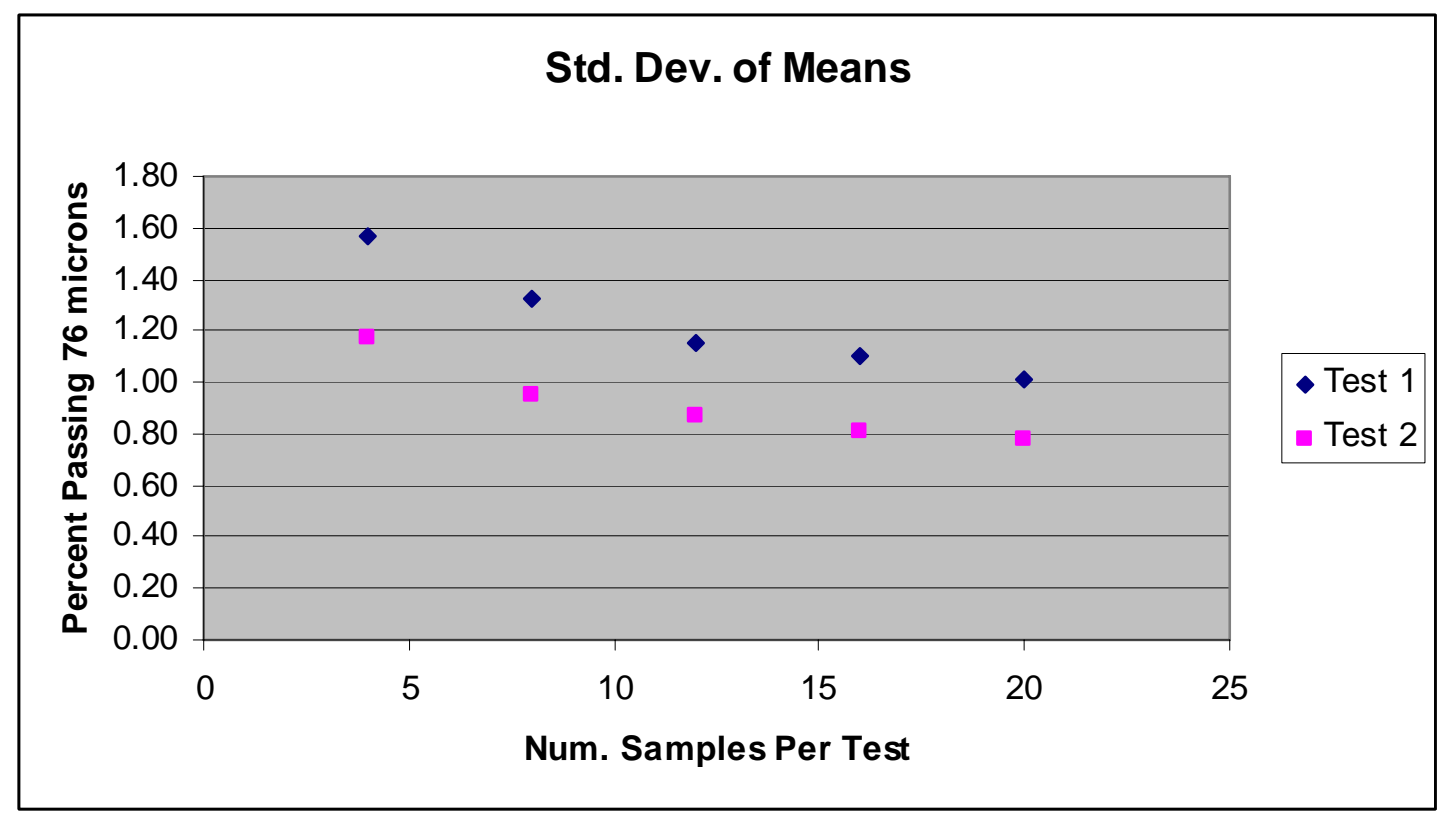

Figure 2.14. Lack of significant improvement of the standard deviation of means after 10-12 samples. 


\section{Results and Discussion}

The data are first presented followed by analysis. Tests 1 and 2 were part of the initial seed grant project and, therefore, did not include coal quality analysis. The only sample analysis that was done in Tests 1 and 2 was PSD of pulverized coal.

\subsection{Data from Tests}

\subsubsection{Feed (Raw) Coal}

The data from raw coal that was fed into the pulverizers are shown in Table 3.1. The main goal of the raw coal analysis was determining the HGI. Other analyses (proximate) were done based on budget outlook. Note that proximate analysis was always done on pulverized coal.

Table 3.1. Raw coal quality data

\begin{tabular}{|l|l|l|l|l|l|l|l|}
\hline & Ash & Moisture & Volatile & Sulfur & $\begin{array}{l}\text { Fixed } \\
\text { Carbon }\end{array}$ & $\mathrm{kJ} / \mathrm{kg}(\mathrm{BTU} / \mathrm{lb})$ & $\mathrm{HGI}$ \\
\hline Test 3 & 11.7 & 27.2 & 34.3 & 0.21 & 26.9 & $16,907(7275)$ & 34 \\
\hline Test 4 & 10.2 & 28.7 & 34.3 & 0.19 & 26.8 & $16,865(7257)$ & 31 \\
\hline Test 5 & 11.9 & 25.2 & 35.2 & 0.22 & 27.7 & $17,309(7448)$ & 31 \\
\hline Test 6 & & & & & & & 32 \\
\hline Test 7 & & & & & & & 33 \\
\hline Test 8 & & & & & & & 31 \\
\hline Test 9 & 12.7 & 27.5 & 31.2 & 0.20 & 28.3 & $16,331(7027)$ & 37 \\
\hline Test 10 & 12.2 & 27.4 & 31.7 & 0.19 & 28.7 & $16,479(7091)$ & 34 \\
\hline Test 11 & 11.8 & 27.5 & 32.2 & 0.19 & 28.5 & $16,633(7157)$ & 36 \\
\hline Test 12 & 12.3 & 27.5 & 32.0 & 0.21 & 28.2 & $16,461(7083)$ & 36 \\
\hline Test 13 & 13.5 & 27.5 & 31.3 & 0.21 & 27.8 & $16,349(7035)$ & 36 \\
\hline Test 14 & 12.3 & 27.0 & 31.6 & 0.22 & 29.2 & $16,747(7206)$ & 34 \\
\hline Test 15 & 11.4 & 27.3 & 32.4 & 0.22 & 28.9 & $16,954(7295)$ & 32 \\
\hline Test 16 & 12.7 & 27.1 & 32.3 & 0.21 & 28.0 & $16,540(7117)$ & 33 \\
\hline Test 17 & 14.0 & 27.2 & 31.7 & 0.19 & 27.1 & & 35 \\
\hline Test 18 & 13.9 & 27.2 & 32.3 & 0.19 & 26.7 & & 35 \\
\hline Test 19 & 13.6 & 26.6 & 32.3 & 0.20 & 27.5 & & 36 \\
\hline Test 20 & 12.3 & 26.1 & 33.1 & 0.18 & 28.5 & & 36 \\
\hline Test 21 & 14.1 & 28.2 & 30.8 & 0.20 & 27.0 & & 40 \\
\hline Test 22 & 12.8 & 28.3 & 31.2 & 0.20 & 27.7 & & 39 \\
\hline Test 23 & 13.8 & 29.3 & 32.5 & 0.21 & 24.5 & & 36 \\
\hline Test 24 & 13.3 & 31.3 & 31.8 & 0.20 & 23.6 & & \\
\hline Test 25 & 11.4 & 37.2 & 29.5 & 0.18 & 21.8 & & \\
\hline Test 26 & 13.4 & 29.0 & 33.2 & 0.20 & 24.4 & & \\
\hline
\end{tabular}

NOTE: All values are as received (unless otherwise mentioned). 


\subsubsection{Pulverized Coal}

The pulverized coal was sampled for proximate analysis and PSD analysis.

Table 3.2. Quality analysis of pulverized coal

\begin{tabular}{|l|l|l|l|l|l|l|}
\hline & Ash & Moisture & Volatile & $\mathrm{kJ} / \mathrm{kg}(\mathrm{BTU} / \mathrm{lb})$ & $\begin{array}{l}\text { Fixed } \\
\text { Carbon }\end{array}$ & Sulfur \\
\hline Test 1 & 15.8 & 14.1 & 38.7 & $19,094(8216)$ & 31.4 & \\
\hline Test 2 & 14.1 & 12.9 & 39.2 & $20,026(8617)$ & 33.9 & \\
\hline Test 3 & 13.8 & 15.6 & 40.0 & $19,329(8317)$ & 30.5 & 0.26 \\
\hline Test 4 & 12.9 & 16.7 & 40.0 & $19,324(8315)$ & 30.4 & 0.24 \\
\hline Test 5 & 13.0 & 16.0 & 40.4 & $19,552(8413)$ & 30.7 & 0.25 \\
\hline Test 6 & 11.1 & 19.9 & 37.6 & $18,838(8106)$ & 31.4 & 0.23 \\
\hline Test 7 & 11.6 & 18.4 & 37.7 & $19,096(8217)$ & 32.7 & 0.24 \\
\hline Test 8 & 10.3 & 18.5 & 37.9 & $19,296(8303)$ & 33.3 & 0.23 \\
\hline Test 9 & 13.6 & 17.5 & 36.3 & $18,564(7988)$ & 32.6 & 0.24 \\
\hline Test 10 & 14.3 & 13.3 & 38.8 & $19,640(8451)$ & 33.9 & 0.24 \\
\hline Test 11 & 14.1 & 13.1 & 38.0 & $19,856(8544)$ & 34.9 & 0.24 \\
\hline Test 12 & 14.2 & 12.5 & 38.2 & $20,038(8622)$ & 35.2 & 0.24 \\
\hline Test 13 & 15.5 & 15.5 & 36.7 & $18,941(8150)$ & 32.3 & 0.25 \\
\hline Test 14 & 14.9 & 15.3 & 37.4 & $19,236(8277)$ & 32.5 & 0.27 \\
\hline Test 15 & 14.5 & 15.0 & 37.6 & $19,310(8309)$ & 32.9 & 0.26 \\
\hline Test 16 & 16.1 & 15.2 & 37.0 & $18,766(8075)$ & 31.7 & 0.24 \\
\hline Test 17 & 15.6 & 15.1 & 39.9 & $19,868(8162)$ & 29.4 & \\
\hline Test 18 & 16.2 & 13.4 & 39.0 & $19,154(8242)$ & 31.4 & \\
\hline Test 19 & 15.6 & 12.9 & 39.3 & $19,459(8373)$ & 32.2 & \\
\hline Test 20 & 15.8 & 13.1 & 38.9 & $19,347(8325)$ & 32.2 & \\
\hline Test 21 & 15.1 & 17.9 & 37.4 & $18,357(7899)$ & 29.6 & \\
\hline Test 22 & 16.5 & 14.9 & 36.7 & $18,917(8140)$ & 31.9 & \\
\hline Test 23 & 13.9 & 17.9 & 39.0 & $19,029(8188)$ & 29.2 & \\
\hline Test 24 & 13.2 & 18.5 & 40.3 & $18,957(8157)$ & 28.1 & \\
\hline Test 25 & 14.9 & 18.0 & 38.1 & $18,671(8034)$ & 29.1 & \\
\hline Test 26 & 16.3 & 16.9 & 37.8 & $18,713(8052)$ & 29.0 & \\
\hline
\end{tabular}

NOTE: All values are as received (unless otherwise mentioned)

Note (by comparing Tables 3.1 and 3.2) the seeming enrichment of the coal (in terms of heating value) by grinding. This occurs due to the loss of moisture during grinding. 
The PSD76 data in the form of average percentage passing 76 microns (200 mesh) are given in Table 3.3.

Table 3.3. The average PSD76 (\% passing 76 microns or 200 mesh) for the tests

\begin{tabular}{|l|c|}
\hline & PSD76 \\
\hline Test 1 & 49 \\
\hline Test 2 & 42 \\
\hline Test 3 & 46 \\
\hline Test 4 & 48 \\
\hline Test 5 & 48 \\
\hline Test 6 & 50 \\
\hline Test 7 & 52 \\
\hline Test 8 & 46 \\
\hline Test 9 & 55 \\
\hline Test 10 & 54 \\
\hline Test 11 & 52 \\
\hline Test 12 & 46 \\
\hline Test 13 & 51 \\
\hline Test 14 & 52 \\
\hline Test 15 & 52 \\
\hline Test 16 & 51 \\
\hline Test 17 & 46 \\
\hline Test 18 & 49 \\
\hline Test 19 & 48 \\
\hline Test 20 & 50 \\
\hline Test 21 & 66 \\
\hline Test 22 & 70 \\
\hline Test 23 & 75 \\
\hline Test 24 & 67 \\
\hline Test 25 & 78 \\
\hline Test 26 & 81 \\
\hline
\end{tabular}

The average entire PSD, or percentage passing 1180 microns, 600 microns, 300 microns, 150 microns, 76 microns, and 38 microns (or 16 mesh, 28 mesh, 48 mesh, 100 mesh, 200 mesh, and 400 mesh, respectively), is presented as Rosin-Rammler (RR) plots in Appendix I. This is because such data are best understood graphically. RR plots are a standard way to visualize pulverized coal PSD. Notice how very little coal is retained coarser than 300 microns; that is, the points to the right of 300 microns (50 mesh) are close to zero. Also, as should be expected, the 3 points at 300, 150, and 76 microns usually form a straight line. 


\subsubsection{Fly Ash Data}

The fly ash samples were analyzed for ash; the carbon content in them was computed as 100 - percent $a s h_{d r y}$ basis. The unburned carbon in fly ash for the various tests is given in Table 3.4.

Table 3.4. The average unburned carbon in fly ash for the tests

\begin{tabular}{|l|c|}
\hline & $\begin{array}{c}\text { Carbon in fly } \\
\text { ash (\%) }\end{array}$ \\
\hline Test 3 & 3.6 \\
\hline Test 4 & 3.1 \\
\hline Test 5 & 4.1 \\
\hline Test 6 & 3.1 \\
\hline Test 7 & 2.6 \\
\hline Test $\mathbf{8}$ & 2.7 \\
\hline Test 9 & 3.6 \\
\hline Test 10 & 3.7 \\
\hline Test 11 & 3.7 \\
\hline Test 12 & 4.2 \\
\hline Test 13 & 2.8 \\
\hline Test 14 & 3.0 \\
\hline Test 15 & 3.4 \\
\hline Test 16 & 3.2 \\
\hline Test 17 & 1.9 \\
\hline Test 18 & 1.9 \\
\hline Test 19 & 2.6 \\
\hline Test 20 & 2.6 \\
\hline Test 21 & 2.4 \\
\hline Test 22 & 2.5 \\
\hline Test 23 & 1.2 \\
\hline Test 24 & 1.3 \\
\hline Test 25 & 1.0 \\
\hline Test 26 & 0.8 \\
\hline & \\
\hline
\end{tabular}




\subsubsection{Bottom Ash Data}

The bottom ash samples were analyzed for ash; the carbon content in them was computed as 100 - percent $a h_{\text {dry basis. }}$. The unburned carbon in bottom ash for the various tests is given in Table 3.5 .

Table 3.5. The average unburned carbon in bottom ash for the tests

\begin{tabular}{|l|c|}
\hline & $\begin{array}{c}\text { Carbon in } \\
\text { bottom ash }(\%)\end{array}$ \\
\hline Test 3 & 18.1 \\
\hline Test 4 & 4.6 \\
\hline Test 5 & 22.6 \\
\hline Test 6 & 17.4 \\
\hline Test 7 & 22.3 \\
\hline Test 8 & 25.4 \\
\hline Test 9 & 5.0 \\
\hline Test 10 & 5.9 \\
\hline Test 11 & 3.5 \\
\hline Test 12 & 4.3 \\
\hline Test 13 & 6.9 \\
\hline Test 14 & - \\
\hline Test 15 & 3.4 \\
\hline Test 16 & 4.4 \\
\hline Test 17 & 3.6 \\
\hline Test 18 & 3.6 \\
\hline Test 19 & 5.8 \\
\hline Test 20 & 5.8 \\
\hline Test 21 & 1.9 \\
\hline Test 22 & 0.9 \\
\hline Test 23 & 4.3 \\
\hline Test 24 & 7.1 \\
\hline Test 25 & 3.2 \\
\hline Test 26 & 5.2 \\
\hline
\end{tabular}




\subsubsection{Emissions Data}

Table 3.6 lists the total Hg (mercury) data (particle bound, oxidized, and elemental) on the stack gas samples taken for Tests 23 and 24. Note that Hg testing was added to the project at the very end. A contractor (Alaska Source Testing, Anchorage, AK) was hired to sample the stack gases and measure Hg emissions using the Ontario-Hydro method.

Table 3.6. Hg emissions through the stack

\begin{tabular}{|l|c|c|c|c|}
\hline \multirow{2}{*}{} & \multirow{2}{*}{$\mathrm{Hg}, \mathrm{kg} / \mathrm{hr}(\mathrm{lb} / \mathrm{hr})$} & \multicolumn{3}{|c|}{ Hg type (percent of total) } \\
\cline { 3 - 5 } & & $\begin{array}{c}\text { Particle } \\
\text { bound }\end{array}$ & Oxidized & Elemental \\
\hline Test 23 (finer) & $0.000408(0.000760)$ & 0.19 & 34.03 & 65.78 \\
\hline Test 24 (coarser) & $0.000300(0.000663)$ & 0.66 & 14.02 & 85.31 \\
\hline
\end{tabular}

The other emissions- $\mathrm{SO}_{2}, \mathrm{NO}_{\mathrm{x}}, \mathrm{CO}$, and $\mathrm{CO}_{2}$ - were measured using the automated CEMS. The data are presented in Table 3.7.

Table 3.7. Emissions data from continuous emissions monitoring system

\begin{tabular}{|l|c|c|c|c|}
\hline & $\begin{array}{l}\mathrm{SO}_{2} \\
(\mathrm{ppm})\end{array}$ & $\begin{array}{l}\mathrm{NO}_{x} \\
(\mathrm{ppm})\end{array}$ & $\begin{array}{l}\mathrm{CO} \\
(\mathrm{ppm})\end{array}$ & $\begin{array}{l}\mathrm{CO}_{2} \\
(\%)\end{array}$ \\
\hline Test 3 & 113 & 164 & 817 & 11.3 \\
\hline Test 4 & 104 & 158 & 1423 & 11.2 \\
\hline Test 5 & 113 & 175 & 1474 & 10.6 \\
\hline Test 6 & 120 & 151 & 937 & 11.9 \\
\hline Test 7 & 119 & 150 & 918 & 11.9 \\
\hline Test 8 & 131 & 157 & 797 & 11.8 \\
\hline Test 9 & 121 & 147 & 1654 & 11.6 \\
\hline Test 10 & 107 & 145 & 2708 & 11.7 \\
\hline Test 11 & 115 & 149 & 1779 & 11.3 \\
\hline Test 12 & 121 & 150 & 1725 & 11.4 \\
\hline Test 13 & 120 & 153 & 1300 & 11.8 \\
\hline Test 14 & 129 & 156 & 2715 & 11.8 \\
\hline Test 15 & 107 & 165 & 561 & 11.3 \\
\hline Test 16 & 119 & 168 & 1990 & 11.7 \\
\hline Test 17 & 114 & 165 & 363 & 11.2 \\
\hline Test 18 & 115 & 166 & 411 & 11.3 \\
\hline Test 19 & 107 & 161 & 483 & 11.4 \\
\hline Test 20 & 144 & 164 & 549 & 11.5 \\
\hline Test 21 & 137 & 159 & 321 & 12.9 \\
\hline Test 22 & 135 & 153 & 718 & 12.5 \\
\hline Test 23 & 112 & 134 & 1096 & 12.3 \\
\hline Test 24 & 123 & 136 & 1489 & 12.4 \\
\hline Test 25 & 133 & 154 & 221 & 12.4 \\
\hline Test 26 & 136 & 156 & 201 & 12.5 \\
\hline
\end{tabular}




\subsubsection{Operational Data}

The operational data from CEMS are given in Table 3.8.

Table 3.8. Operational data from CEMS

\begin{tabular}{|l|c|c|c|c|}
\hline & $\begin{array}{l}\text { Coal flow } \\
\text { rate kg/hr }\end{array}$ & Oxygen & $\begin{array}{l}\text { Mean } \\
\text { MW } \\
\text { generated }\end{array}$ & $\begin{array}{l}\text { Mill } \\
\text { amps }\end{array}$ \\
\hline Test 3 & 22,615 & 2.60 & 28.12 & 83.5 \\
\hline Test 4 & 23,709 & 2.54 & 28.29 & 88.9 \\
\hline Test 5 & 22,828 & 2.96 & 27.92 & 87.4 \\
\hline Test 6 & 22,850 & 2.30 & 28.47 & 89.5 \\
\hline Test 7 & 23,780 & 2.37 & 28.24 & 90.0 \\
\hline Test 8 & 22,460 & 2.29 & 28.45 & 88.6 \\
\hline Test 9 & 22,778 & 3.18 & 28.28 & 80.9 \\
\hline Test 10 & 22,505 & 3.20 & 28.33 & 77.5 \\
\hline Test 11 & 22,377 & 3.66 & 28.26 & 75.3 \\
\hline Test 12 & 22,429 & 3.79 & 28.29 & 72.1 \\
\hline Test 13 & 23,346 & 2.29 & 28.11 & 90.3 \\
\hline Test 14 & 23,084 & 2.57 & 28.11 & 88.3 \\
\hline Test 15 & 22,729 & 2.76 & 28.07 & 85.8 \\
\hline Test 16 & 23,466 & 2.75 & 28.03 & 81.2 \\
\hline Test 17 & 22,635 & 2.75 & 28.14 & 74.6 \\
\hline Test 18 & 22,719 & 2.74 & 28.05 & 74.2 \\
\hline Test 19 & 22,279 & 2.49 & 28.04 & 74.1 \\
\hline Test 20 & 22,365 & 2.51 & 27.99 & 74.8 \\
\hline Test 21 & 22,761 & 2.75 & 28.41 & 91.1 \\
\hline Test 22 & 22,967 & 2.73 & 28.55 & 91.9 \\
\hline Test 23 & 22,663 & 2.00 & 27.88 & 93.7 \\
\hline Test 24 & 22,721 & 2.08 & 28.06 & 91.5 \\
\hline Test 25 & 22,465 & 2.33 & 28.07 & 93.7 \\
\hline Test 26 & 22,688 & 2.25 & 28.05 & 92.9 \\
\hline
\end{tabular}

Note that the oxygen data are presented here to satisfy reader curiosity. The presented oxygen data are very difficult to use in any analysis since the plant setup (the path taken by the air and the location of the oxygen sensor) does not allow a direct relationship to be drawn between the oxygen and the nature of combustion. 


\subsection{Analysis}

In this section, the important relationships are presented first, followed by other interesting observations.

\subsubsection{PSD Versus Power Plant Efficiency}

The efficiency of the power plant was computed as the ratio of energy burned as coal to energy generated as electricity. The energy burned as coal is computed from the coal flow rate (Table 3.8) during a test and the coal calorific value (Table 3.2), while the MW generated is directly obtained (Table 3.8).

Table 3.9 presents the efficiency of the tests.

Table 3.9. The average PSD76 (\% passing 76 microns or 200 mesh) and power plant efficiency for the tests

\begin{tabular}{|l|c|c|}
\hline & PSD76 & Efficiency \\
\hline Test 1 & 49 & 0.2299 \\
\hline Test 2 & 42 & 0.2305 \\
\hline Test 3 & 46 & 0.231 \\
\hline Test 4 & 48 & 0.222 \\
\hline Test 5 & 48 & 0.225 \\
\hline Test 6 & 50 & 0.238 \\
\hline Test 7 & 52 & 0.224 \\
\hline Test 8 & 46 & 0.236 \\
\hline Test 9 & 55 & 0.240 \\
\hline Test 10 & 54 & 0.230 \\
\hline Test 11 & 52 & 0.229 \\
\hline Test 12 & 46 & 0.226 \\
\hline Test 13 & 51 & 0.228 \\
\hline Test 14 & 52 & 0.228 \\
\hline Test 15 & 52 & 0.230 \\
\hline Test 16 & 51 & 0.229 \\
\hline Test 17 & 46 & 0.236 \\
\hline Test 18 & 49 & 0.232 \\
\hline Test 19 & 48 & 0.232 \\
\hline Test 20 & 50 & 0.233 \\
\hline Test 21 & 66 & 0.244 \\
\hline Test 22 & 70 & 0.236 \\
\hline Test 23 & 75 & 0.2323 \\
\hline Test 24 & 67 & 0.2342 \\
\hline Test 25 & 78 & 0.2406 \\
\hline Test 26 & 81 & 0.2377 \\
\hline
\end{tabular}


The relationship between the PSD76 and efficiency is weak, as shown in Figure 3.1.

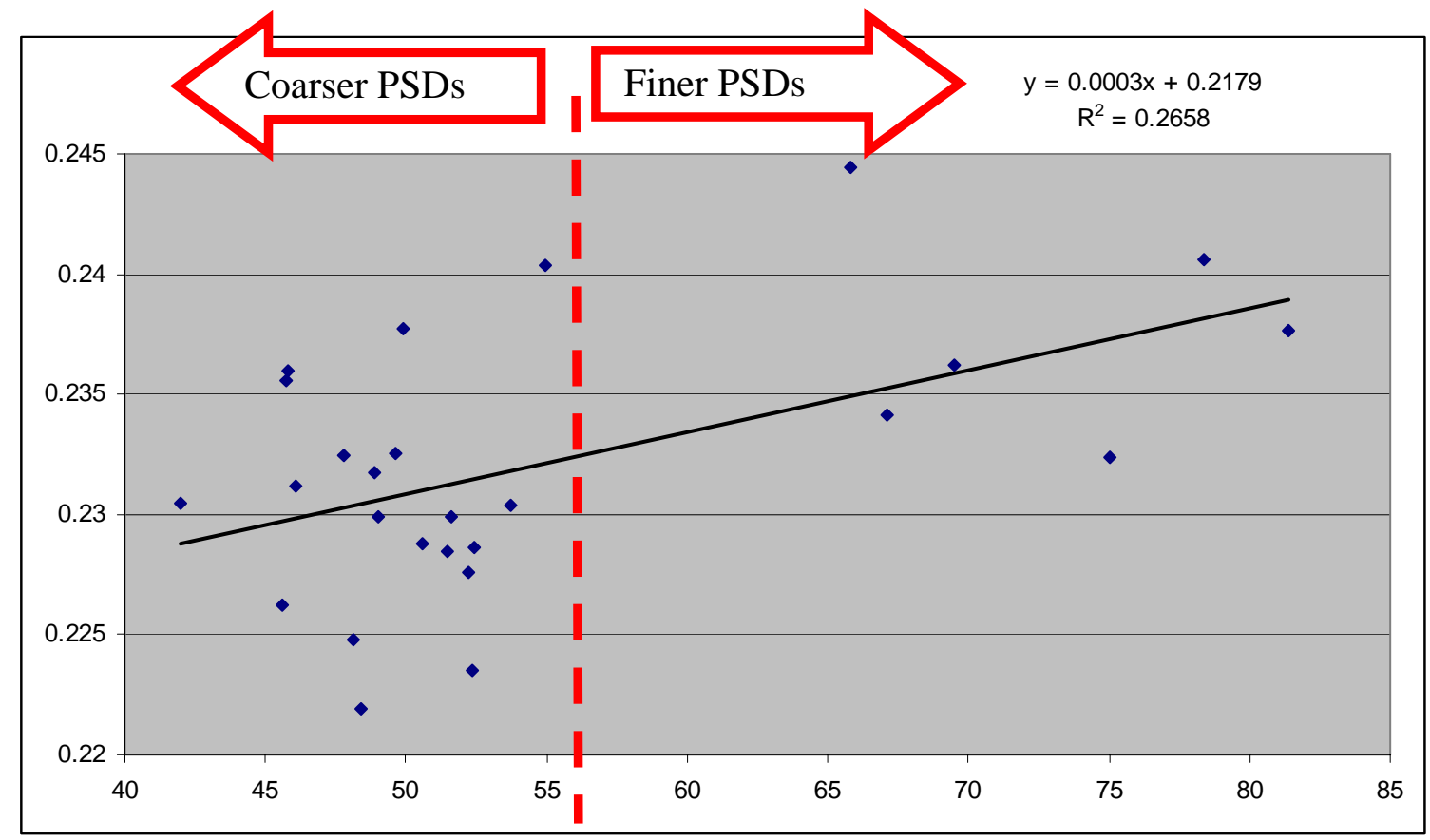

Figure 3.1. PSD of pulverized coal vs. plant efficiency.

The plot in Figure 3.1 makes the presence of two clusters of PSD76, one to the left of 60 (coarser PSD76) and the other to the right (finer PSD76), very evident. Therefore, it is tempting to compare the two clusters. The coarser PSD76 averaged 50\% passing 76 microns, while the finer PSD76 averaged 73\% passing 76 microns.

Table 3.10 presents the previous table (Table 3.9) as two separate clusters. 
Table 3.10. The two separate groups of PSD76 tested in the project

\begin{tabular}{|l|c|c|}
\hline \multicolumn{3}{|c|}{ Cluster 1: Coarse PSD76 } \\
\hline & PSD76 & Efficiency \\
\hline Test 2 & 42 & 0.2305 \\
\hline Test 3 & 46 & 0.231 \\
\hline Test 8 & 46 & 0.236 \\
\hline Test 12 & 46 & 0.226 \\
\hline Test 17 & 46 & 0.236 \\
\hline Test 4 & 48 & 0.222 \\
\hline Test $\mathbf{5}$ & 48 & 0.225 \\
\hline Test 19 & 48 & 0.232 \\
\hline Test 1 & 49 & 0.2299 \\
\hline Test 18 & 49 & 0.232 \\
\hline Test 6 & 50 & 0.238 \\
\hline Test 20 & 50 & 0.233 \\
\hline Test 13 & 51 & 0.228 \\
\hline Test 16 & 51 & 0.229 \\
\hline Test 7 & 52 & 0.224 \\
\hline Test 11 & 52 & 0.229 \\
\hline Test 14 & 52 & 0.228 \\
\hline Test 15 & 52 & 0.23 \\
\hline Test 10 & 54 & 0.23 \\
\hline Test 9 & 55 & 0.24 \\
\hline
\end{tabular}

\begin{tabular}{|l|c|c|}
\hline \multicolumn{3}{|c|}{ Cluster 2: Fine PSD76 } \\
\hline & PSD76 & Efficiency \\
\hline Test 21 & 66 & 0.244 \\
\hline Test 24 & 67 & 0.2342 \\
\hline Test 22 & 70 & 0.236 \\
\hline Test 23 & 75 & 0.2323 \\
\hline Test 25 & 78 & 0.2406 \\
\hline Test 26 & 81 & 0.2377 \\
\hline
\end{tabular}

The average efficiencies of the two groups are 0.2305 and 0.2375 , with the finer PSD76 having an efficiency about 3\% higher than the coarser PSD76. However, the almost similar efficiencies are statistically different ( $t$-stat: 3.44$)$ when their means are compared by $t$-tests (assuming unequal variances). The $t$-test could be done since efficiency and PSD76 data in the two groups were normally distributed.

To explore if the difference in efficiency can be explained by factors other than PSD76, the coal quality (ash, volatile content, moisture, unburned carbon in fly ash and bottom ash, and oxygen) differences were studied. Note, however, that coal quality can only be used as a very broad guide when discussing combustion, since similar coals can often have very different combustion performance/characteristics while different coals have similar performance/characteristics (Carpenter et al., 2007). 


\section{Fuel Type Comparison}

Table 3.11a summarizes the coal quality comparison. A comparison based on $t$-test was not done for any data group that failed the Anderson-Darling test for normality. Such groups are identified with an "N/A" under the $t$-stat column.

Table 3.11a. Comparison in the coal quality of the coal burned in coarser PSD76 tests and finer PSD76 tests (quality values are for pulverized coal unless mentioned otherwise)

\begin{tabular}{|c|c|c|c|c|}
\hline & \multicolumn{2}{|c|}{ Average } & \multirow[t]{2}{*}{ t-stat } & \multirow{2}{*}{$\begin{array}{l}\text { Significant } \\
\text { difference? }\end{array}$} \\
\hline & Coarser & Finer & & \\
\hline Ash & 14.15 & 14.98 & 1.28 & No \\
\hline Volatile content & 38.43 & 38.22 & 0.37 & No \\
\hline Volatile content $^{\mathrm{RC}}$ & 32.5 & 31.5 & 1.66 & No \\
\hline Moisture & 15.2 & 17.35 & N/A & N/A \\
\hline Moisture ${ }^{\mathrm{RC}}$ & 27.1 & 30.6 & MWT & Yes \\
\hline $\begin{array}{l}\text { Heat Val, kJ/kg } \\
\text { (BTU) }\end{array}$ & $\begin{array}{l}19,337 \\
(8320)\end{array}$ & $\begin{array}{l}18,774 \\
(8078)\end{array}$ & 4.1 & Yes \\
\hline Fixed carbon content & 32.3 & 29.5 & N/A & N/A \\
\hline HGI & 34 & 37.8 & 3.8 & Yes \\
\hline
\end{tabular}

The ash and volatile contents are statistically similar for the two groups, with the pulverized coal volatile content being almost identical. However, there appears to be a difference in the moisture content, though the significance of the difference cannot be estimated for pulverized coal. The Mann-Whitney ${ }^{2}$ test, which could be applied to the raw coal data (for moisture), implied that the moisture content was higher for finer PSD76. Higher moisture coals are more reactive, leading to more complete combustion and higher efficiencies. In this case, the finer grinds had over $14 \%$ more moisture than coarser PSD76. But higher moisture also means loss of heat in converting the moisture to steam, thereby lowering efficiency.

The fixed carbon content is higher in the coarser test coals. Since the fixed carbon data for the fine group were not normally distributed, a significance test could not be done to compare the two groups based on fixed carbon. Therefore, whether the difference is significant is unknown. When combined with their lower moisture contents, it is no surprise that they (coarser test coals) have higher heating values, though the heating value is impacted by more than just moisture and fixed carbon. Also, heating value is not an indicator of the quality and nature of combustion (Carpenter et al., 2007).

While the moisture content and fixed carbon probably help improve the efficiency of the coarser tests, their lower HGIs probably hurt their efficiencies. It is not possible to know, of course, if these two factors compensated for each other.

\section{Unburned Carbon Comparison}

\footnotetext{
${ }^{2}$ http://faculty.vassar.edu/lowry/utest.html
} 
The unburned carbon (Table 3.11b) was also examined to understand the performance of the tests. The $t$-test was not applicable for bottom ash data, as the data for unburned carbon in bottom ash (coarse group) were not normally distributed.

Table 3.11b. Comparison of unburned carbon

\begin{tabular}{|l|c|c|c|c|}
\hline & \multicolumn{2}{|c|}{ Average } & t-stat & $\begin{array}{c}\text { Significant } \\
\text { difference? }\end{array}$ \\
\cline { 2 - 5 } & Coarser & Finer & & Yes \\
\hline $\begin{array}{l}\text { Unburned carbon } \\
\text { (fly ash) }\end{array}$ & 3.1 & 1.53 & 4.65 & N/A \\
\hline $\begin{array}{l}\text { Unburned carbon } \\
\text { (bottom ash) }\end{array}$ & 9.56 & 3.77 & N/A & *at 95\% confidence \\
\hline
\end{tabular}

The unburned carbon in both fly ash and bottom ash are higher for coarser PSD76, which would suggest that there was loss of carbon when coal was burned coarser. This type of observation is standard in bituminous coal and could explain the lower efficiencies of coarser grind combustion. However, with Alaskan low-rank coal (according to US DOE researchers Freeman et al., 1996), almost complete burnout is typical even at significantly coarser grinds. Also, the higher unburned carbon contents can be very easily explained by the fixed carbon contents of the two groups. As presented earlier, the coarser tests had higher fixed carbon content than finer grinds, which could have resulted in higher unburned carbon. This is especially possible since the fixed carbon content percentage applies to the entire tonnage that is burned, while the unburned carbon percentage applies only to a small portion of the total tonnage.

An additional issue that prevents the aggressive use of unburned carbon values in differentiating the two groups would be the quality of bottom ash samples. As described in section 2.3.4, the bottom ash sampling was not ideal since samples had to be collected from whatever bottom ash washed out. Whether these samples are representative of the bottom ash is anybody's guess. As seen in Table 3.5, bottom ash values have had a wide range.

\section{Coarse Versus Fine Efficiency Comparison: Summary}

The aforementioned factors provide a fuzzy picture with regard to efficiency. One should also take into account that the finer grind group has only 6 data points compared with the coarse group, which has 18-20 data points. Since the difference in efficiency is small, a single high/low data point in the finer group (in a future test) could blur the differences. Also notable is that 7 out of the 20 tests in the coarse group have efficiency values that are within the fine group PSD76 range. 


\subsubsection{PSD76 Versus $\mathrm{SO}_{2}, \mathrm{NO}_{\mathrm{x}}, \mathrm{CO}$, and $\mathrm{CO}_{2}$ Emissions}

Figures 3.2 to 3.5 show the relationship between PSD76 and $\mathrm{SO}_{2}(\mathrm{ppm}), \mathrm{NO}_{\mathrm{x}}(\mathrm{ppm}), \mathrm{CO}$ (ppm), and $\mathrm{CO}_{2}(\%)$.

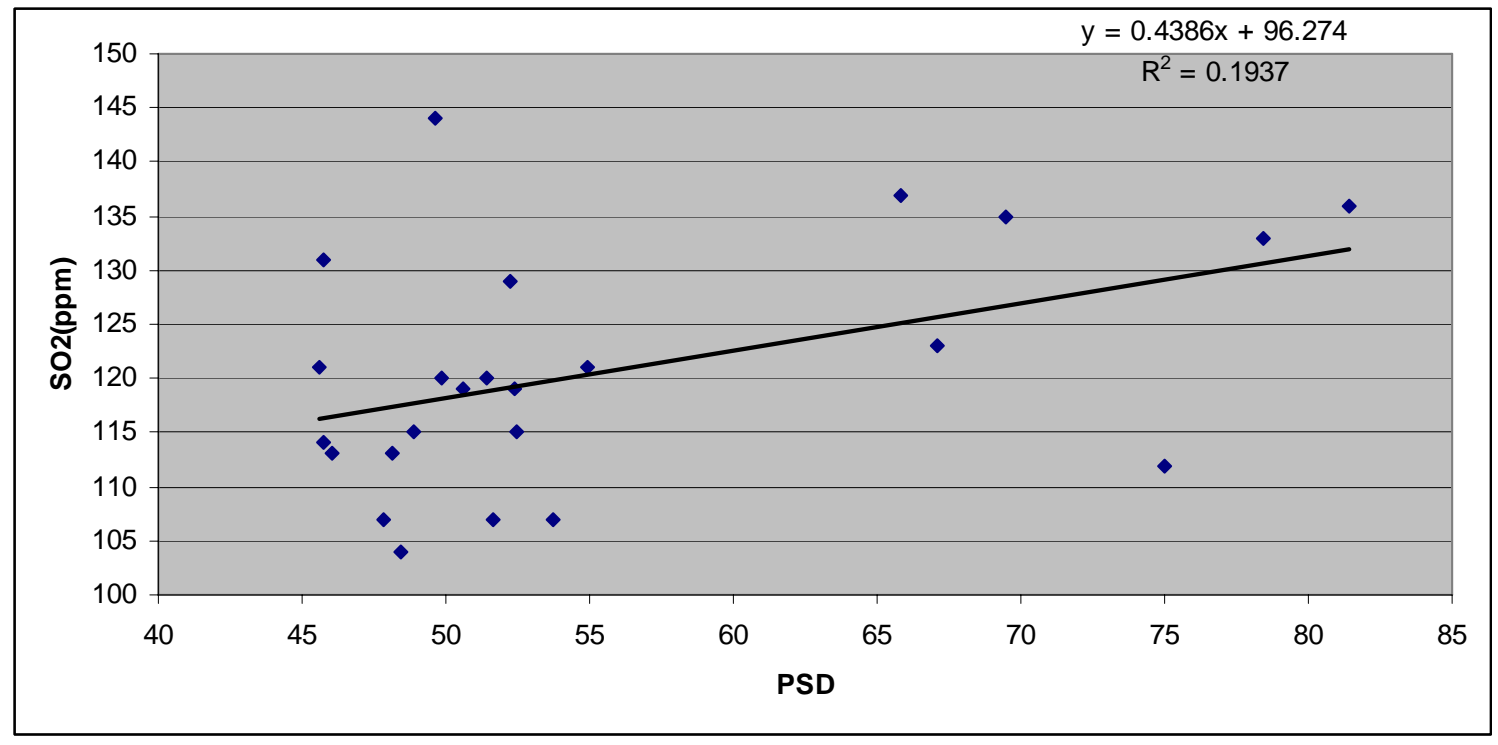

Figure 3.2. PSD76 vs. $\mathrm{SO}_{2}$ (ppm).

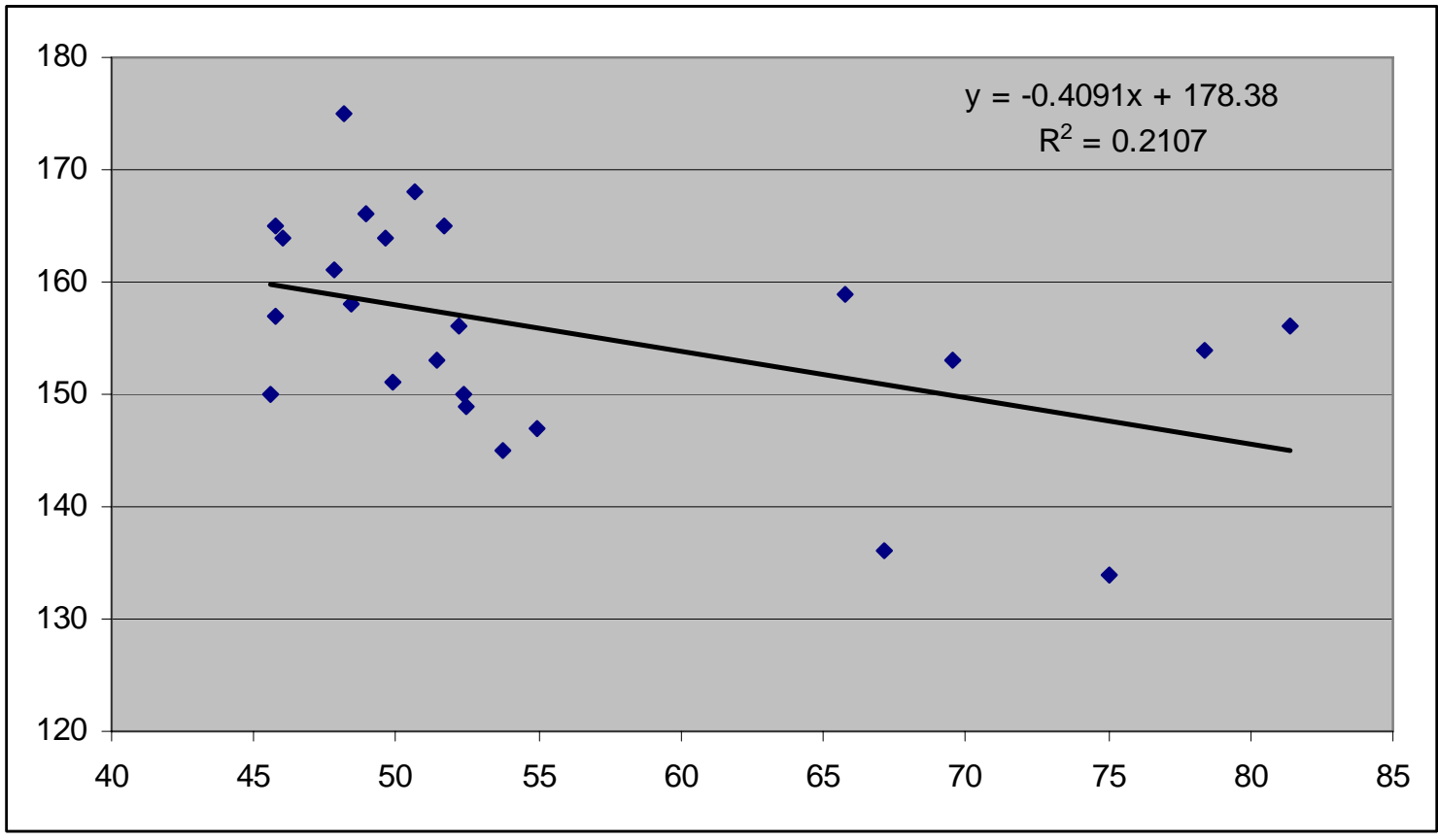

Figure 3.3. PSD76 vs. $\mathrm{NO}_{\mathrm{x}}(\mathrm{ppm})$. 


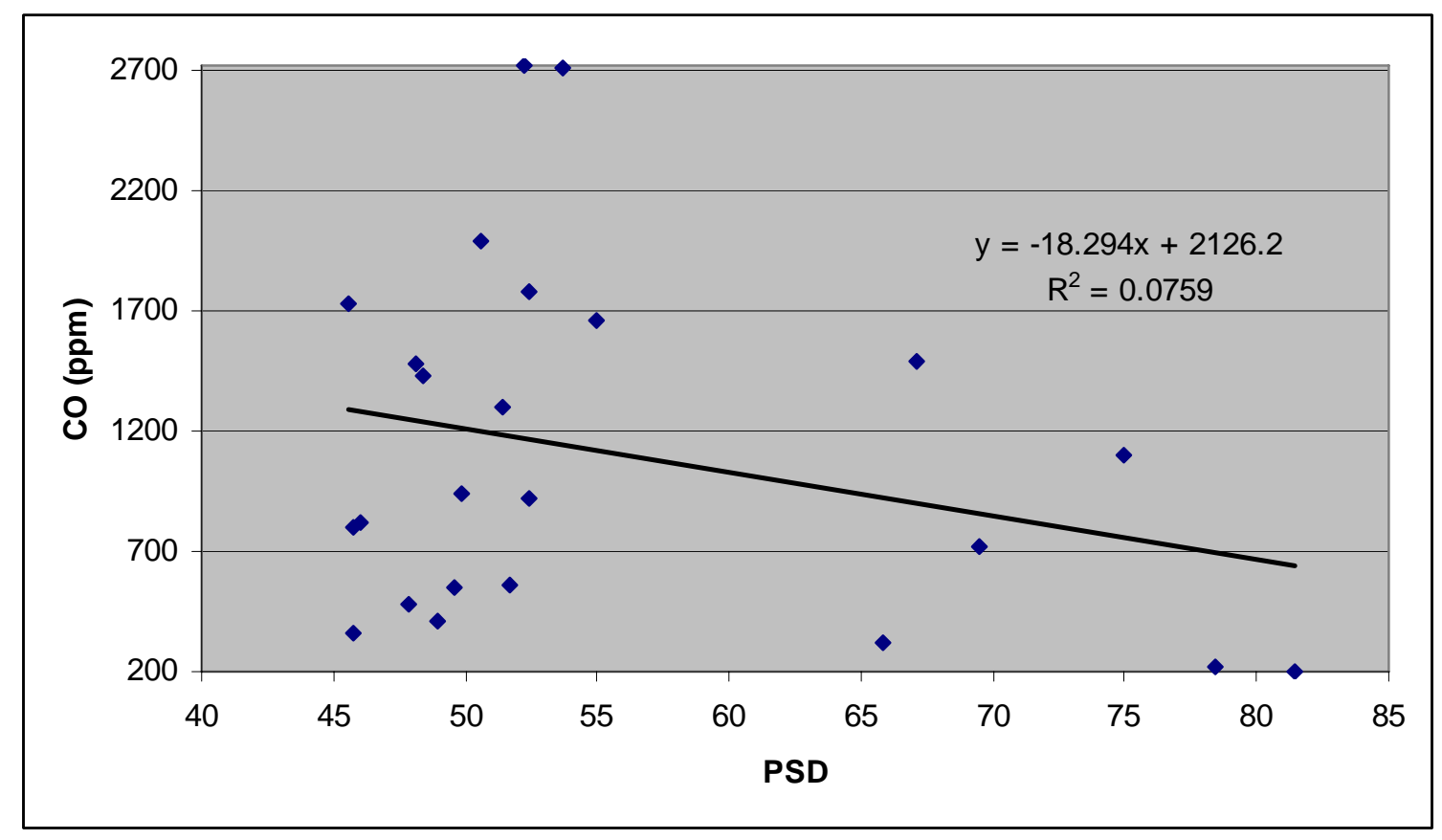

Figure 3.4. PSD76 vs. CO (ppm).

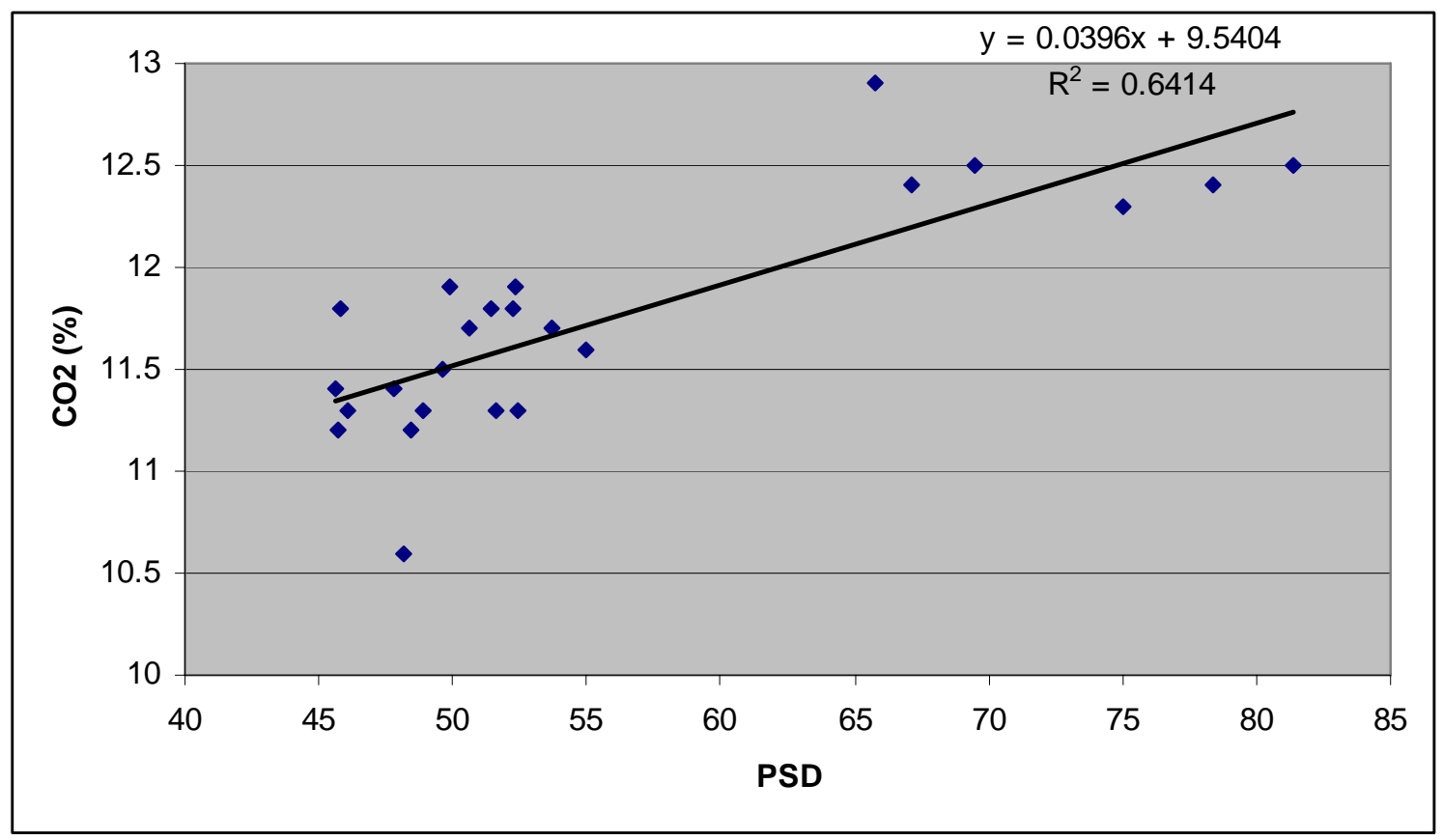

Figure 3.5. PSD76 vs. $\mathrm{CO}_{2}(\%)$. 
Other than PSD76 versus $\mathrm{CO}_{2}$, all the other relationships appear weak. As was done before, the tests were split into two groups: coarse (percent passing 76 microns at 55 and below) and fine.

Table 3.12. Comparison of emissions between coarser PSD76 tests and finer PSD76 tests

\begin{tabular}{|l|c|c|c|c|}
\hline & \multicolumn{2}{|c|}{ Average } & \multirow{2}{*}{ t-stat } & $\begin{array}{c}\text { Significant } \\
\text { difference? }\end{array}$ \\
\cline { 2 - 5 } & Coarser & Finer & & Yes \\
\hline $\mathrm{SO}_{2}$ & 118 & 129 & 2.5 & No \\
\hline $\mathrm{NO}_{\mathrm{x}}$ & 158 & 149 & 1.9 & No \\
\hline $\mathrm{CO}$ & 1256 & 674 & 2.1 & Yes \\
\hline $\mathrm{CO}_{2}$ & 11.5 & 12.5 & 8.8 & \multicolumn{3}{l}{} \\
* at 95\% confidence interval & \multicolumn{4}{l}{}
\end{tabular}

$\mathrm{SO}_{2}$ and $\mathrm{CO}_{2}$ emissions seem to rise with finer grind. When sulfur (from Table 3.1) was explored as a possible reason for higher $\mathrm{SO}_{2}$, it was found that there was no correlation $\left(\mathrm{R}^{2}\right.$ of 0.001$)$ between the two $\left(\mathrm{S}\right.$ and $\left.\mathrm{SO}_{2}\right)$. The sulfur contents of the coarse group could not be compared to the fine group since the sulfur data of the fine group was not normally distributed.

As regards $\mathrm{CO}_{2}$, fixed carbon was explored as a reason. As presented earlier, the fixed carbon contents of pulverized coal were higher for coarser grinds (mean: 32.3\%) than for finer grinds (mean: 29.5\%). Thus, the $\mathrm{CO}_{2}$ emissions are contrary to what would be suggested by the fixed carbon contents. The finer tests did have higher moisture content, as seen in Table 3.11a. Higher moisture content could have increased $\mathrm{CO}_{2}$ and $\mathrm{SO}_{2}$ emissions, though a direct correlation between them (moisture content of pulverized coal and $\mathrm{CO}_{2}$ and $\mathrm{SO}_{2}$ concentration) shows negligible correlation (Figure 3.6).

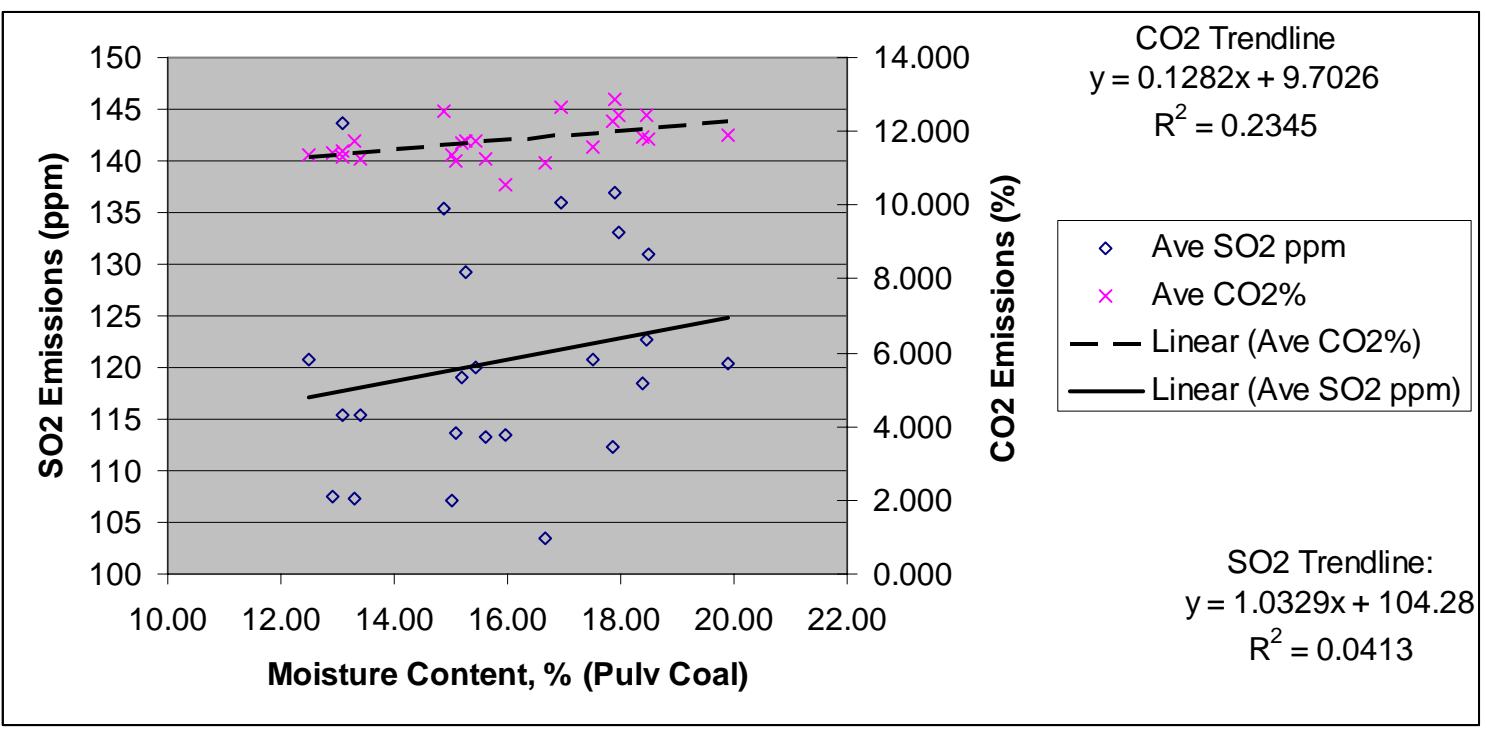

Figure 3.6. Negligible correlation between moisture content of coal and $\mathrm{SO}_{2}$ and $\mathrm{CO}_{2}$ emissions. 
Note that higher moisture content (as for finer grinds) usually results in higher amounts of flue gases. Therefore, higher concentrations (in higher amounts of flue gases) of emissions are especially significant.

The $\mathrm{CO}_{2}$ observation is critical in light of the current global sensitivity to $\mathrm{CO}_{2}$ emissions. The implication of Figure 3.5 and Table 3.12 is that by burning low-rank Alaskan coal at a PSD76 of $50 \%$ instead of $70 \%$, one could reduce the $\mathrm{CO}_{2}$ emissions concentration by about $8 \%$ (the difference between $11.5 \%$ and $12.5 \%$ concentration), though reducing the concentration of emissions is not the same as reducing the total quantity of emissions. Unfortunately, total $\mathrm{CO}_{2}$ emissions could not be studied, as neither the power plant nor the research was set up to conduct a carbon mass balance at the level necessary to conclude on $\mathrm{CO}_{2}$ emissions. Additionally, it is difficult to explain the relationship. Measurement bias in the CEMS is a possibility since $\mathrm{CO}_{2}$ data from 2005 (on days of the test but not during the test) reveal lower values of emitted $\mathrm{CO}_{2}$ compared to 2006 and 2008. Since $\mathrm{CO}_{2}$ tonnage values are based on many constants and assumptions, it is possible that a change was made to a factor that resulted in slightly higher values of $\mathrm{CO}_{2}$. Note that this is only a suspicion and could not be verified.

Given the current importance of $\mathrm{CO}_{2}$, $\mathrm{PSD}-\mathrm{CO}_{2}$ relationship may be worth examining.

\subsubsection{PSD76 Versus Hg}

Not much can be said about the relationship of PSD76 versus HG besides to note that Hg emissions through the stack are very small. These emissions are so close to detection limits that the difference evident in Table 3.6, where the coarser test had the lower Hg emissions, is negligible.

\subsubsection{PSD76 Versus Mill Power Consumption}

Ganguli and Bandopadhyay (2008) examined the relationship between mill power consumption and PSD76 based on data from Tests 3-22. A direct relationship between mill power consumption and PSD76 was not observed (Figure 3.7a). 


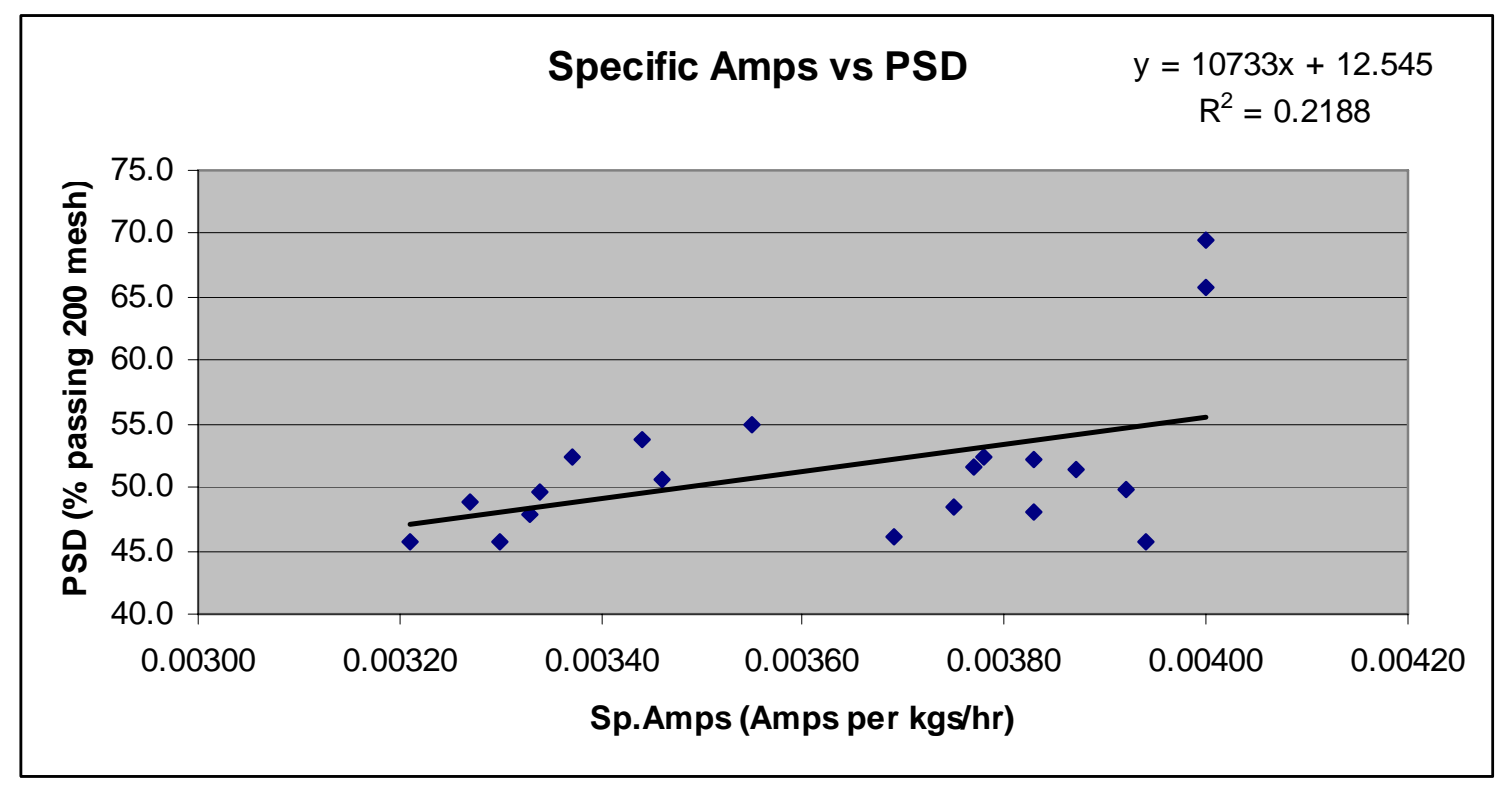

Figure 3.7a. Almost negligible relationship between PSD76 and specific mill amperage (Ganguli and Bandopadhyay, 2008).

When HGI and coal flow rates were factored in, the following relationship was observed:

$$
\text { Amps }=-26.3113+0.908 * \text { PSD76 }-1.652 * \text { HGI }+0.00523 * \text { Flow }
$$

where Amps is the combined amperage of the two mills and Flow is the coal flow rate in $\mathrm{kg} / \mathrm{hr}$.

The correlation coefficient for the relationship jumped from 0.22 (Figure 3.7a) to 0.64. Additionally, the coefficients for PSD76, HGI, and Flow were all significant, implying that these factors play a role in influencing Amps. Since PSD76 and Flow had positive coefficients, the relationship implies that as PSD76 and Flow go up, so do Amps, which makes sense.

When Figure 3.7a was updated with data from Tests 23-26, a direct correlation between PSD76 and power consumption appeared (Figure 3.7b). 


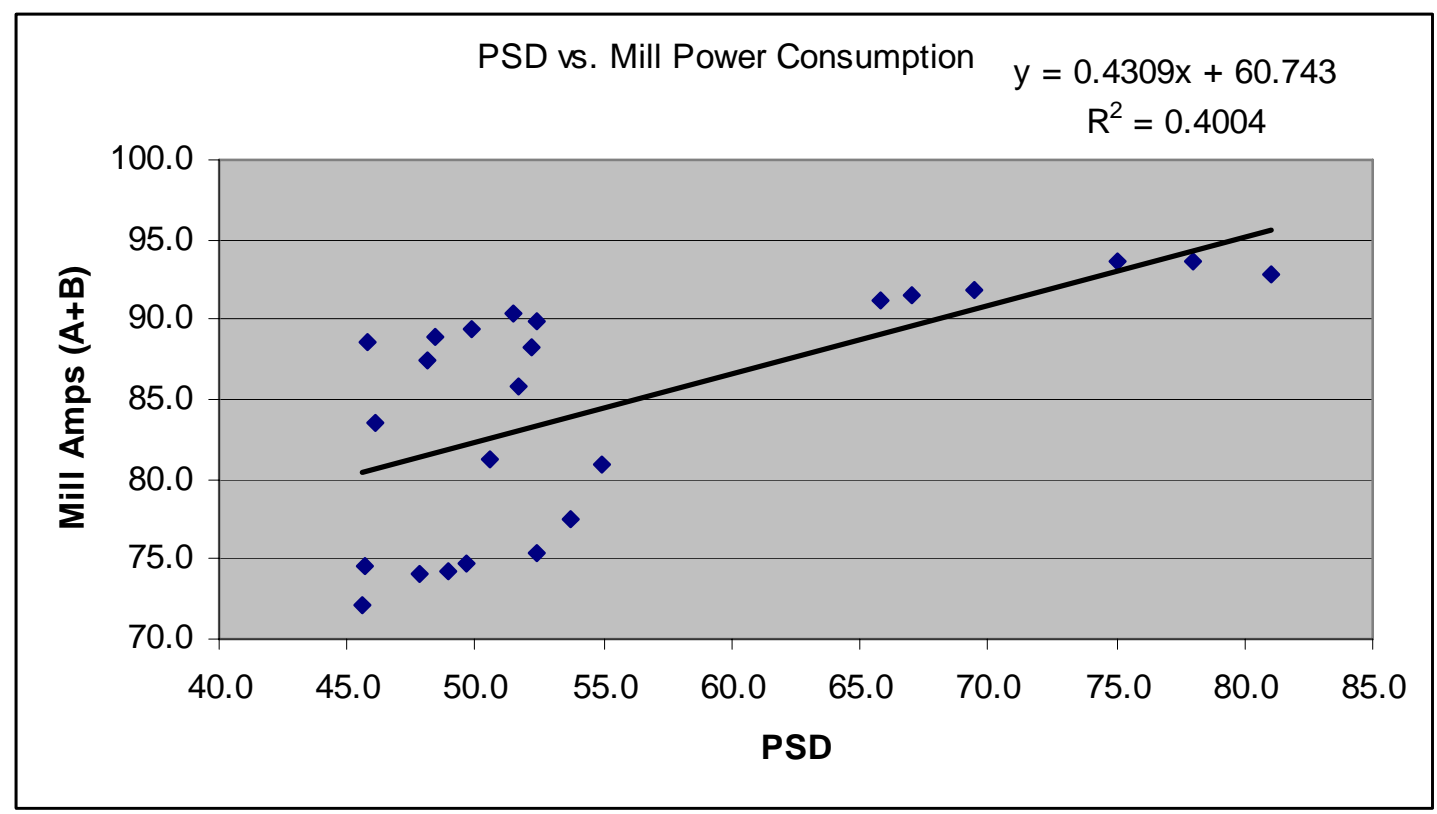

Figure 3.7b. Power consumption increases as PSD76 increases (becomes finer).

Equation (3.1) was updated also with the data from Tests 23-26:

$$
\text { Amps }=-76.7+0.584 * \text { PSD }-0.942 * \text { HGI }+0.0071 * \text { Flow }
$$

The addition of the new data further improved the correlation coefficient to 0.68 . The coefficients for PSD76, HGI, and Flow were all significant. The residuals from applying Equation (3.2) were centered at zero and passed the Anderson-Darling test for normality, thus validating Equation (3.2).

When the mill power consumption was studied on a coarse grind versus fine grind basis (Tables 3.8 and 3.10 ), the coarse grind tests consumed $13.34 \%$ less power ( 0.0036 amps per $\mathrm{kg} / \mathrm{hr}$ ) than the fine grind tests $(0.0041 \mathrm{amps}$ per $\mathrm{kg} / \mathrm{hr})$. The $t$-test was not applicable to the data; hence, no estimate of the significance of the difference is provided.

Equation (3.2) can be utilized to compute the savings in mill power consumption from coarse grinding. The electricity costs for the mill can be computed by the equation

$$
\text { Amps*Voltage* } \sqrt{3} * \text { power factor*Hours*Cost of saving electricity }
$$


Since the mills are run at about $2.4 \mathrm{kV}, 0.7$ power factor, 365 days a year, with a 95\% availability, the cost is (at 20 cents per $\mathrm{kwh}^{3}$ at Healy Unit \#1)

$$
\text { Cost }=\text { Amps } * 2.4 * 1.732 * 0.7 *(365 * 24) * 0.95 * 0.2
$$

If the power plant were to be run at 50\% passing 76 microns instead of $70 \%$ passing 76 microns, the savings would be (from Equation [3.3])

$$
\left(\mathrm{Amps}_{70}-\mathrm{Amps}_{50}\right) * 4843
$$

For the same HGI and Flow, applying Equations (3.2) to (3.4),

$$
\begin{aligned}
& \text { Savings }=0.584 *(70-50) * 4843 \\
& =\$ 56,566
\end{aligned}
$$

Ganguli and Bandopadhyay (2008) did not consider power factor, three-phase motors (which introduces the $\sqrt{3}$ in Equation [3.3]), and power source selection methodology in their computation.

\subsubsection{Other Relationships}

In this section, issues or relationships not directly related to project objectives are discussed/presented.

\subsubsection{Effect of Lower Weight Sample}

As evident from the previous sections, Alaskan low-rank coal is very moist, which makes sampling difficult. The moist pulverized coal had a tendency to run and clog the sampler. This often caused samples to be lower in weight than the recommended weight. Therefore, it was of interest to see if the lower-weight (LW) samples had a different PSD (and PSD76) than the recommended-weight samples.

The recommended weight is computed based on the coal flow, sampling aperture, and sampling duration as follows:

$$
W=(a / A) * \text { Flow in Pipe/minute }
$$

where $W$ is the sample to be collected per minute, $a$ is the area of the aperture in the sampling probe, $A$ is the internal area of the pipe, and Flow in Pipe/minute is selfexplanatory. Since the sampling duration was 2 minutes for the first 22 tests, the computed sample weight was $2 \mathrm{~W}$. The recommended weight, $\mathrm{W}_{\mathrm{r}}$, was

$90 \%$ of $2 \mathrm{~W}<=\mathrm{W}_{\mathrm{r}}<=110 \%$ of $2 \mathrm{~W}$

\footnotetext{
${ }^{3}$ The in-plant cost to generate electricity is $6.5 \$ / \mathrm{kwh}$. However, reduced mill power consumption makes more electricity available for the grid. Since the cheapest power source is always selected by the grid, more available power implies cutting down on electricity that is otherwise $20-25 \$ / \mathrm{kwh}$.
} 
For example, in Test 1 the flow rate was 11,583 kg/hour for mill A, or $5791.5 \mathrm{~kg} / \mathrm{hr}$ through pipes A1 and A2. The ratio of the areas was 0.001726, resulting in $\mathrm{W}=333.2$ grams. Therefore, the recommended weight was between 299.9 grams and 366.5 grams. Note that the above method does not apply to data from tests that used the ISO sampling method (Tests 23-26).

Tests 1 and 2 had samples that were either recommended weight or under weight.

Therefore, they presented an excellent opportunity for comparison. WR is the ratio of the actual weight of the sample to the recommended weight. Since multiple samples were taken in each test, each sample usually being just minutes apart from the next one, this was an appropriate comparison. The comparison is done on a pipe basis as PSDs between pipes can and do vary (discussed later).

Tables 3.13a-3:13e present the results, while Figures 3.8-3.12 present the RosinRammler (RR) plots. Note in the figures that the x-axis is labeled in SI units at the top and in US mesh sizes at the bottom, while the y-axis is percentage retained (and not percentage passing, as in the tables).

From the tables, it is apparent that particle sizes coarser than 150 microns are captured in identical proportions in samples of all sizes, while the RR plots and Figure 3.13 show that the PSD76 (the benchmark number since it was used in all analyses) is near-identical between lower-weight and recommended-weight samples in each case. In other words, the same line is a good fit no matter whether we fit the "red" dots or the "blue" dots. Table 3.13a. PSD76 (\% passing) of lower-weight samples vs. recommended-weight samples for Pipe A1 in Test 1

\begin{tabular}{|l|c|c|c|c|c|c|c|}
\hline \multirow{2}{*}{$\begin{array}{l}\text { Sample } \\
\text { size }\end{array}$} & \multicolumn{4}{|c|}{ Lower weight } & \multicolumn{3}{c|}{ Recommended weight } \\
\cline { 2 - 8 } & \multicolumn{3}{|c|}{} & \multicolumn{1}{|c|}{ Ave } & & 93.6 & 93.9 \\
\hline WR & 81.5 & 60.5 & 86.5 & 76.2 & 93.2 & 94.6 & 100 \\
\hline $\begin{array}{l}600- \\
1180+\end{array}$ & 100 & 100 & 100 & 100.0 & 100 & 100 & 100 \\
\hline $300-600$ & 100 & 100 & 100 & 100.0 & 100 & 100 & 100 \\
\hline $150-300$ & 98.9 & 100 & 98.9 & 99.3 & 98.7 & 100 & 99.4 \\
\hline $76-150$ & 83 & 87.21 & 87.5 & 85.9 & 84.3 & 86.9 & 85.6 \\
\hline $38-76$ & 44.5 & 57.0 & 52.4 & 51.3 & 49.1 & 50.0 & 49.6 \\
\hline $0-38$ & 19.9 & 27.7 & 25.0 & 24.2 & 23.1 & 20.3 & 21.7 \\
\hline & & & & & & & \\
\hline PSD76 & & & & $\mathbf{5 1 . 3}$ & & & $\mathbf{4 9 . 6}$ \\
\hline
\end{tabular}




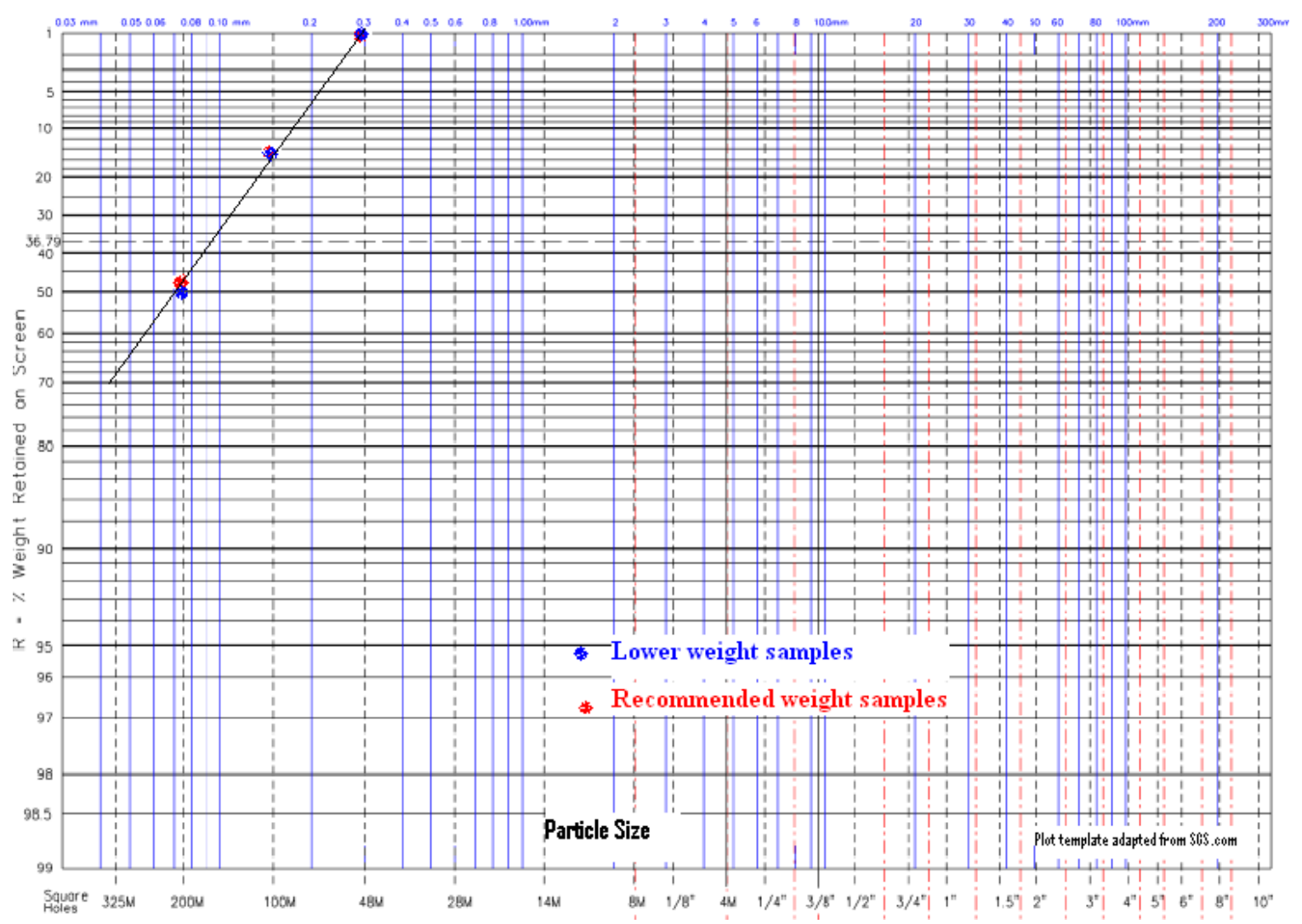

Figure 3.8. Rosin-Rammler plot of the average particle size distribution for the lower-weight samples and those of recommended weights (Pipe A1, Test 1). 
Table 3.13b. PSD76 (\% passing) of lower-weight samples vs. recommended-weight samples for Pipe A2 in Test 1

\begin{tabular}{|l|c|c|c|c|c|c|}
\hline \multirow{2}{*}{ Sample size } & \multicolumn{5}{|c|}{ Lower weight } & Recommended \\
& \multicolumn{7}{|c|}{} & Ave & \\
\cline { 2 - 6 } & \multicolumn{7}{|c|}{} & & \\
\hline WR & 77.1 & 88.7 & 48.3 & 58.5 & 68.2 & 105.0 \\
\hline $1180+$ & 100 & 100 & 100 & 100.0 & 100.0 & 100.0 \\
\hline $600-1180$ & 100 & 100 & 100 & 100.0 & 100.0 & 100.0 \\
\hline $300-600$ & 100 & 100 & 100 & 100.0 & 100.0 & 100 \\
\hline $150-300$ & 98.9 & 99.0 & 100 & 98.5 & 99.1 & 100 \\
\hline $76-150$ & 85.4 & 84.8 & 89.1 & 80.4 & 84.9 & 85.7 \\
\hline $38-76$ & 50.5 & 48.9 & 59.2 & 40.4 & 49.8 & 50.1 \\
\hline $0-38$ & 22.1 & 22.3 & 29.3 & 18.3 & 23.0 & 23.2 \\
\hline & & & & & & $\mathbf{4 9 . 8}$ \\
\hline PSD76 & & & & & $\mathbf{5 0 . 1}$ \\
\hline
\end{tabular}

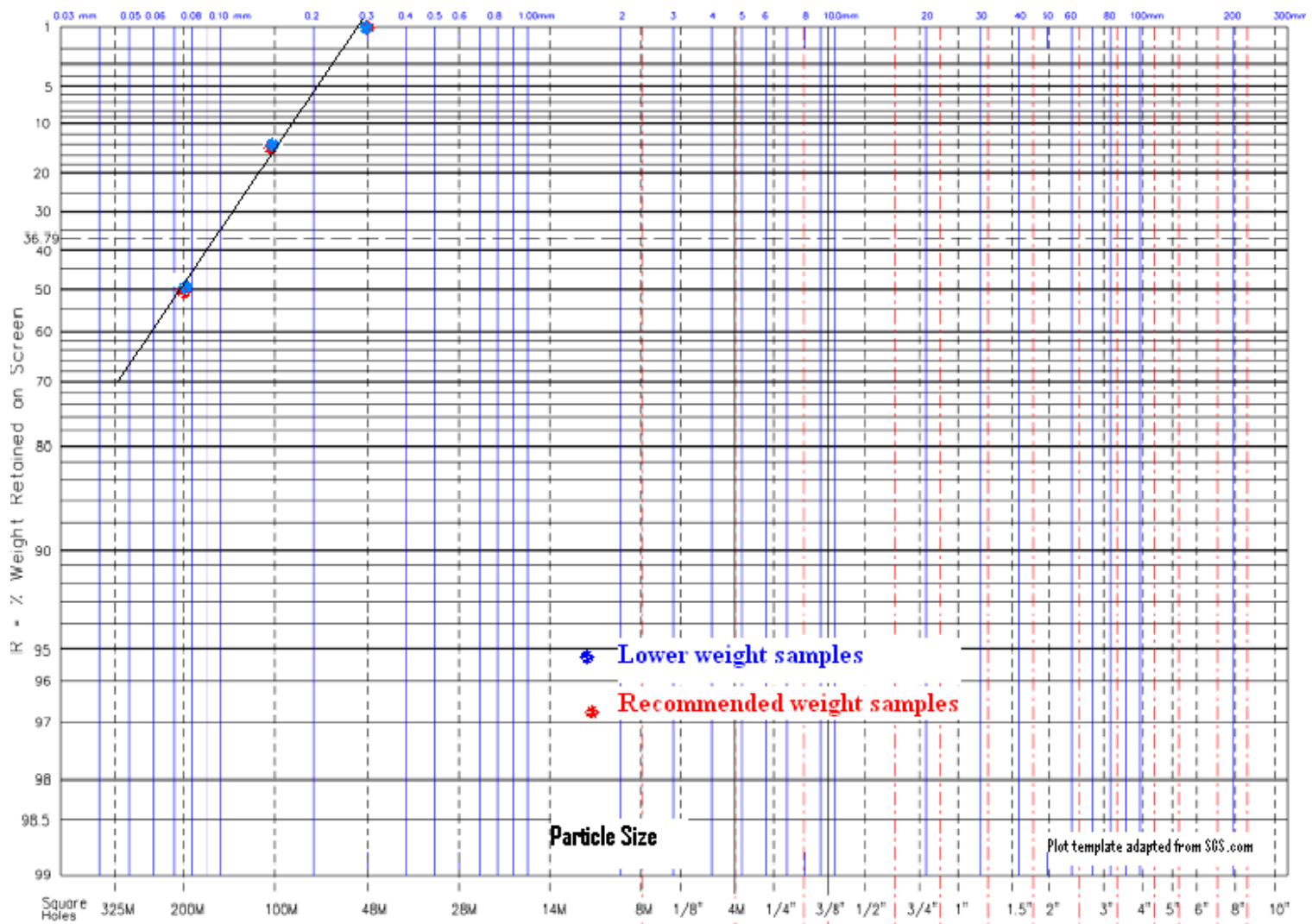

Figure 3.9. Rosin-Rammler plot of the average particle size distribution for the lowerweight samples and those of recommended weights (Pipe A2, Test 1). 
Table 3.13c. PSD76 (\% passing) of lower-weight samples vs. recommended-weight samples for Pipe A2 in Test 2

\begin{tabular}{|c|c|c|c|c|c|c|c|}
\hline \multirow{2}{*}{$\begin{array}{l}\text { Sample } \\
\text { size }\end{array}$} & \multicolumn{4}{|c|}{ Lower weight } & \multicolumn{3}{|c|}{ Recommended weight } \\
\hline & & & & Ave & & & Ave \\
\hline WR & 55.6 & 73.8 & 86.6 & 72 & 103.9 & 91.2 & 97.55 \\
\hline $1180+$ & 100 & 100 & 100 & 100 & 100 & 100 & 100 \\
\hline $\begin{array}{l}600- \\
1180\end{array}$ & 100 & 100 & 100 & 100 & 100 & 100 & 100 \\
\hline $300-600$ & 100 & 100 & 100 & 100 & 100 & 100 & 100 \\
\hline $150-300$ & 98.7 & 98.7 & 100.0 & 99.1 & 100 & 98.37 & 99.2 \\
\hline $76-150$ & 86.2 & 80.5 & 80.1 & 82.3 & 80.35 & 80.51 & 80.4 \\
\hline $38-76$ & 52.0 & 47.6 & 43.4 & 47.6 & 46.48 & 40.75 & 43.6 \\
\hline $0-38$ & 26.5 & 25.2 & 21.9 & 24.5 & 21.14 & 19.31 & 20.2 \\
\hline PSD76 & & & & 47.6 & & & 43.6 \\
\hline
\end{tabular}

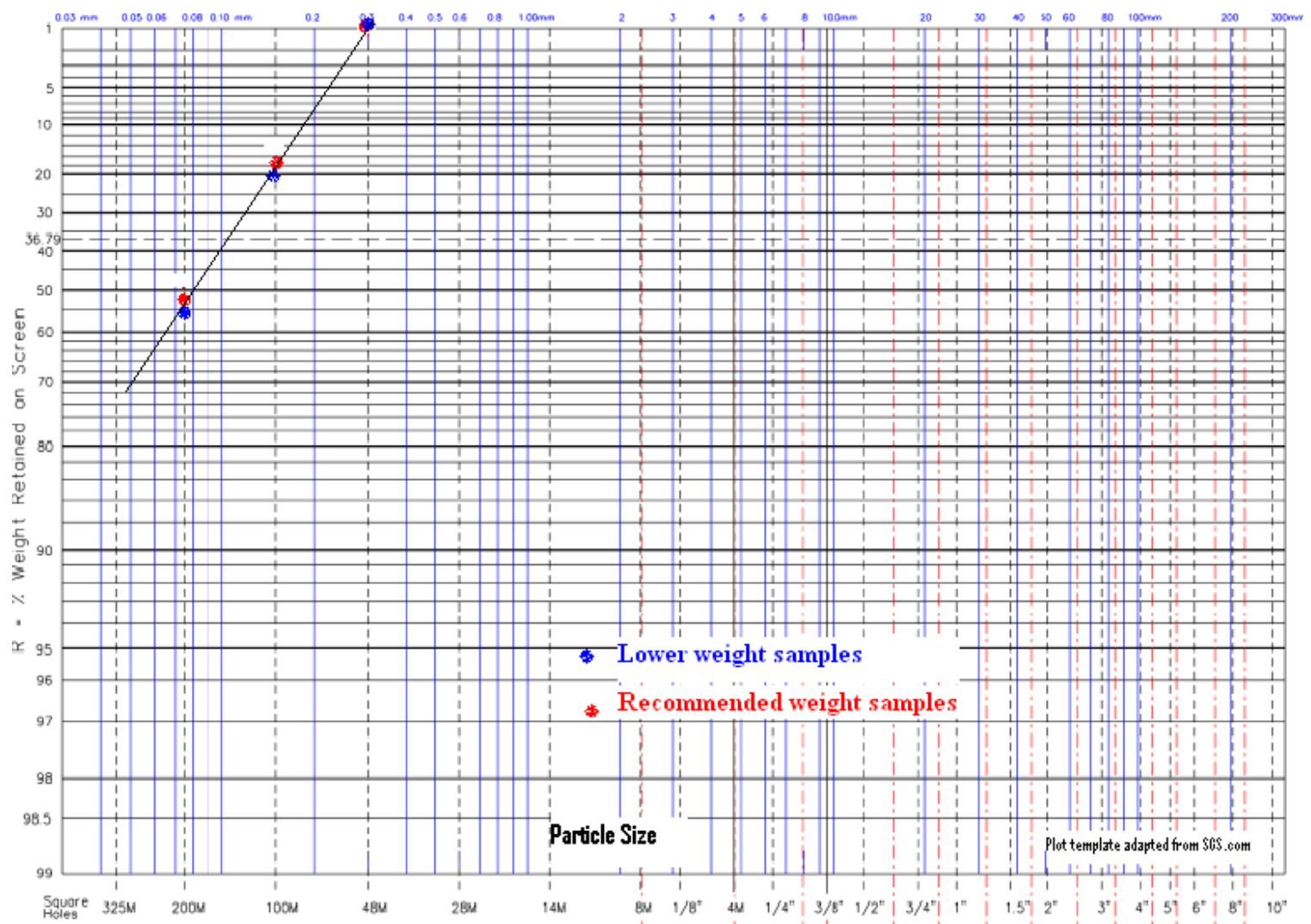

Figure 3.10. Rosin-Rammler plot of the average particle size distribution for the lowerweight samples and those of recommended weights (Pipe A2, Test 2). 
Table 3.13d. PSD76 (\% passing) of lower-weight samples vs. recommended-weight samples for Pipe B1 in Test 2

\begin{tabular}{|l|c|c|c|c|c|c|c|}
\hline \multirow{2}{*}{$\begin{array}{l}\text { Sample } \\
\text { size }\end{array}$} & \multicolumn{3}{|c|}{ Lower weight } & \multicolumn{3}{c|}{ Recommended weight } \\
\cline { 2 - 8 } & \multicolumn{3}{|c|}{} & Ave & \multicolumn{4}{c|}{ Ave } \\
\hline WR & 88.5 & 82.0 & 85.3 & 92.1 & 104.2 & 97.1 & 97.8 \\
\hline $1180+$ & 100 & 100 & 100 & 100 & 100 & 100 & 100 \\
\hline $\begin{array}{l}600- \\
1180\end{array}$ & 100 & 100 & 100 & 100 & 100 & 100 & 100 \\
\hline $300-600$ & 100 & 100 & 100 & 100 & 100 & 100 & 100 \\
\hline $150-300$ & 97.3 & 100 & 98.7 & 97.6 & 100 & 100 & 99.2 \\
\hline $76-150$ & 70.6 & 73.5 & 72.1 & 75.4 & 71.35 & 75.0 & 73.9 \\
\hline $38-76$ & 36.6 & 38.5 & 37.5 & 38.7 & 36.4 & 38.9 & 38.0 \\
\hline $0-38$ & 17.5 & 17.7 & 17.6 & 17.5 & 17.5 & 18.81 & 17.9 \\
\hline & & & & & & & \\
\hline PSD76 & & & 37.5 & & & & $\mathbf{3 8 . 0}$ \\
\hline
\end{tabular}

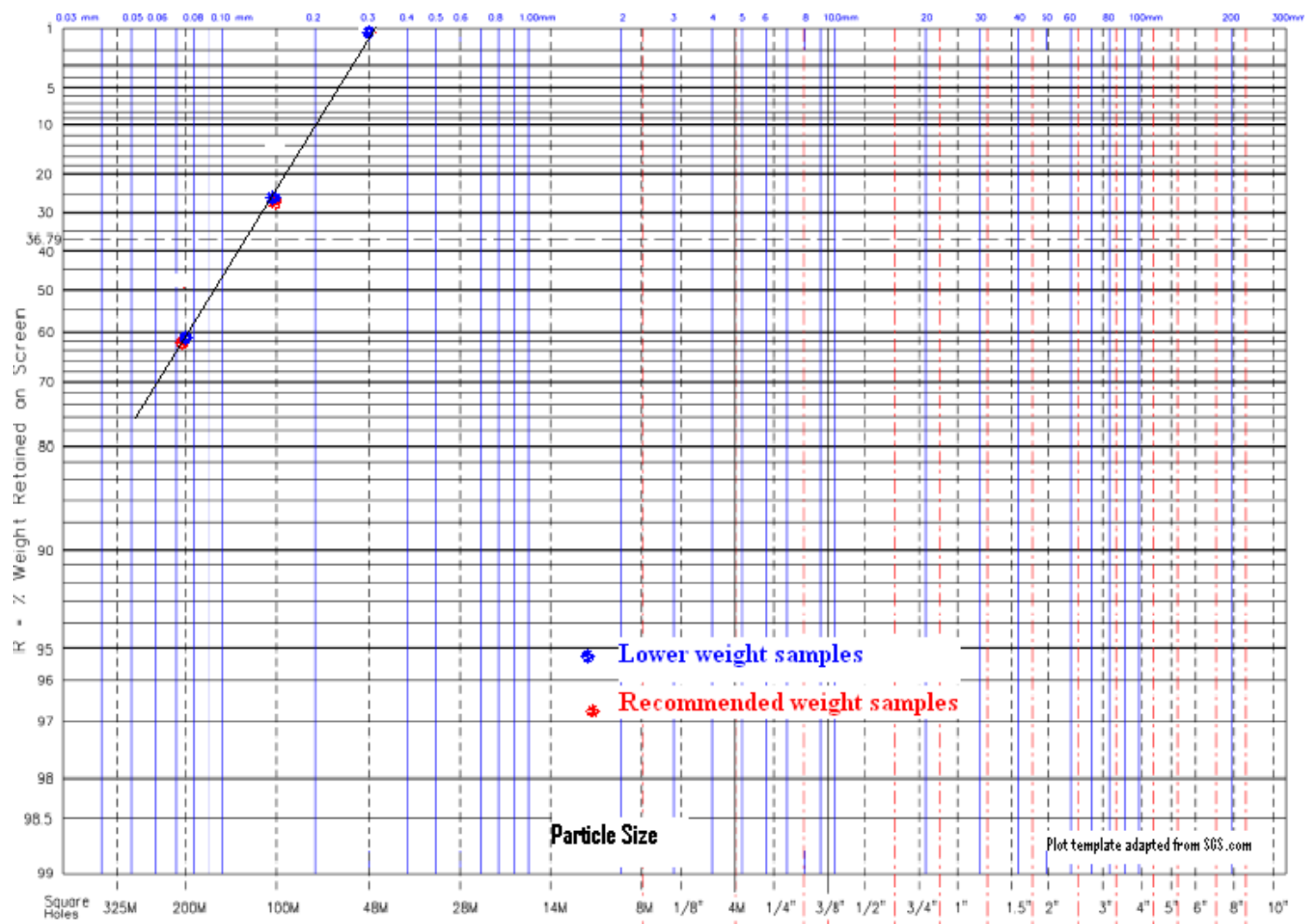

Figure 3.11. Rosin-Rammler plot of the average particle size distribution for the lowerweight samples and those of recommended weights (Pipe B1, Test 2). 
Table 3.13e. PSD76 (\% passing) of lower-weight samples vs. recommended-weight samples for Pipe B2 in Test 2

\begin{tabular}{|c|c|c|c|c|c|c|c|}
\hline \multirow{2}{*}{$\begin{array}{l}\text { Sample } \\
\text { size }\end{array}$} & \multicolumn{6}{|c|}{ Lower weight } & \multirow{2}{*}{$\begin{array}{l}\text { Recommended } \\
\text { weight }\end{array}$} \\
\hline & & & & & & Ave & \\
\hline WR & 86.3 & 77.4 & 70.9 & 54.5 & 54.8 & 68.78 & 92.1 \\
\hline $1180+$ & 100 & 100.0 & 100.0 & 100.0 & 100.0 & 100 & 100 \\
\hline $600-1180$ & 100 & 100.0 & 100.0 & 100.0 & 100.0 & 100 & 100 \\
\hline $300-600$ & 100 & 100.0 & 100.0 & 100.0 & 100.0 & 100 & 100 \\
\hline $150-300$ & 97.6 & 100.0 & 97.7 & 97.7 & 100.0 & 98.6 & 100 \\
\hline $76-150$ & 74.9 & 74.3 & 77.9 & 78.3 & 77.3 & 76.5 & 71.9 \\
\hline $38-76$ & 38.3 & 44.1 & 44.4 & 46.4 & 47.0 & 44.0 & 43.2 \\
\hline $0-38$ & 18.6 & 20.6 & 22.9 & 23.5 & 24.0 & 21.9 & 22 \\
\hline PSD76 & & & & & & 44.0 & 43.2 \\
\hline
\end{tabular}

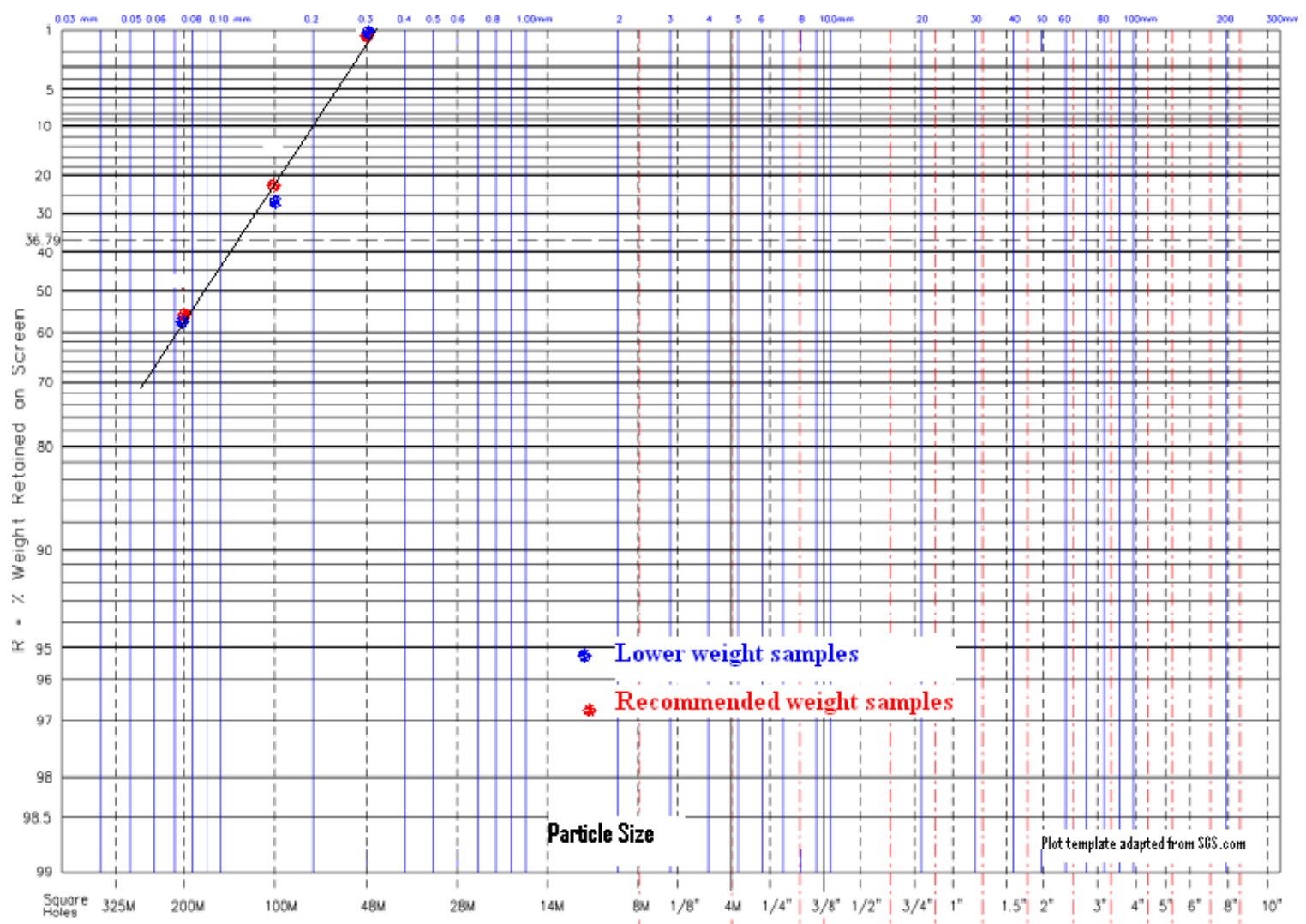

Figure 3.12. Rosin-Rammler plot of the average particle size distribution for the lowerweight samples and those of recommended weights (Pipe B2, Test 2). 


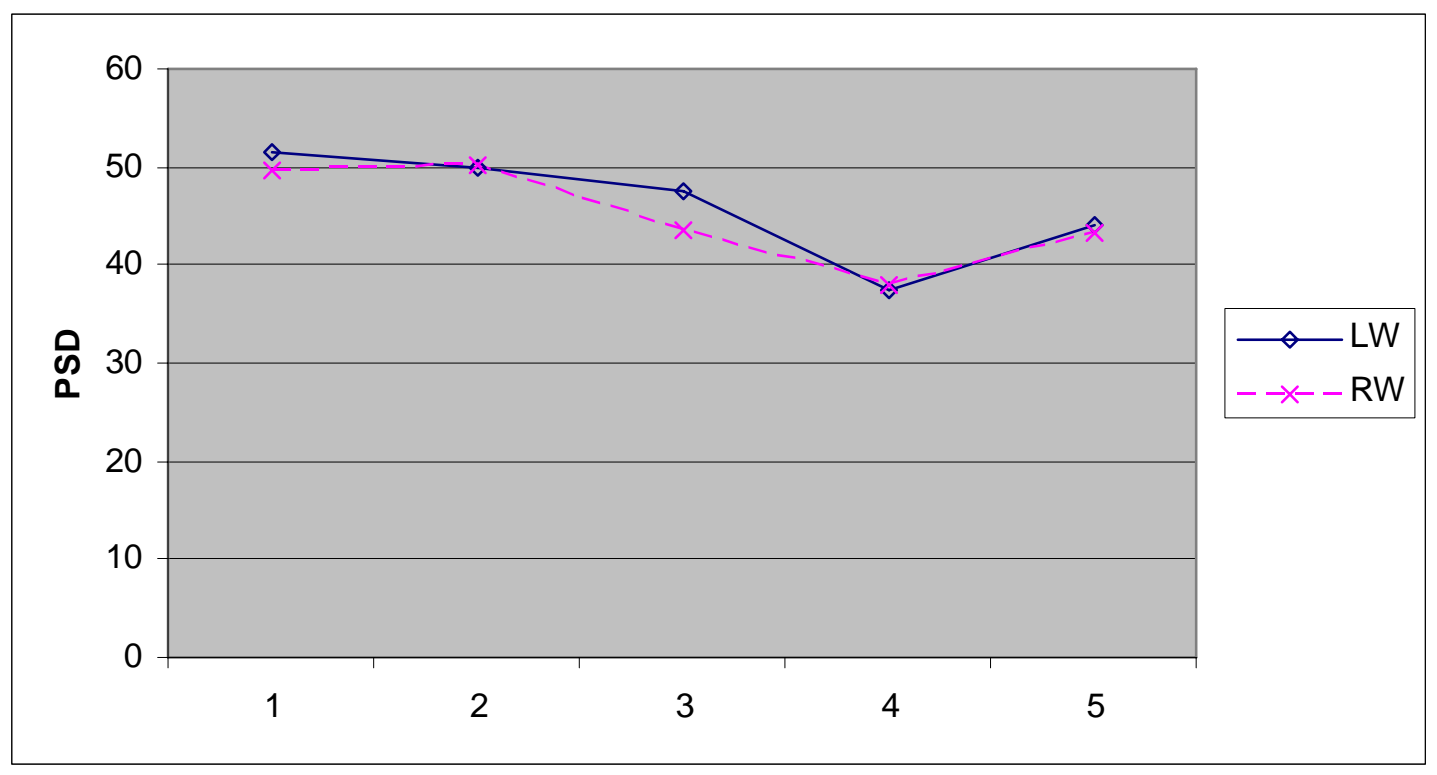

Figure 3.13. Comparing the PSD76 of the samples that are lower weight (LW) to those that are of recommended weight (RW).

The average PSD76 of the two sets were 46 and 45, respectively, for LW and RW.

In summary, it can be concluded that underweight samples were similar to the samples with the recommended weight.

\subsubsection{PSD in Different Pipes}

Table 3.14 presents the average PSD76 (percent passing 76 microns) in each of the four pipes for the various tests. Remember that A1 and A2 carry coal from mill A, while B1 and B2 carry coal from mill B. From Figures 3.14 and 3.15, it appears that while A1 and A2 seemed to have a consistent difference in their PSD76 (with A2 always being a bit finer), that was not the case for B1 and B2. However, the data demonstrate that in any particular test it was possible that the four pipes could have PSD76s that are different from each other. In other words, in any test, all four pipes should be sampled to determine the average PSD76 being burned. 
Table 3.14. The average PSD76 in the four pipes for the tests

\begin{tabular}{|l|c|c|c|c|}
\hline & A1 & A2 & B1 & B2 \\
\hline Test 3 & 41.2 & 47.2 & 44.9 & 51.0 \\
\hline Test 4 & 40.3 & 42.8 & 56.2 & 54.2 \\
\hline Test 5 & 41.5 & 51.7 & 49.0 & 50.4 \\
\hline Test 6 & 48.4 & 54.9 & 48.9 & 47.3 \\
\hline Test 7 & 52.7 & 55.6 & 51.7 & 49.5 \\
\hline Test 8 & 46.7 & 50.1 & 40.3 & 46.0 \\
\hline Test 9 & 52.1 & 56.4 & 54.7 & 60.0 \\
\hline Test 10 & 43.2 & 58.9 & 55.2 & 57.6 \\
\hline Test 11 & 42.3 & 65.3 & 48.3 & 53.8 \\
\hline Test 12 & 33.2 & 46.5 & 55.7 & 47.6 \\
\hline Test 13 & 49.1 & 50.2 & 57.0 & 59.0 \\
\hline Test 14 & 40.3 & 56.5 & 55.2 & 54.6 \\
\hline Test 15 & 56.1 & 44.7 & 52.1 & 54.5 \\
\hline Test 16 & 40.9 & 54.0 & 61.5 & 46.0 \\
\hline Test 17 & 37.1 & 50.0 & 51.0 & 44.8 \\
\hline Test 18 & 38.8 & 47.5 & 64.5 & 44.7 \\
\hline Test 19 & 38.6 & 45.8 & 59.9 & 46.9 \\
\hline Test 20 & 39.9 & 49.7 & 58.4 & 50.4 \\
\hline Test 21 & 62.0 & 64.0 & 69.0 & 68.1 \\
\hline Test 22 & 64.6 & 66.3 & 72.9 & 74.2 \\
\hline Test 23 & 79.2 & 77.5 & 74.7 & 68.5 \\
\hline Test 24 & 66.8 & 68.6 & 66.2 & 63.4 \\
\hline Test 25 & 83.8 & 85.7 & 71.4 & 72.7 \\
\hline Test 26 & 84.8 & 86.8 & 77.9 & 76.1 \\
\hline
\end{tabular}




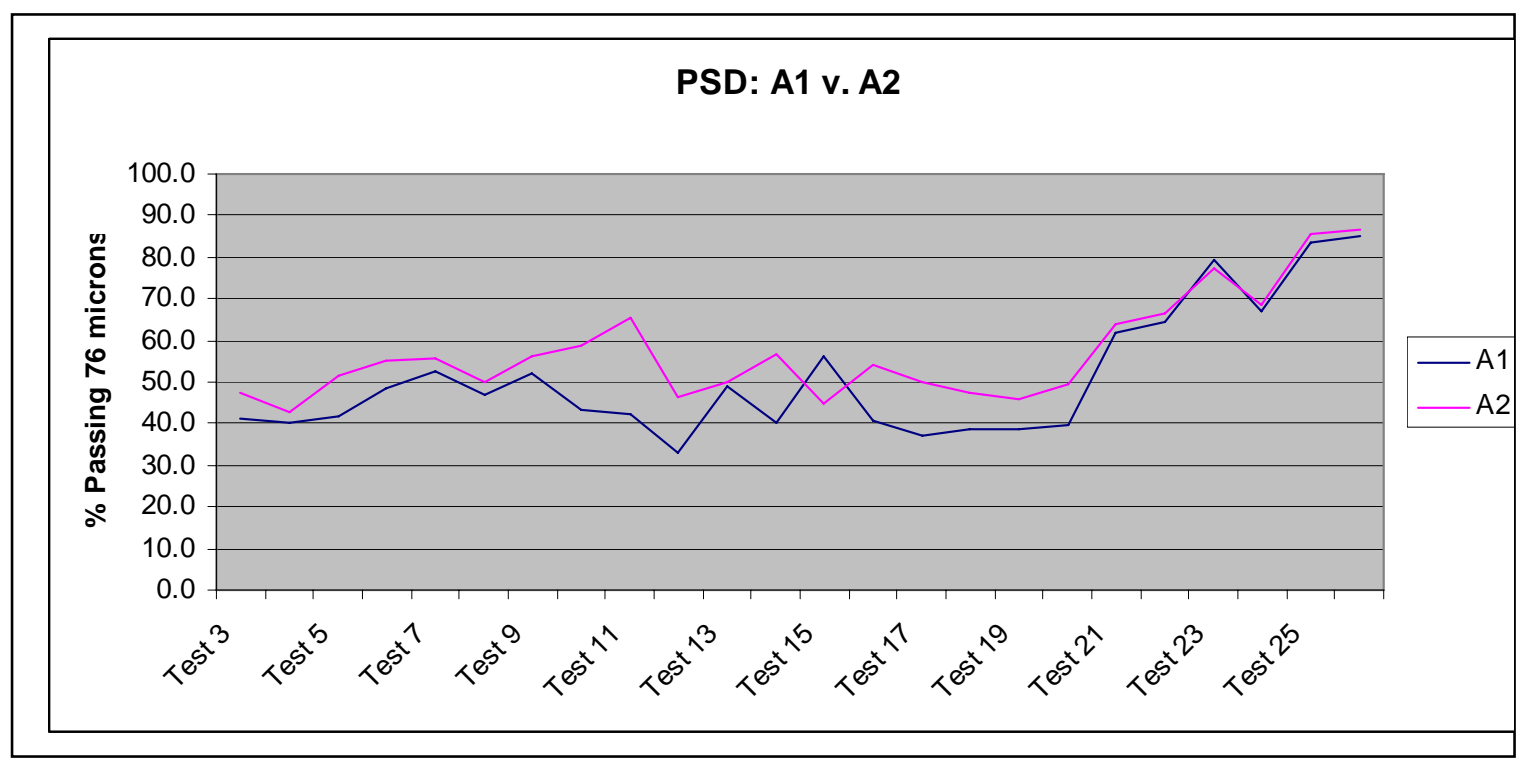

Figure 3.14. The coal in pipe A2 is usually finer than A1.

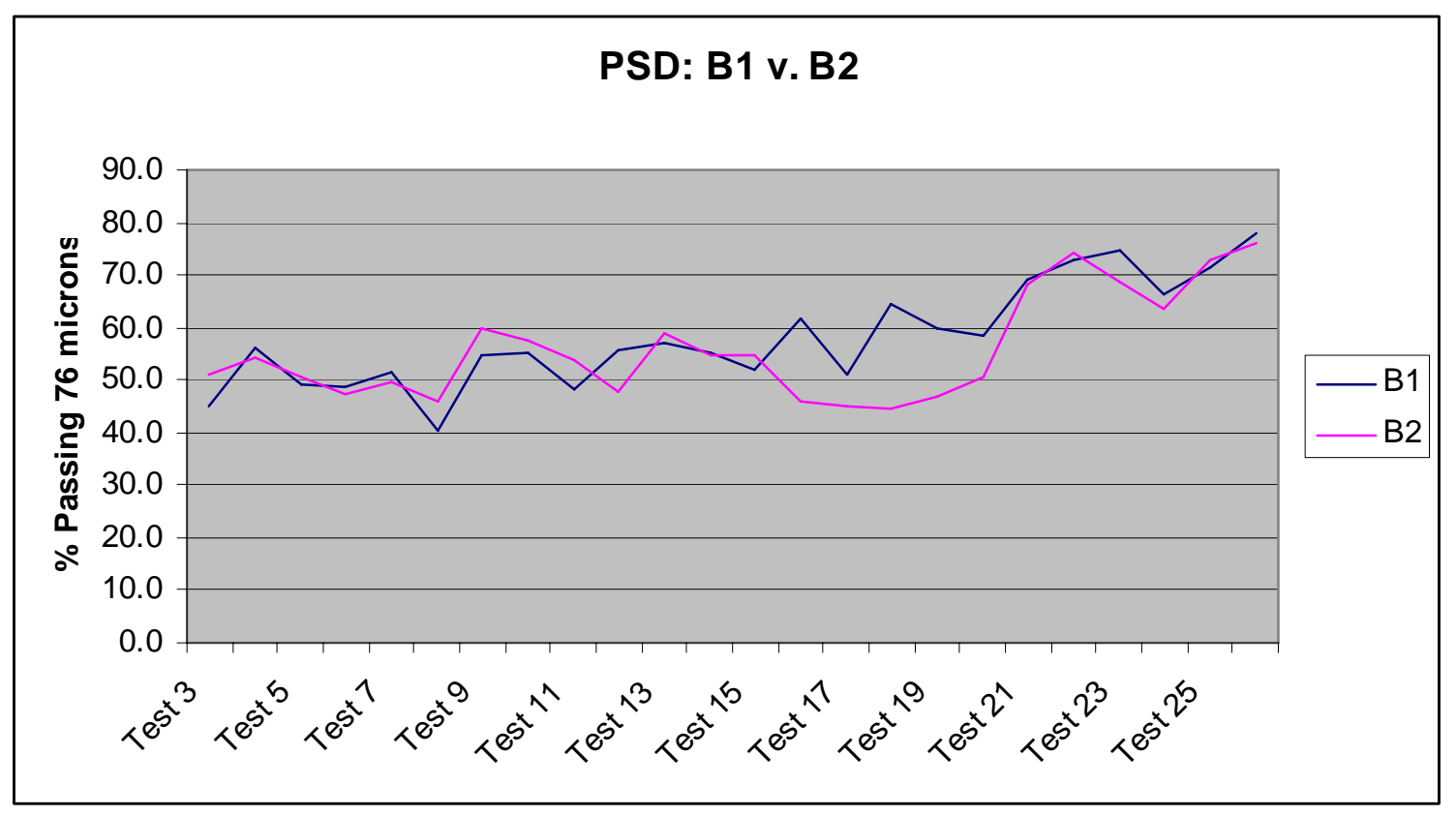

Figure 3.15. No consistent difference in the PSD76 between pipes B1 and B2. 


\section{Conclusions and Recommendations}

\subsection{Conclusions}

Through a series of field tests at GVEA's Healy Unit \#1, this project reached the following conclusions about low-rank high-volatile-content Alaskan coal:

- $\quad$ For PSD76 in the tested range (40-80), there is very little correlation between the PSD76 of pulverized coal and power plant efficiency.

- $\quad$ There is very little correlation between PSD76 and $\mathrm{SO}_{2}, \mathrm{NO}_{\mathrm{x}}$, and CO.

- $\quad$ The data displayed a correlation between PSD and $\mathrm{CO}_{2}$, with finer grinds resulting in higher concentration of $\mathrm{CO}_{2}$. However, this correlation has been difficult to explain. It could be a new revelation or an artifact of measurement errors.

- $\quad$ Mill power consumption is greater when coal is ground more. Additionally, HGI and coal flow rate impact mill power consumption. Harder coal was found to consume more power than softer coal, and power consumption rose as the coal flow rate increased.

o If coal were to be burned at a PSD76 of 50 instead of 70, the $28 \mathrm{MW}$ Healy Unit \#1 would see a savings of over $\$ 56,000$ per year.

- Total Hg emissions are very low.

- When the tests are split into two groups, one that averaged 50\% passing 76 microns (the "coarse” group) and the other that averaged 73\% passing 76 microns (the "fine" group), the following is observed:

o There was a difference in the quality of coal in the two groups. The coal burned in the fine group had more moisture (17.4\%) and less heating value $(18,774 \mathrm{~kJ} / \mathrm{kg}$ or $8078 \mathrm{BTU})$ compared with the coarse group (15.2\% and $19,337 \mathrm{~kJ} / \mathrm{kg}$ or $8320 \mathrm{BTU})$. On a HGI basis, the coal was harder in the coarse group (HGI=34) than in the fine group (HGI=37.8). The fixed carbon content was higher in the coarse group (32.3\%) than in the fine group (29.5\%). There was no difference in the ash and volatile contents.

0 The coarse group had higher unburned carbon in fly and bottom ash. However, this could be explained by its higher fixed carbon content.

o The fine group had an efficiency of $23.75 \%$ compared with $23.05 \%$ for the coarse group. Given that the fine group only had six data points, the observed difference could be due to the very low number of tests in the fine group or due to differences in the coal type.

o The coarse group had lower $\mathrm{SO}_{2}$ emissions, though the two groups had similar sulfur contents.

- Observations not central to the project, but interesting nonetheless, include the following:

o Pulverized coal samples that were underweight had PSD76 samples similar to recommended weight samples.

o The PSD76 sometimes varied between pipes. The coal in pipe A1 was generally coarser than the coal in pipe A2. 


\subsection{Conclusions: Implications}

This project has profound implications for the US coal and power industries, since a significant portion of the two industries involves coal (such as the Powder River Basin [PRB] coal) similar to the tested low-rank high-volatile-content Alaskan coal:

\section{Help Sell Low-Rank Alaskan Coal}

The primary conclusion of the project, that low-rank high volatile coal can be burned at a coarser particle size than the industry standard for bituminous coal, makes Alaskan coal attractive to utilities which otherwise are deterred by its hardness. This project implies that utilities can improve mill throughput simply by not grinding the coal as much. Alaska has had issues exporting its low-rank coal because of hardness concerns. This project will go a long way towards alleviating those concerns, and hopefully will help sell Alaskan coal to Pacific Rim and other nations, which would help the Alaskan economy.

\section{Provide Significant Savings $(\$ \$$ ) in Energy Costs}

Another important implication is the cost savings with coarser grind, which, as the cost of energy rises, will become substantial. The savings for GVEA, which is a relatively small utility, is not insignificant (over \$56,000/year). The savings for larger utilities around the country would be substantially greater, though plants burning blends would see less in savings.

\section{$\underline{\text { Reduce } \mathrm{CO}_{2}} \underline{\text { Emissions }}$}

Though $\mathrm{CO}_{2}$ emissions were specifically not the focus of this project, it may be that the most important, though currently dubious, conclusion of the project is that $\mathrm{CO}_{2}$ emissions are related to the PSD of low-rank coal. In the near future, $\mathrm{CO}_{2}$ emissions will prove very expensive to utilities. What the project data imply is that by simply burning low-rank high-volatile-content coal at a coarser grind, a utility could reduce its emissions by as much as $8 \%$ without incurring any cost or lowering plant efficiency. Power plants burning tested-type coal as part of a blend will not see the entire benefit. Still, given that PRB coals amount to approximately $40 \%$ of the coal-based electricity in the US ${ }^{4}$, the savings or prevented-cost is huge. According to the US $\mathrm{DOE}^{5}$, the cost of $\mathrm{CO}_{2}$ removal is in the $\$ 27 /$ ton to $\$ 70 /$ ton range. An $8 \%$ reduction in $\mathrm{CO}_{2}$ generation will result, therefore, in substantial prevented-cost.

Unfortunately, as mentioned before, the $\mathrm{CO}_{2}$ projections from this project are just observations rather than phenomena explained by other data/observations. That is because this research project was never designed to conduct a carbon mass balance, something that would be essential to make firm conclusions on $\mathrm{CO}_{2}$ emissions. However, given the importance of the issue and the fact that observed data cannot, and should not, be dismissed, this significant observation/conclusion needs more fundamental research for verification and explanation.

\footnotetext{
${ }^{4}$ http://en.wikipedia.org/wiki/Powder_River_Basin

${ }^{5}$ http://www.netl.doe.gov/technologies/carbon_seq/FAQs/benefits.html\#
} 


\subsection{Recommendations}

It is recommended that

- power plants that burn low-rank high-volatile-content coals examine the effect of burning their coals coarser. It is possible that power plants may stand to benefit from grinding the coal less.

- the US DOE initiates a research project examining the relationship between the PSD76 of low-rank high-volatile-content coal and $\mathrm{CO}_{2}$ emissions. 


\section{References}

Carpenter, A.M., Niksa, S., Scott, D.H., and Wu, Z. 2007. Fundamentals of coal combustion. IEA Clean Coal Centre 2007. Online publication (www.coalonline.org).

Freeman, M., Smouse, S., and Walbert, G. 1996. Preliminary Combustion Test Results of Alaskan/Russian Blends. US Dept of Energy - National Energy Technological Laboratory.

Ganguli, R., and Bandopadhyay, S. 2008. Field scale investigation of pulverized coal mill power consumption. Minerals and Metallurgical Processing 25(3):139-142.

Malav, D. 2005. Low rank high volatile matter sub-bituminous coal grinding versus power plant performance. M.S. thesis, University of Alaska Fairbanks, Fairbanks, AK.

Malav, D., Ganguli, R., Dutta, S., and Bandopadhyay, S. 2008. Non-impact of particle size distribution on power generation at a pulverized coal power plant burning low rank Alaska coal. Journal of Fuel Processing Technology 89(5):499-502. 


\section{List of Acronyms and Abbreviations}

$\begin{array}{ll}\text { CEMS } & \text { Continuous emissions monitoring system } \\ \text { GVEA } & \text { Golden Valley Electric Association } \\ \text { HGI } & \text { Hardgrove grindability index } \\ \text { MW } & \text { Megawatt } \\ \text { MWT } & \text { Mann-Whitney Test } \\ \text { PSD } & \text { Particle size distribution } \\ \text { PSD76 } & \text { A specific PSD: percentage passing } 76 \text { microns } \\ & \text { (200 mesh) } \\ \text { UAF } & \text { University of Alaska Fairbanks } \\ \text { UCM } & \text { Usibelli Coal Mine } \\ \text { US DOE } & \text { United States Department of Energy }\end{array}$




\section{Appendix I: Rosin-Rammler Plots}

Test 3

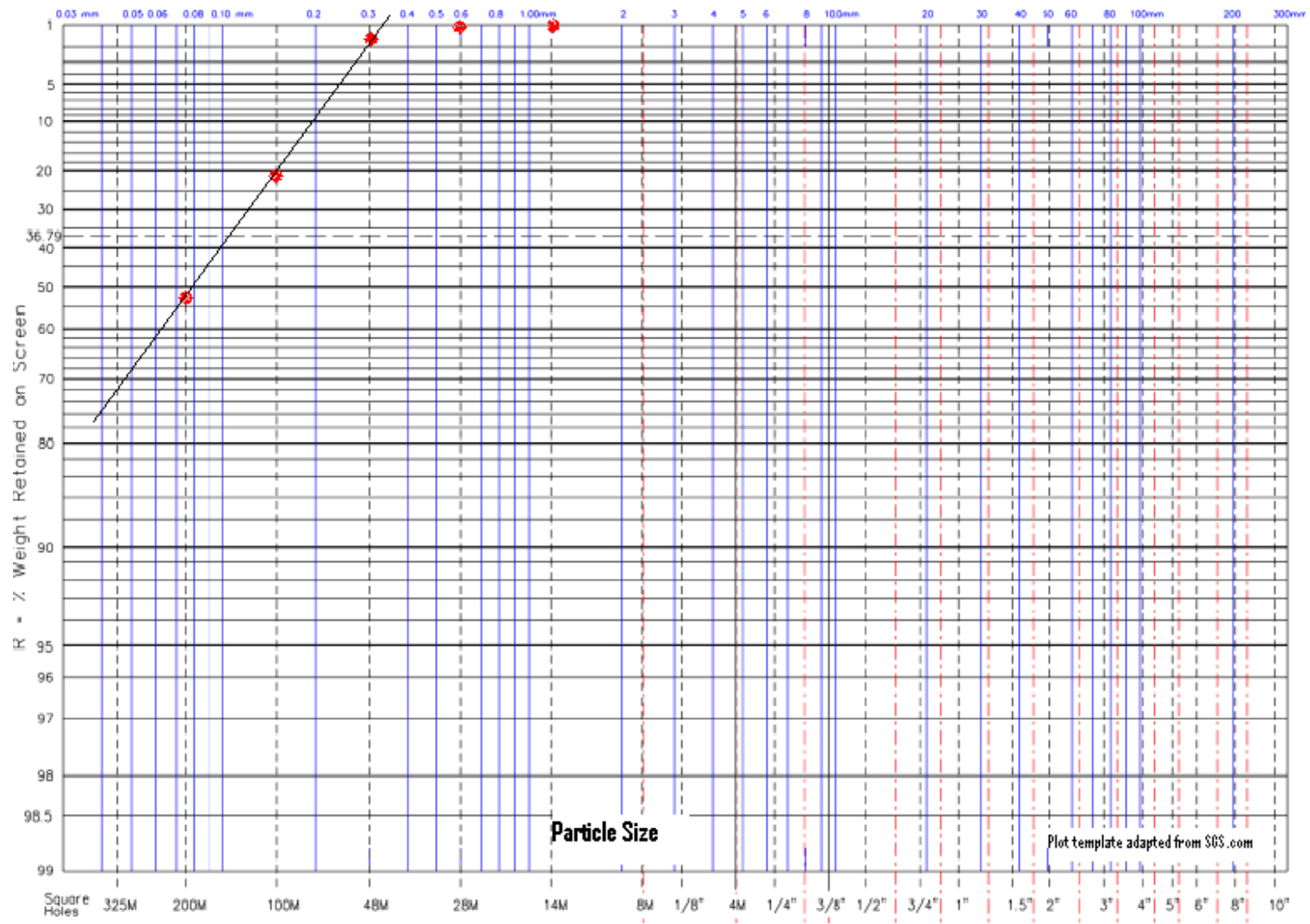




\section{Test 4}

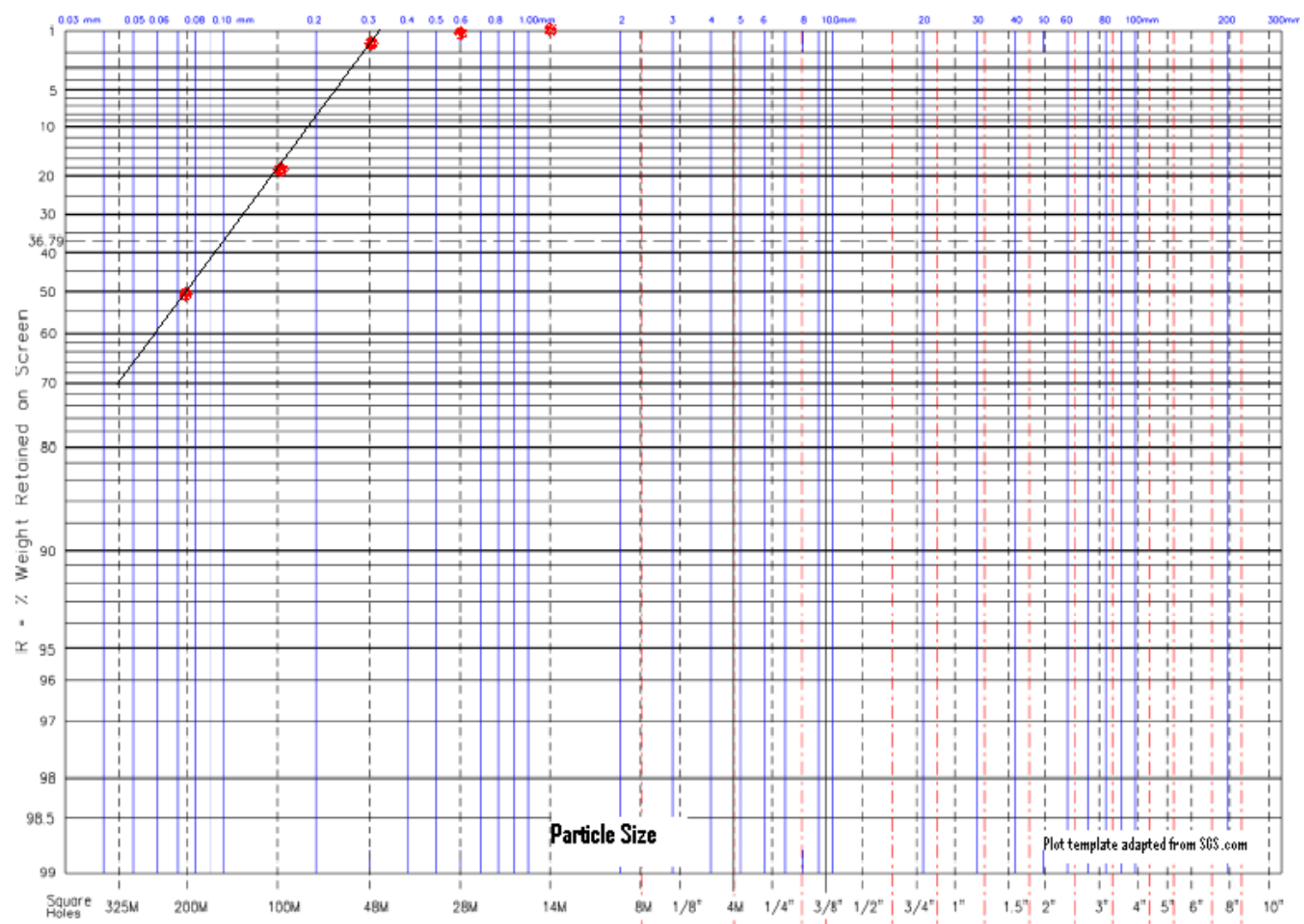

Test 5

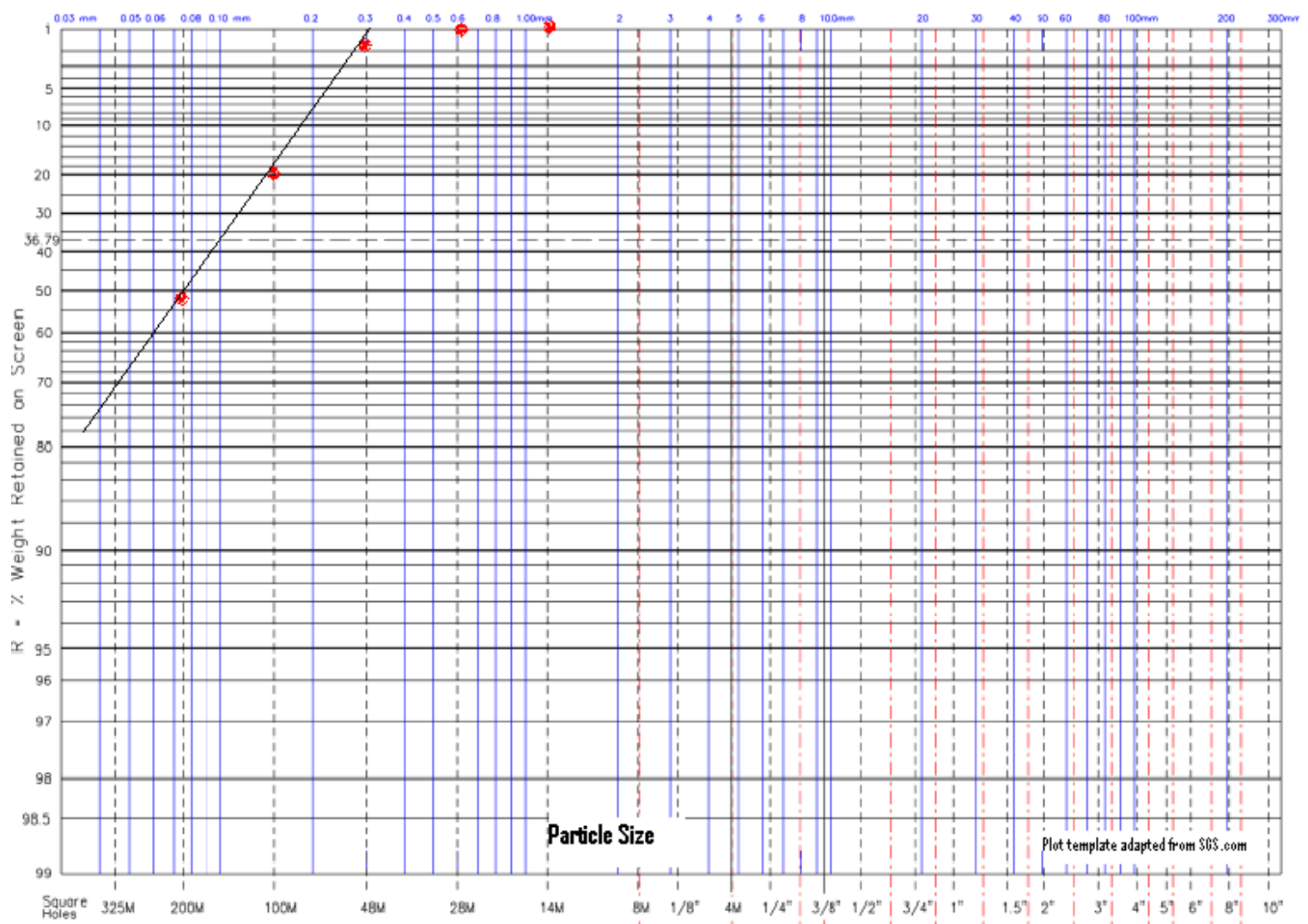




\section{Test 6}

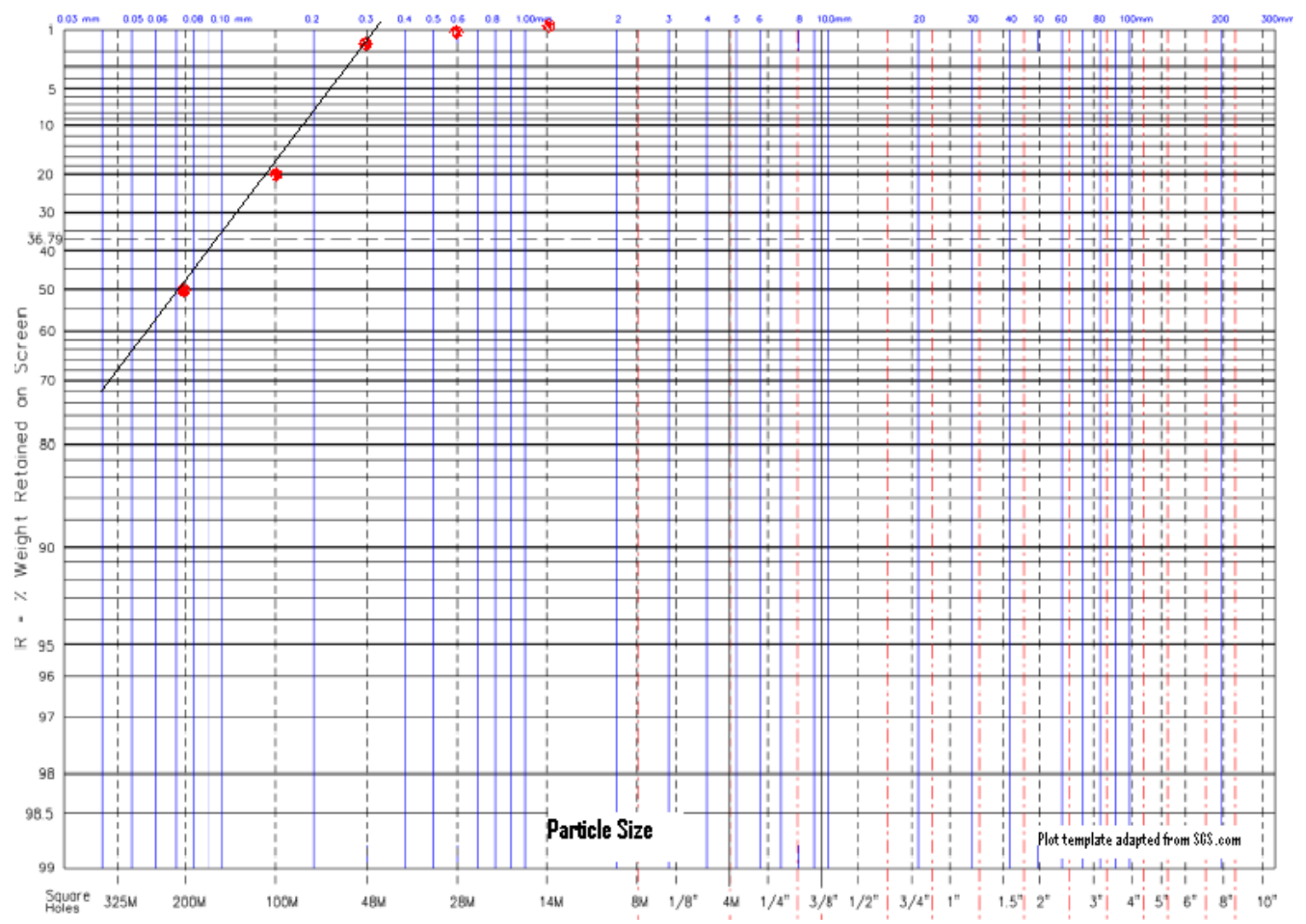

\section{Test 7}

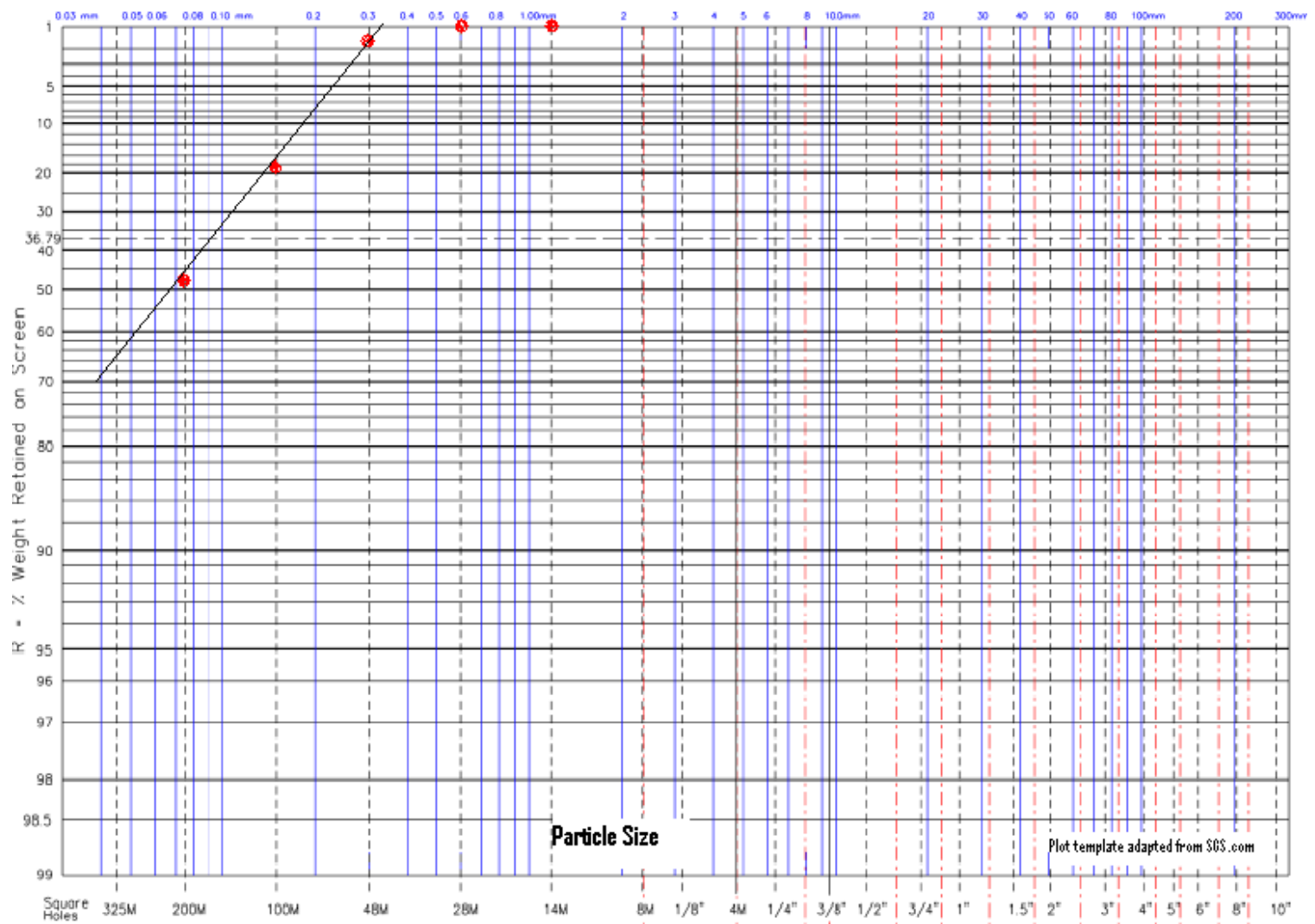




\section{Test 8}

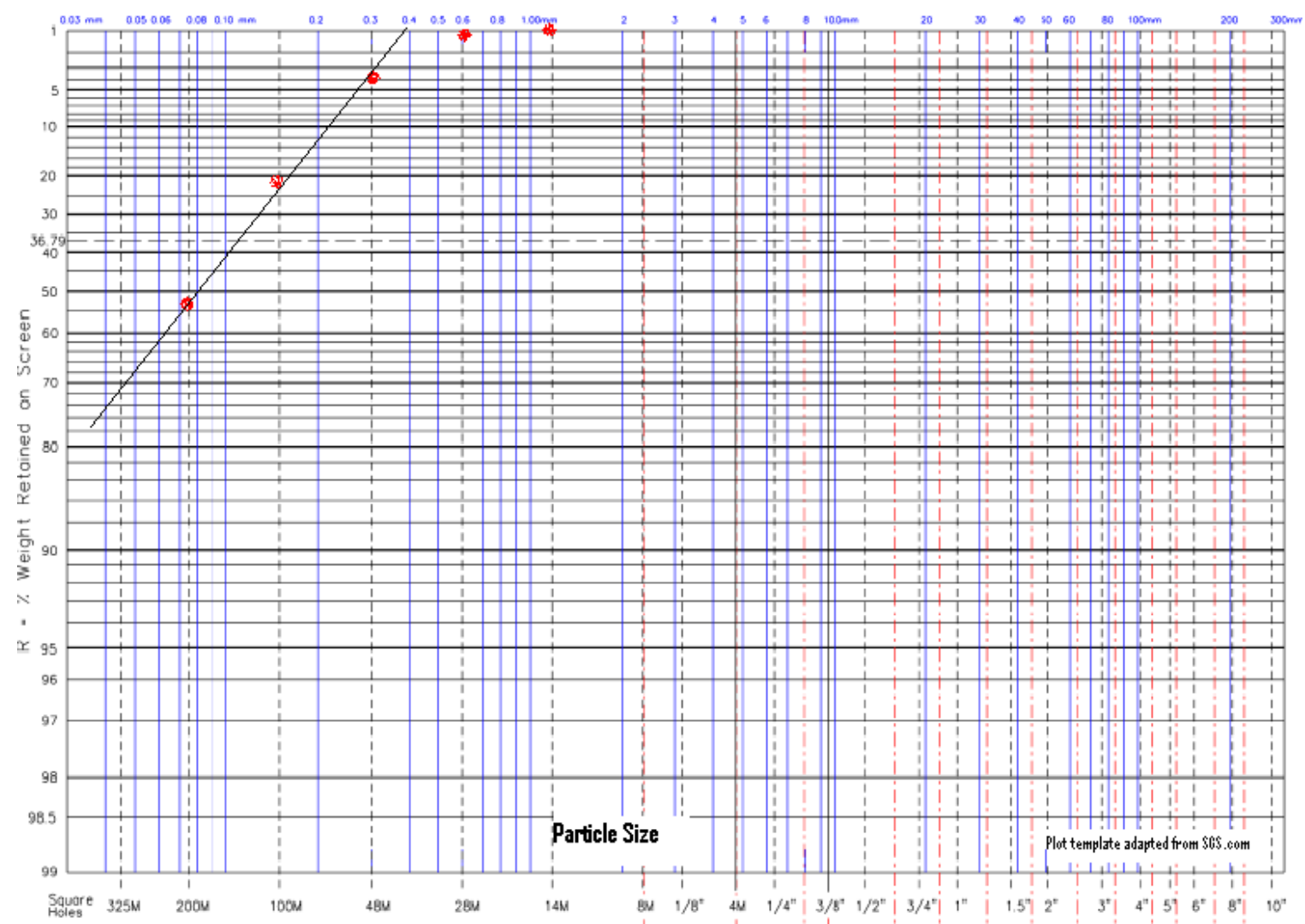

\section{Test 9}

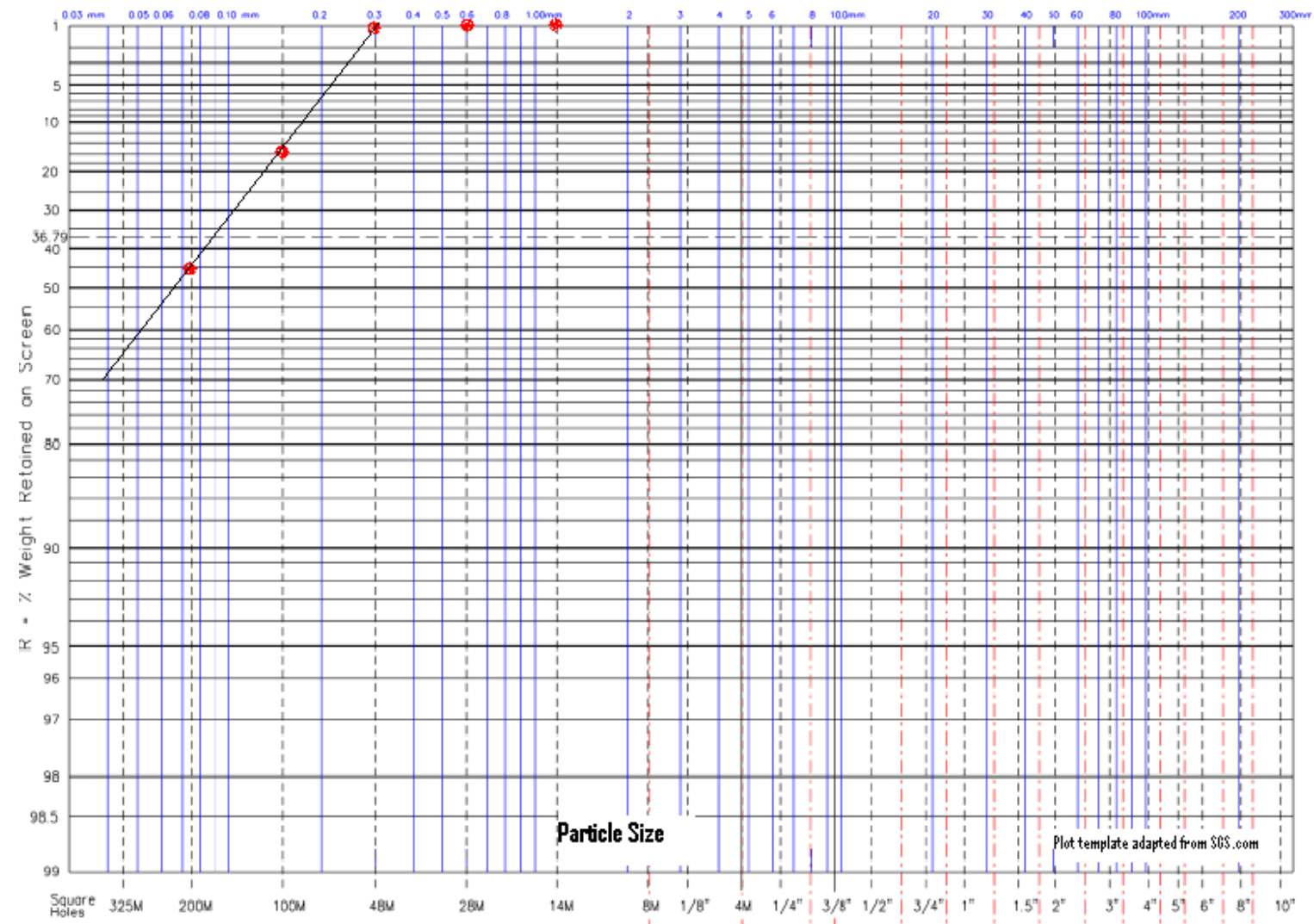




\section{Test 10}

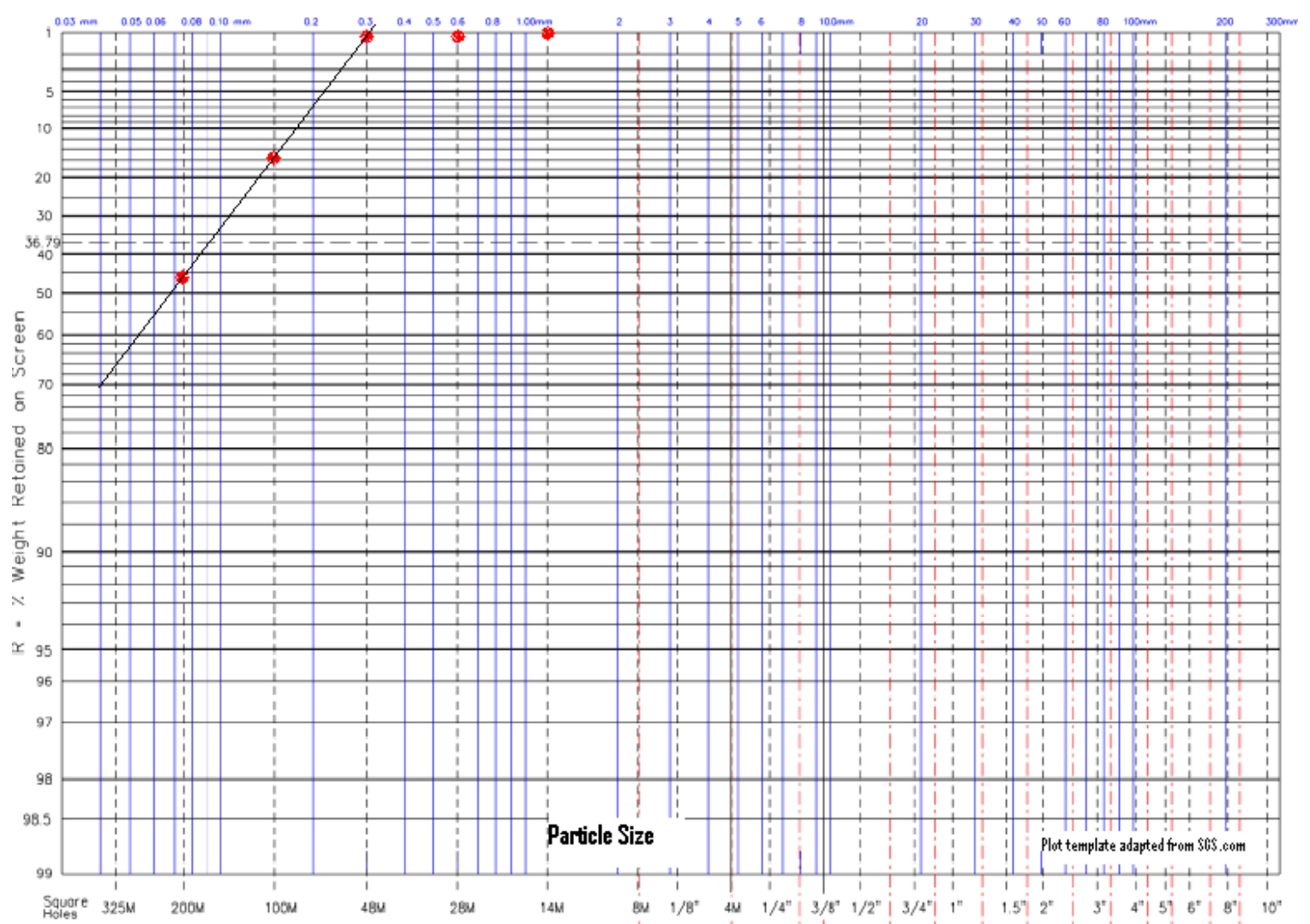

Test 11

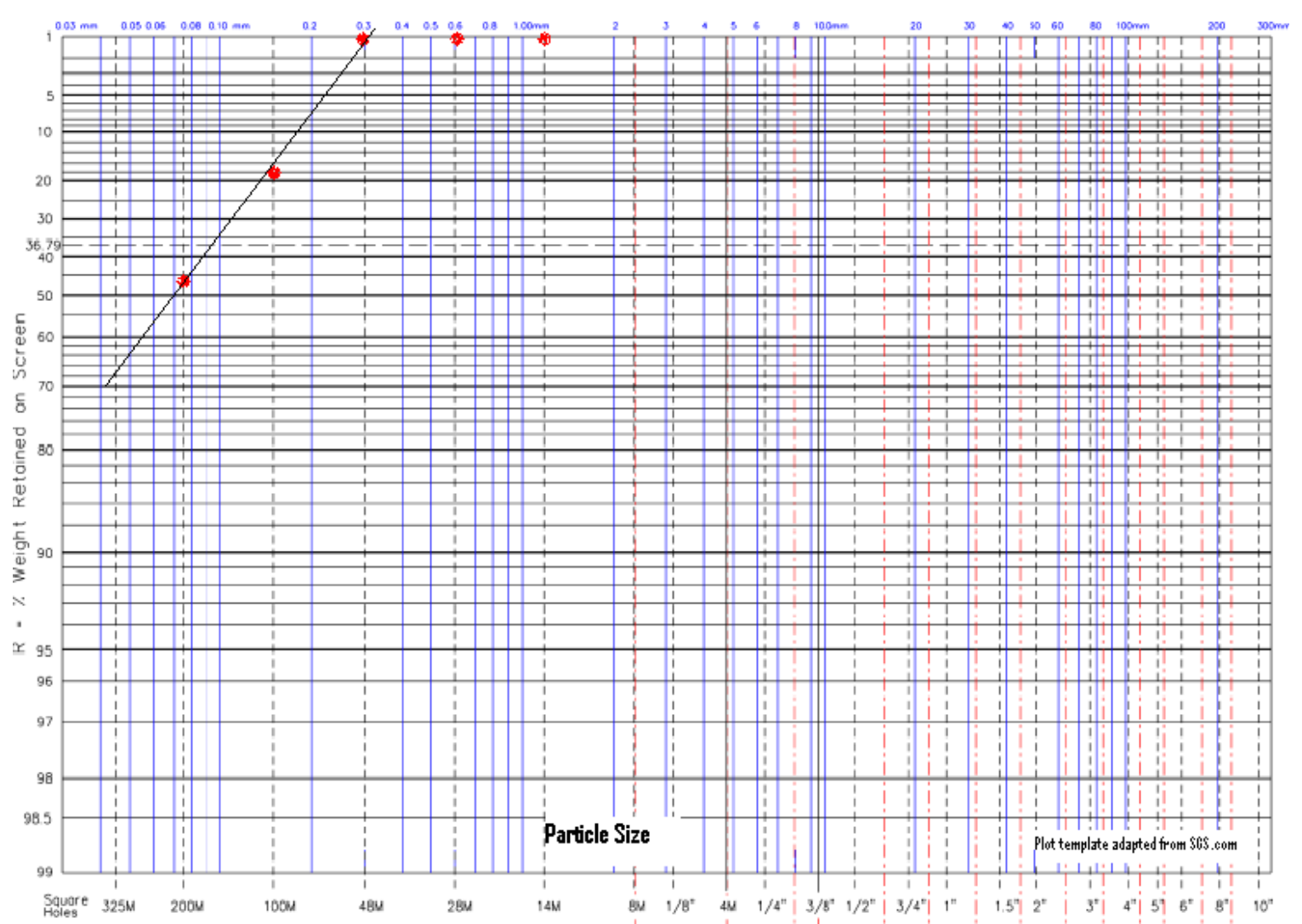




\section{Test 12}

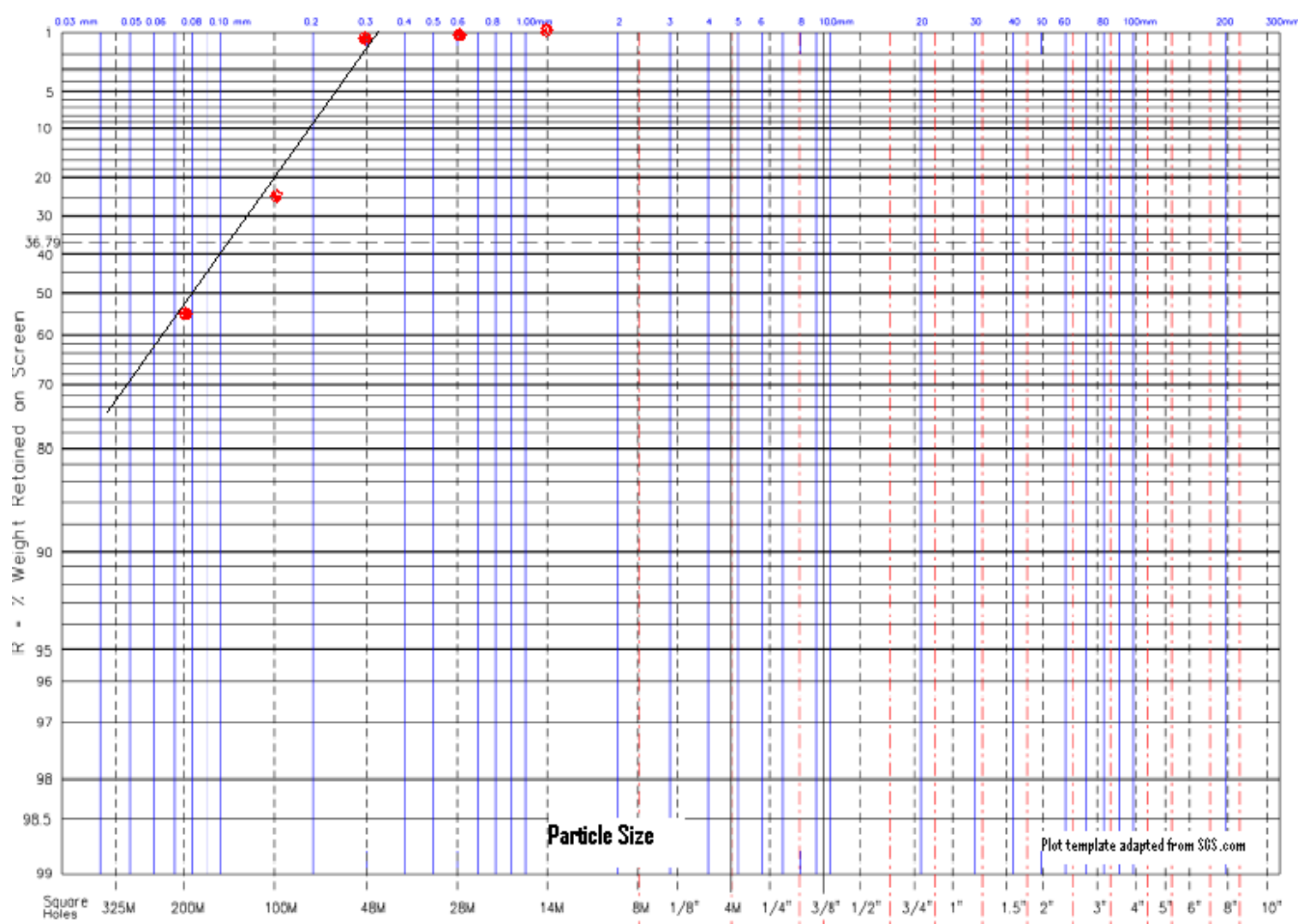

Test 13

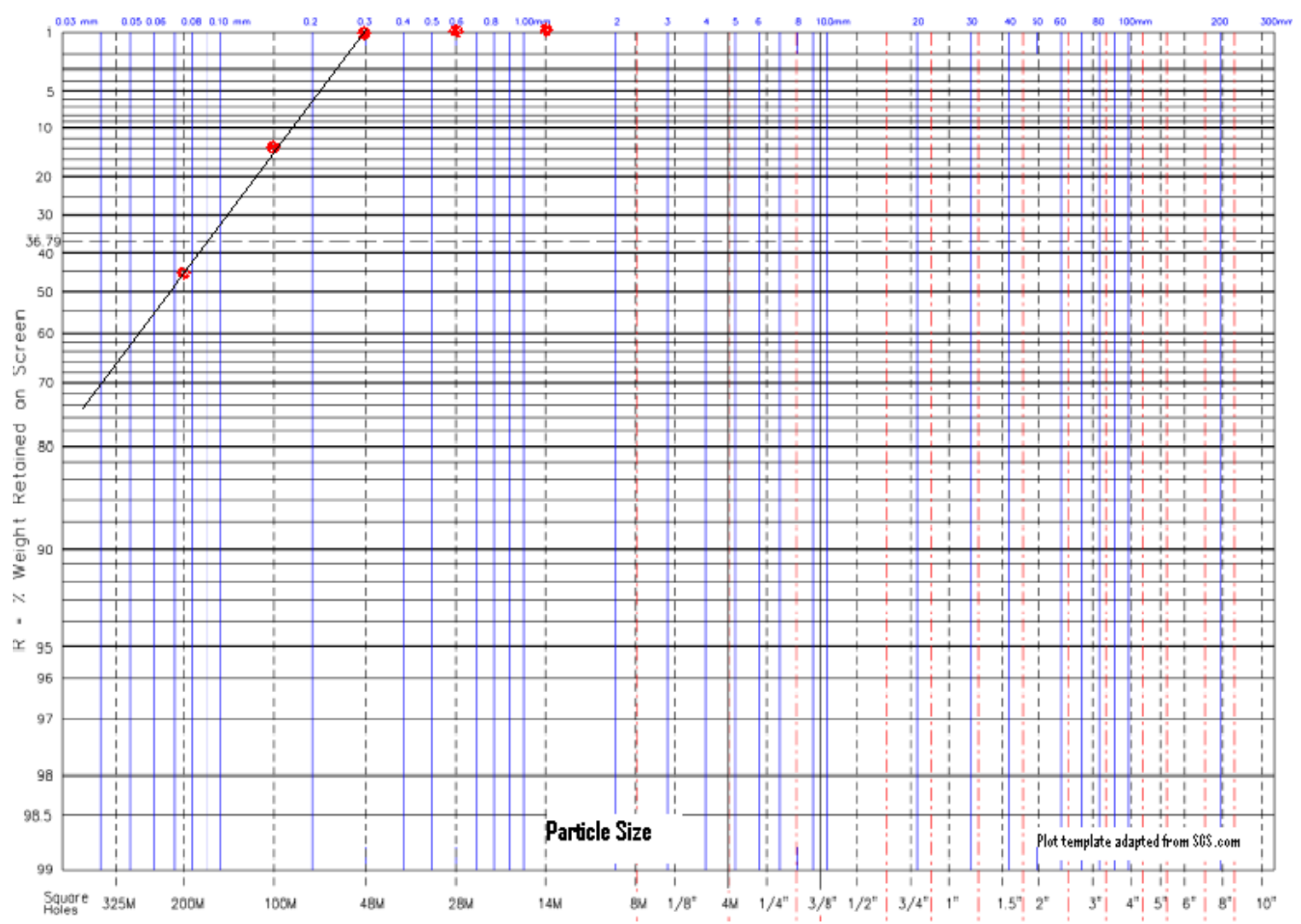




\section{Test 14}

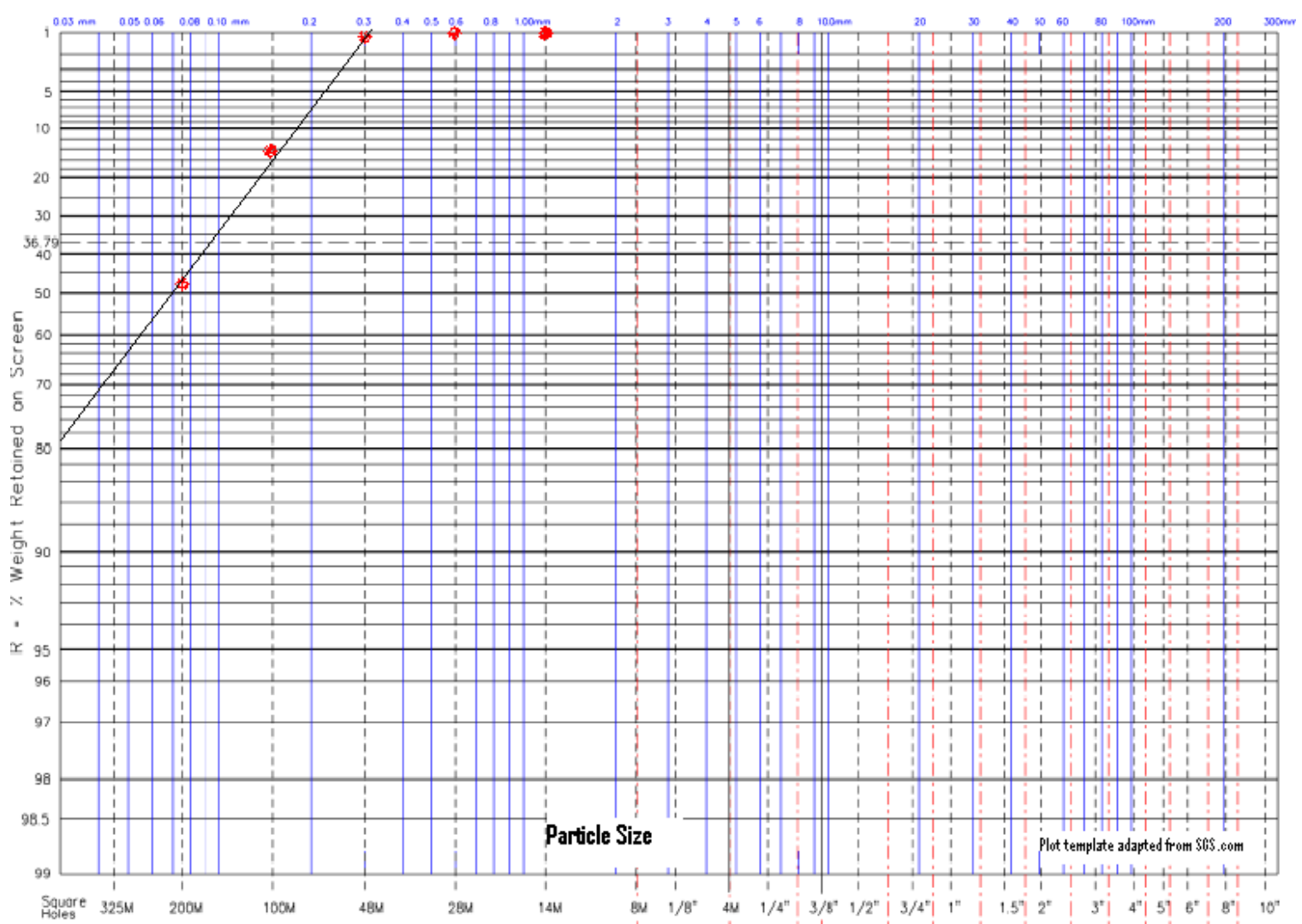

Test 15

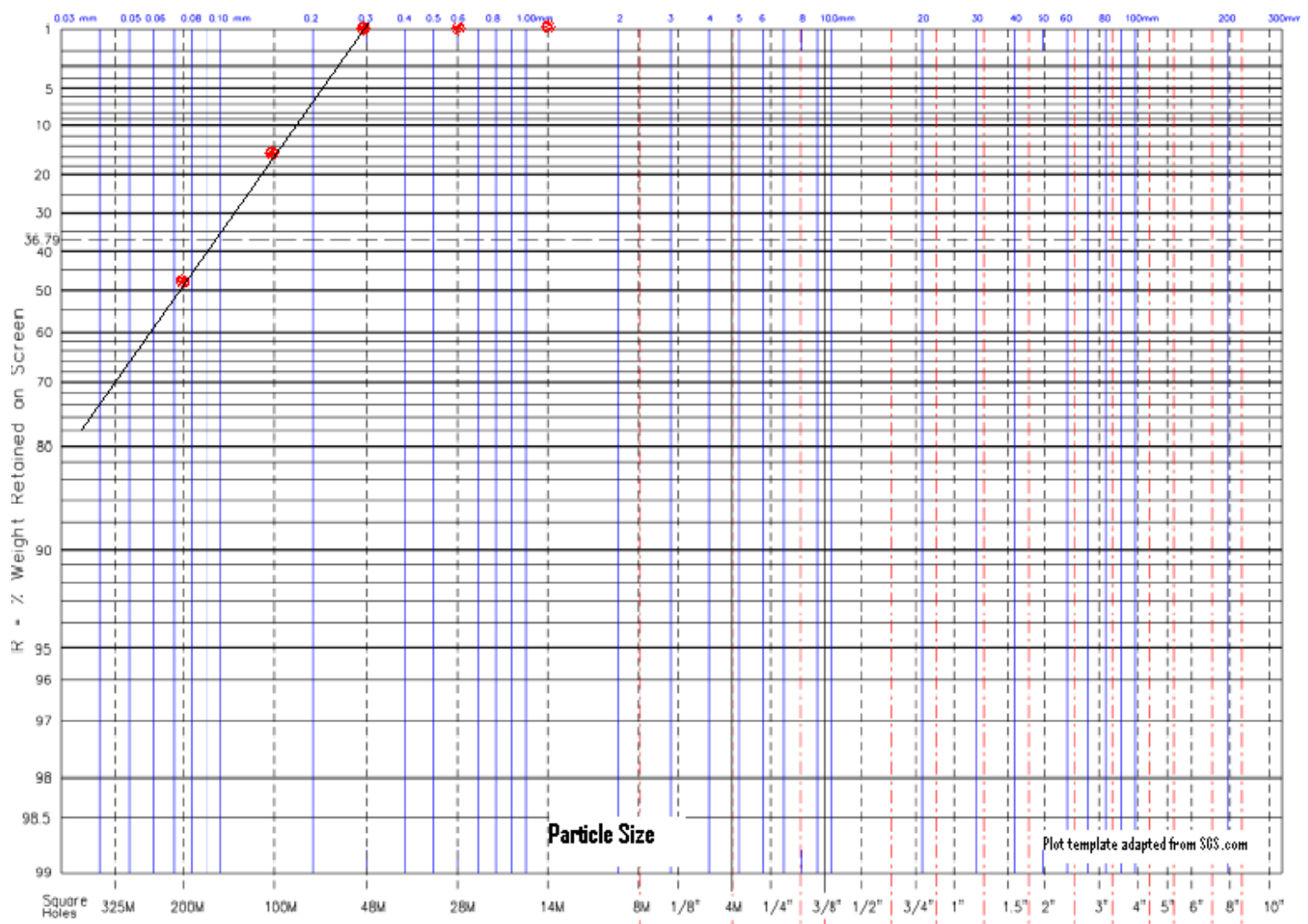




\section{Test 16}

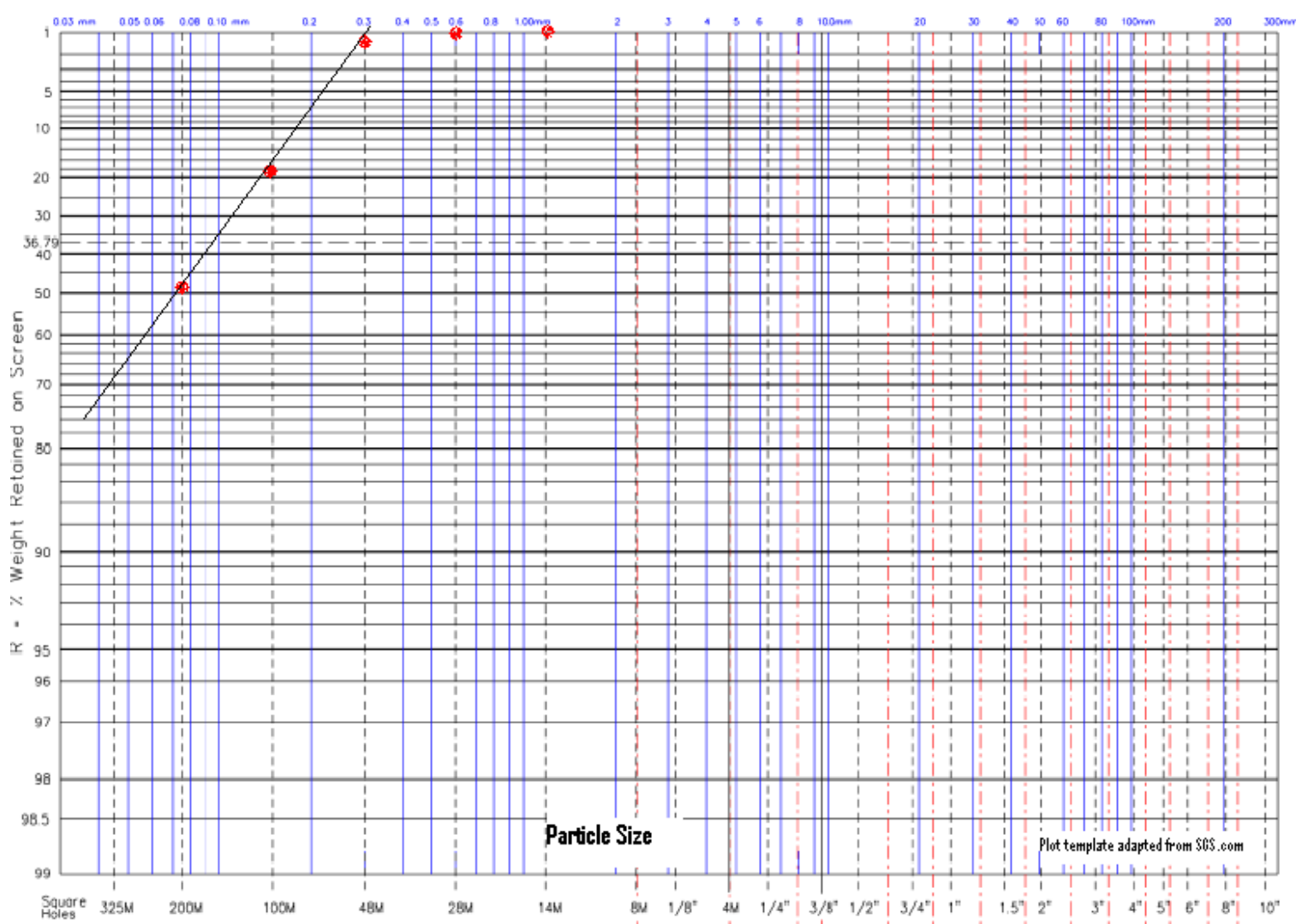

Test 17

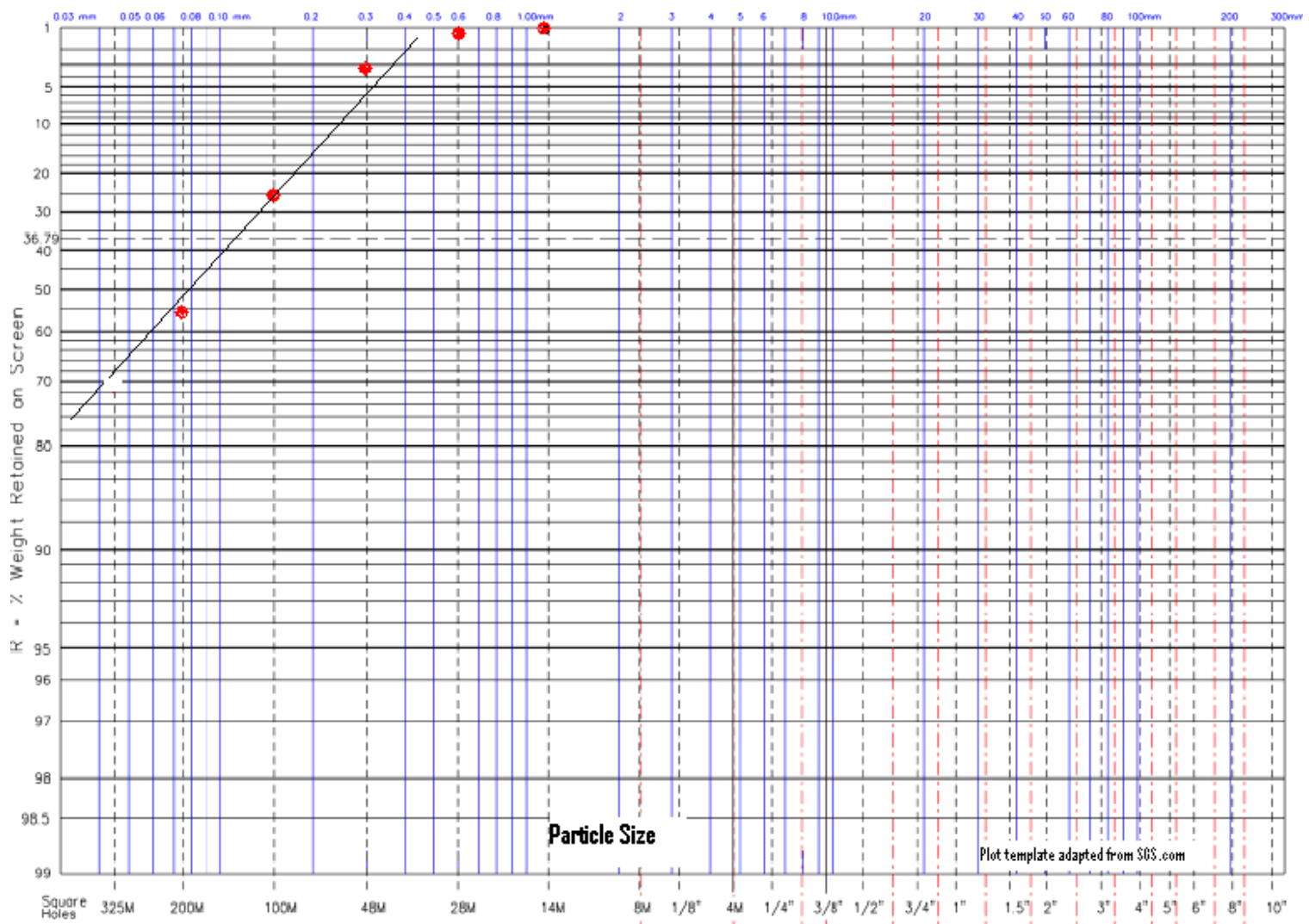




\section{Test 18}

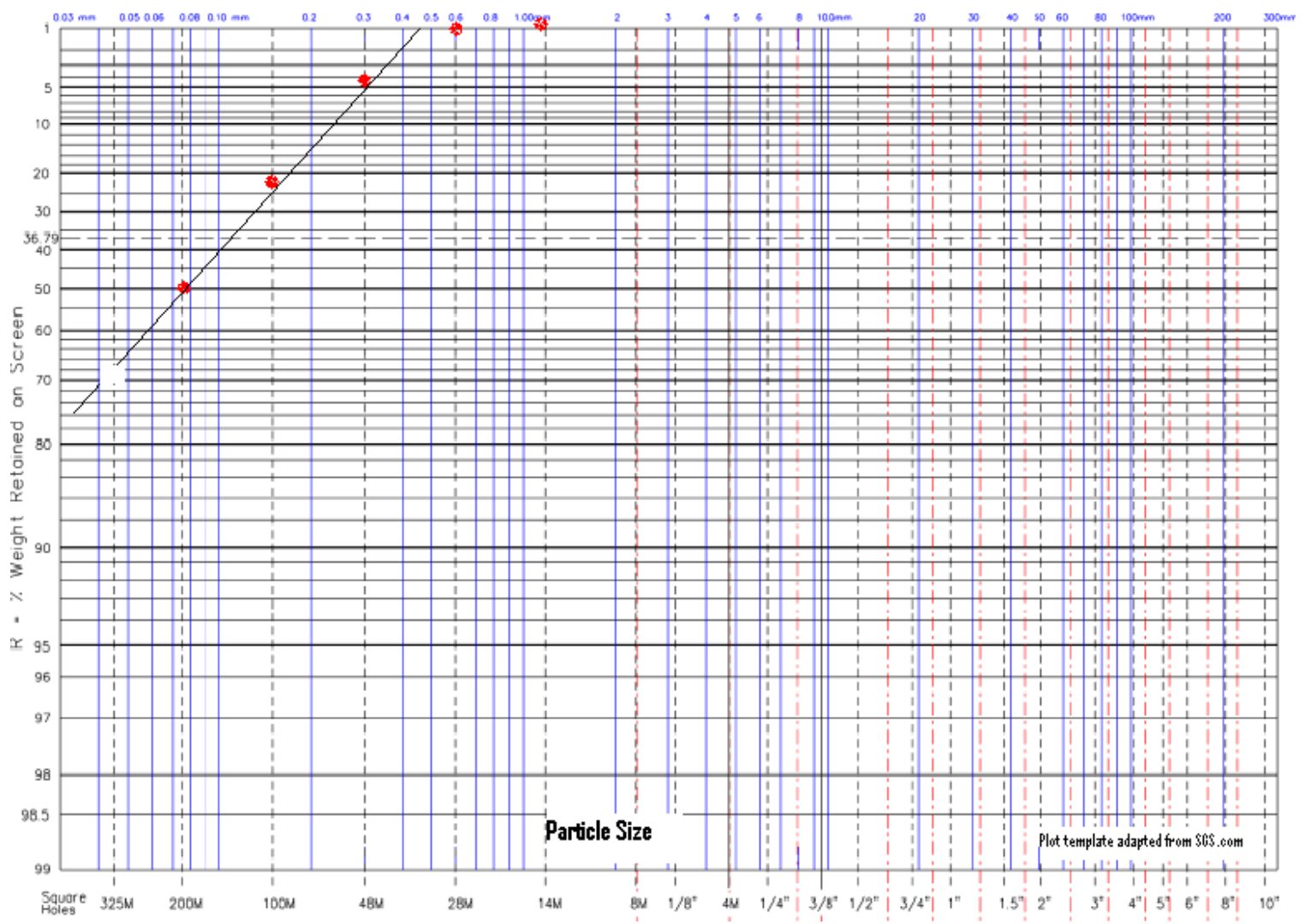

Test 19

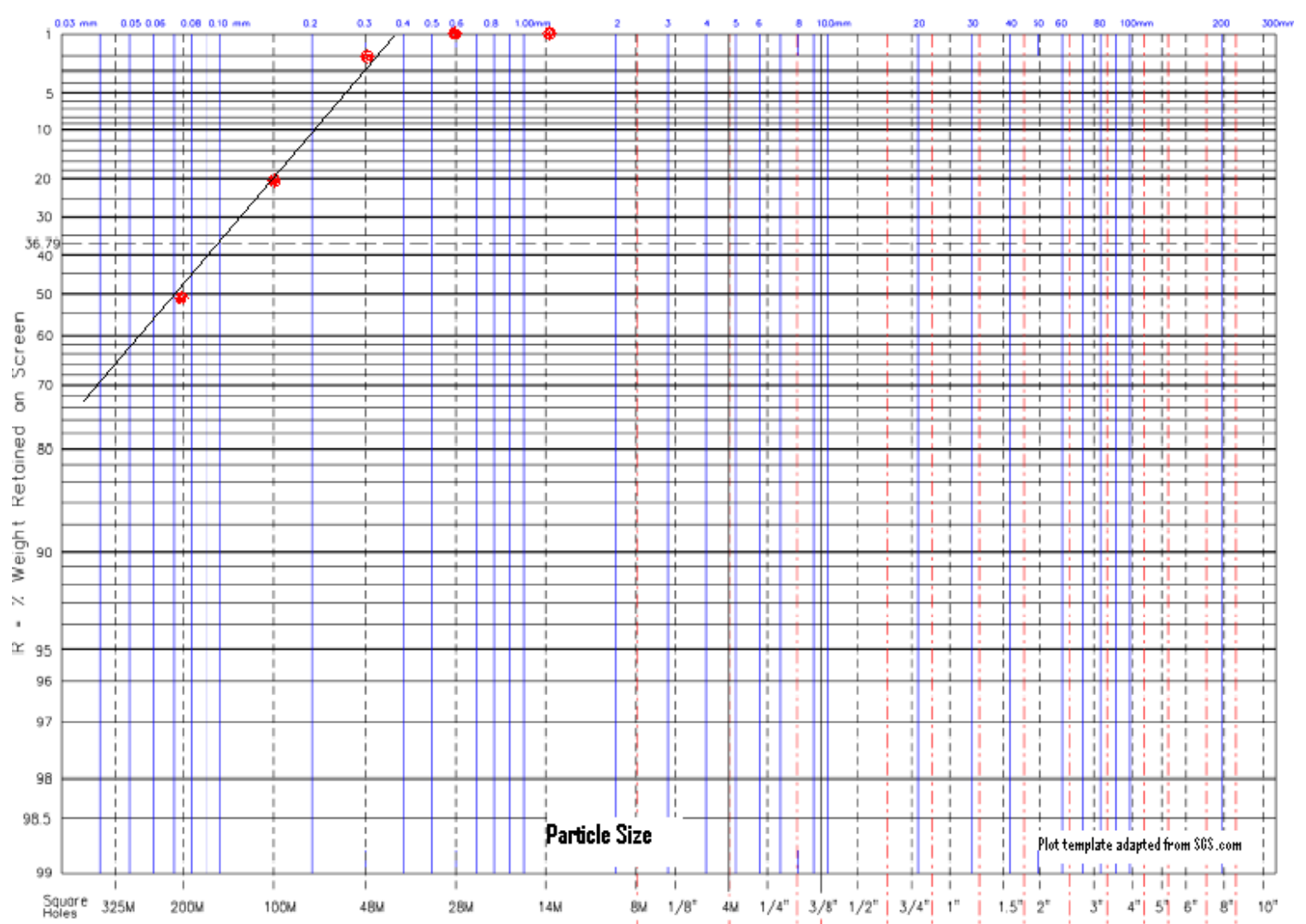




\section{Test 20}

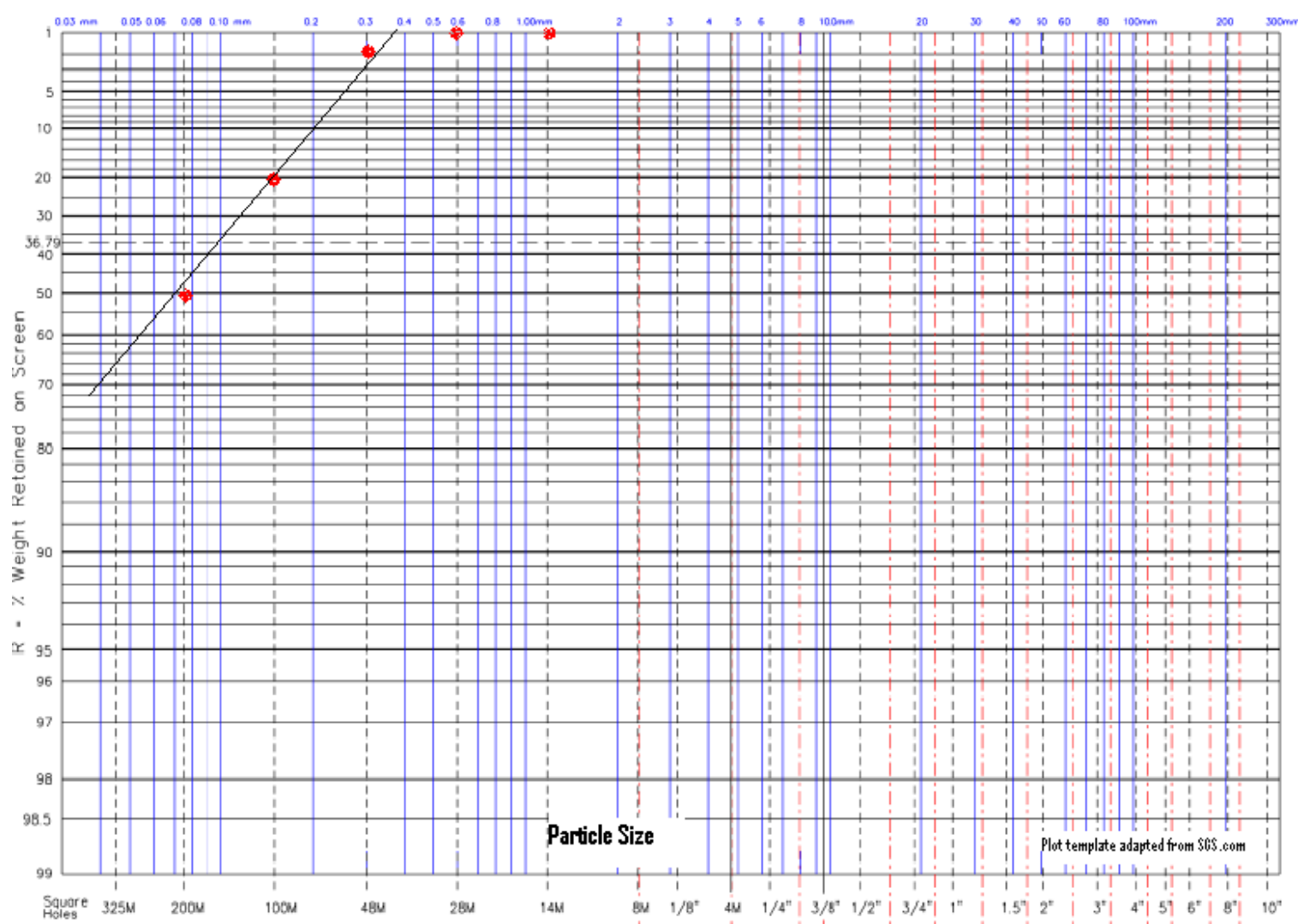

Test 21

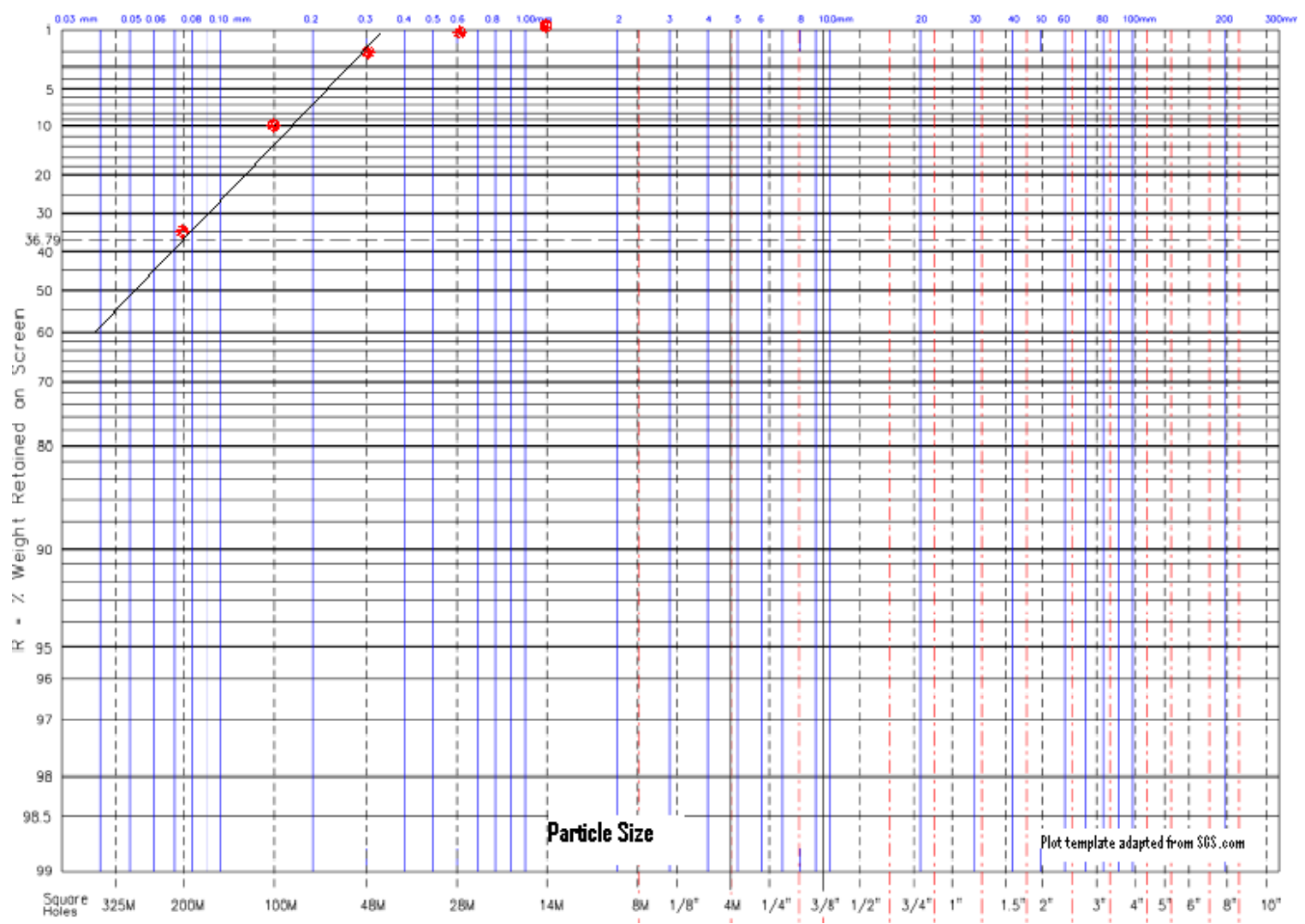




\section{Test 22}

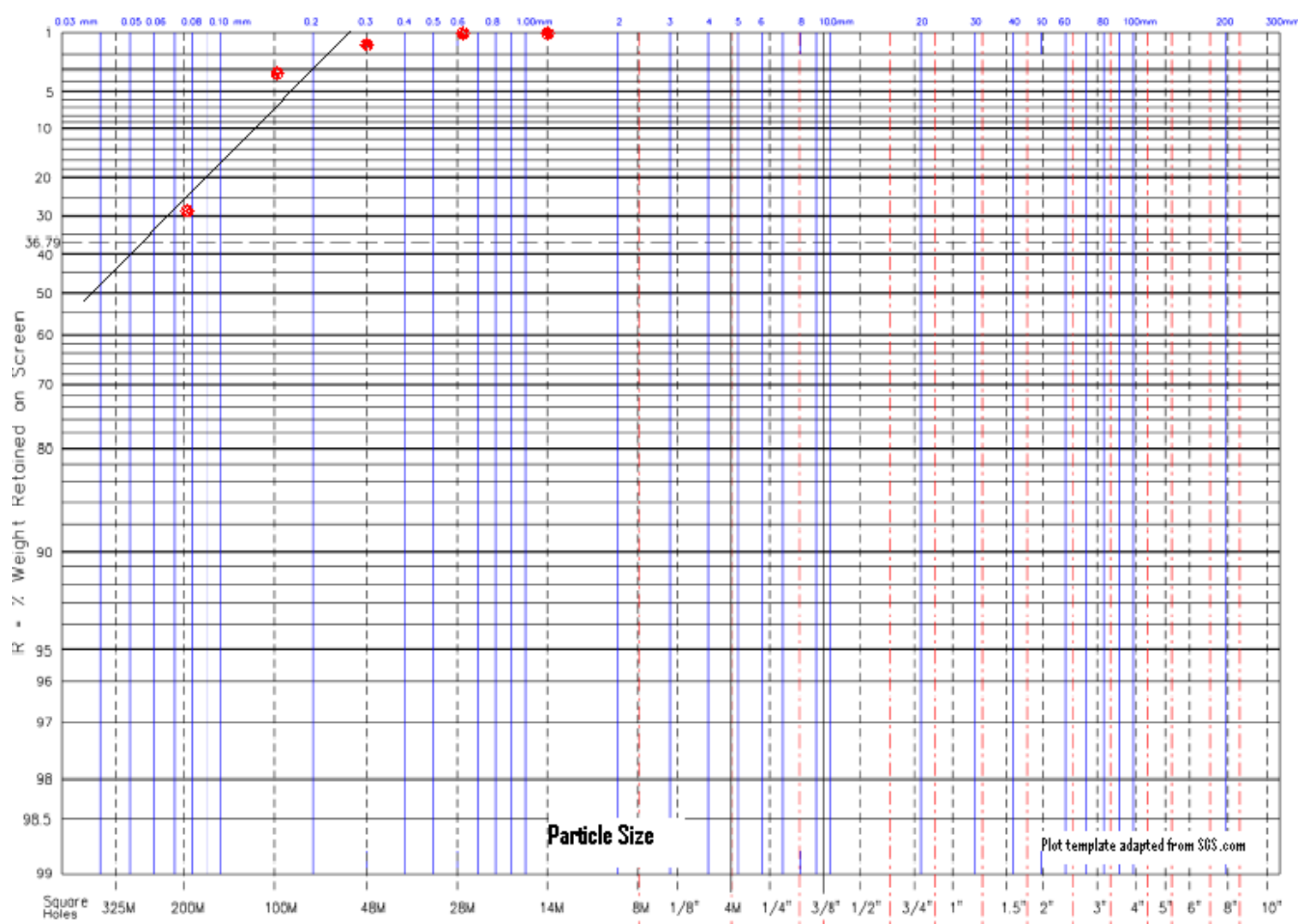

Test 23

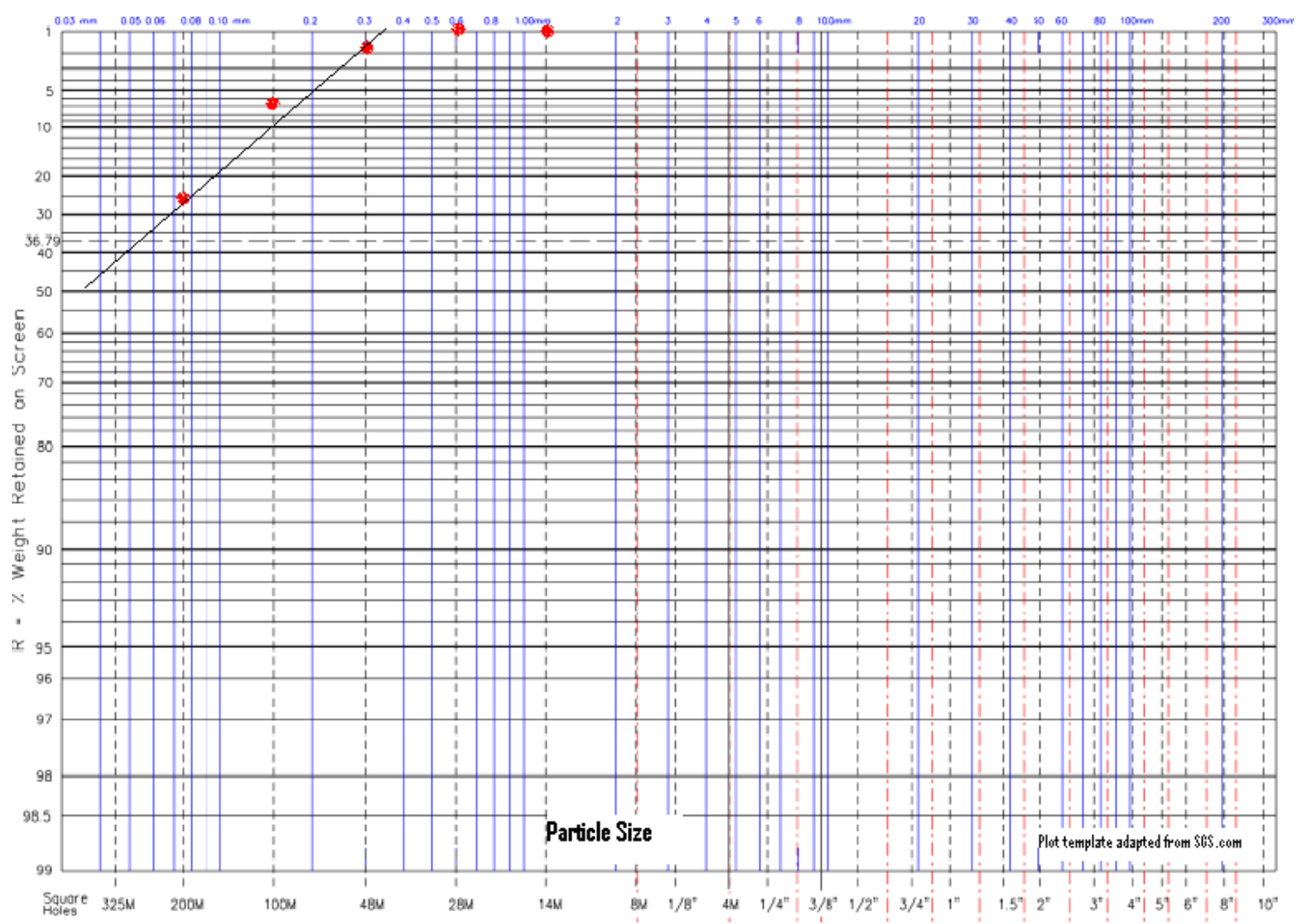


Test 24

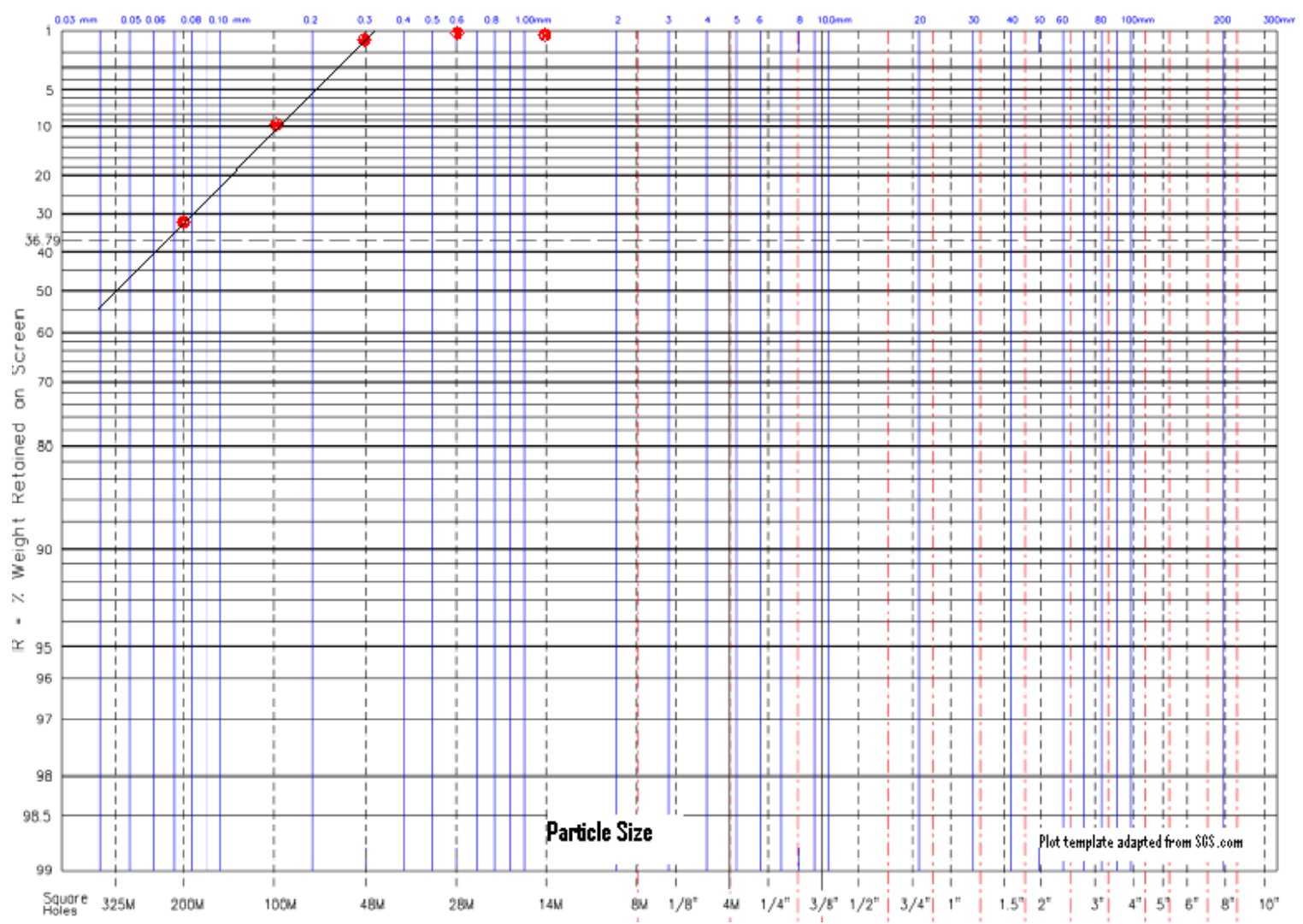

Test 25

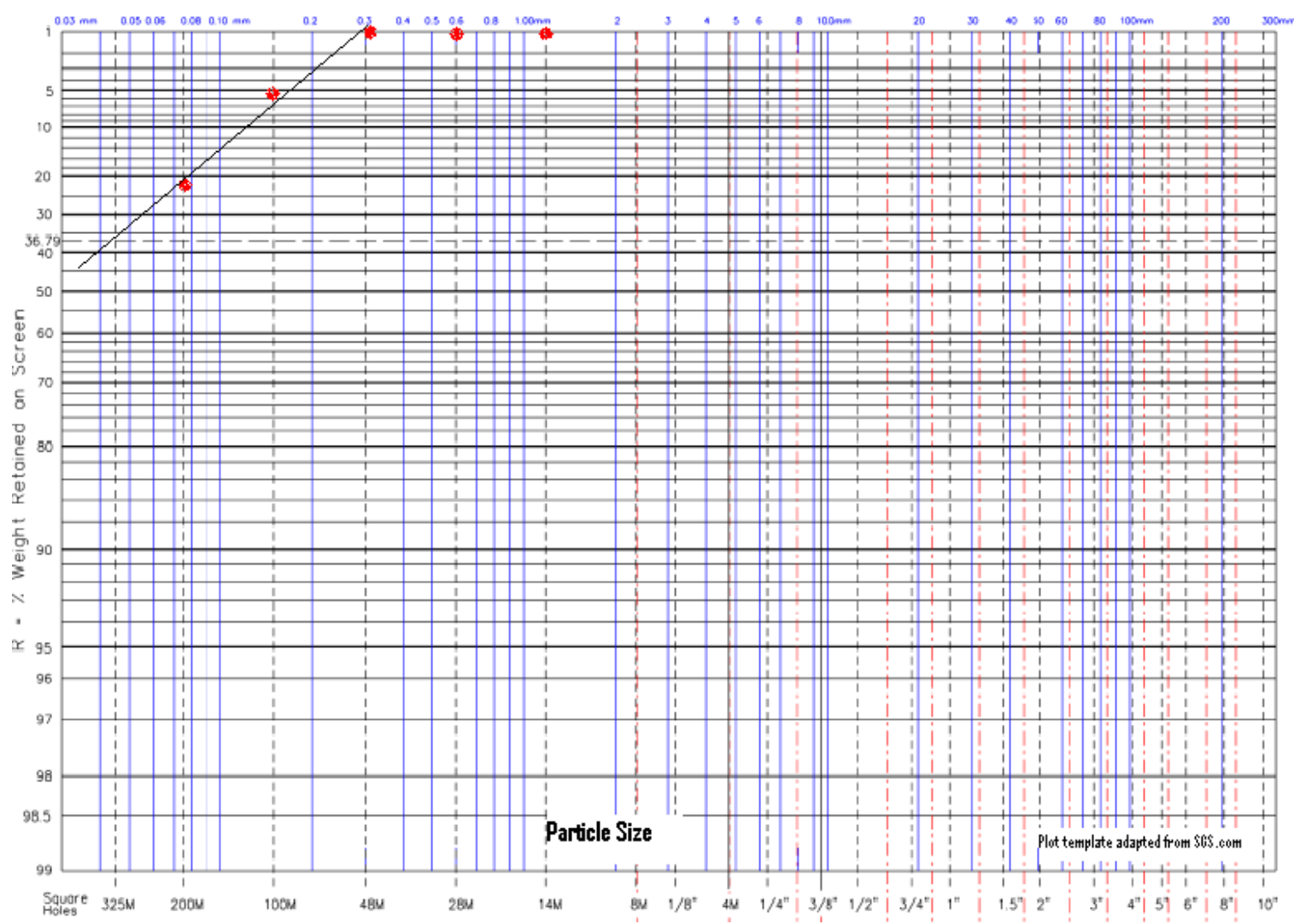




\section{Test 26}

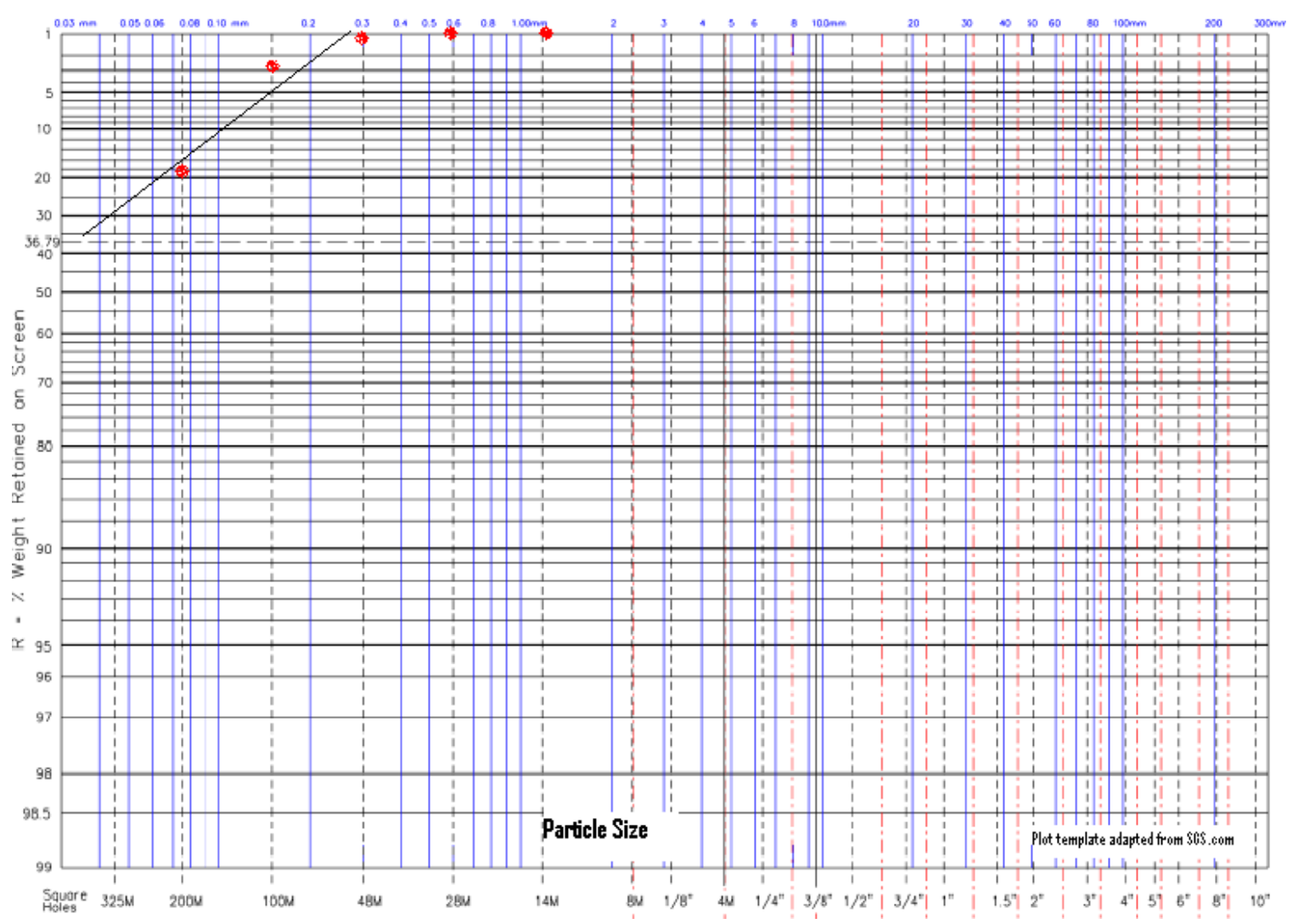

